\title{
Additive manufacturing of steels: a review of achievements and challenges
}

\author{
Nima Haghdadi ${ }^{1, \star}$, Majid Laleh ${ }^{2,3}$, Maxwell Moyle ${ }^{1}$, and Sophie Primig ${ }^{1, *}$ \\ ${ }^{1}$ School of Materials Science and Engineering, UNSW Sydney, Sydney, NSW 2052, Australia \\ ${ }^{2}$ School of Engineering, Deakin University, Waurn Ponds, VIC 3216, Australia \\ ${ }^{3}$ Institute for Frontier Materials, Deakin University, Waurn Ponds, VIC 3216, Australia
}

Received: 30 March 2020

Accepted: 17 July 2020

Published online:

26 August 2020

(C) The Author(s) 2020

\begin{abstract}
Metal additive manufacturing (AM), also known as 3D printing, is a disruptive manufacturing technology in which complex engineering parts are produced in a layer-by-layer manner, using a high-energy heating source and powder, wire or sheet as feeding material. The current paper aims to review the achievements in AM of steels in its ability to obtain superior properties that cannot be achieved through conventional manufacturing routes, thanks to the unique microstructural evolution in AM. The challenges that AM encounters are also reviewed, and suggestions for overcoming these challenges are provided if applicable. We focus on laser powder bed fusion and directed energy deposition as these two methods are currently the most common AM methods to process steels. The main foci are on austenitic stainless steels and maraging/precipitation-hardened (PH) steels, the two so far most widely used classes of steels in AM, before summarising the state-of-the-art of AM of other classes of steels. Our comprehensive review highlights that a wide range of steels can be processed by AM. The unique microstructural features including hierarchical (sub)grains and fine precipitates induced by AM result in enhancements of strength, wear resistance and corrosion resistance of AM steels when compared to their conventional counterparts. Achieving an acceptable ductility and fatigue performance remains a challenge in AM steels. AM also acts as an intrinsic heat treatment, triggering 'in situ' phase transformations including tempering and other precipitation phenomena in different grades of steels such as $\mathrm{PH}$ steels and tool steels. A thorough discussion of the performance of AM steels as a function of these unique microstructural features is presented in this review.
\end{abstract}

Handling Editor: P. Nash.

Nima Haghdadi, Majid Laleh and Maxwell Moyle contributed equally and are therefore listed in alphabetical order.

Address correspondence to E-mail: nima.haghdadi@unsw.edu.au; s.primig@unsw.edu.au 


\section{Introduction}

\section{Overview of additive manufacturing of alloys and steels}

Additive manufacturing (AM), commonly known as $3 \mathrm{D}$ printing, has recently gained huge interest in both academia and industry, with its market value expected to reach $\$ 21$ billion by the end of 2020 [1]. AM refers to a family of layer-upon-layer building technologies capable of producing geometrically intricate parts in a single step [2]. The idea of using a high-energy beam, such as a laser beam, to manufacture objects of any given geometry using powder material was first patented by Pierre Ciraud in 1973 [3]. The invention of laser powder bed fusion (LPBF) dates back to 1996, when a research project at the Fraunhofer Institute for Laser Technology (Frounhofer ILT) yielded the corresponding first patent DE 19649865 [4]. Since the invention of the first AM machine in Austin, TX almost 34 years ago [5], there has been great progress in both the development of various processing techniques and understanding the processing-microstructure-property relationships in AM. Once the underlying microstructural evolution during AM is understood in more detail, manufacturers will be enabled to systematically optimise the AM processing parameters towards superior properties of engineering parts.

AM has been successfully implemented to different metallic systems over time, including $\mathrm{Ti}$ alloys, $\mathrm{Ni}$ based superalloys, Al alloys, and steels [6]. Various groups of metals and alloys can now be processed via AM, with steels currently accounting for about $1 / 3$ of all publications in the metals AM literature. However, this is still only a too small share given that almost $80 \%$ (weight per cent) of all the metallic parts for engineering purposes are made of steel. Steels are still mainly processed through conventional routes including casting, forming, and machining [7]. Although the sustainability of AM is discussed controversially in the literature $[8,9]$, reductions in greenhouse gas emissions could potentially be achieved by producing complex-shaped steel parts through AM, which avoids significant emissions from conventional energy-inefficient production routes [10]. Further, AM unlocks unprecedented design freedom (e.g. complex geometries or hollow structures that are difficult to make through conventional manufacturing), translating into high- performance parts with reduced weight. Considering that steel is a $100 \%$ recyclable metal, AM can therefore play a key role in the circular economy by producing high added-value products from recycled powders and enabling reuse of AM by-products in new products [11].

Although AM has recently undergone significant development, it still has not been widely adopted by many industry sectors. If we consider the cost of a final product as a function of material cost, tooling cost, equipment cost, and overhead cost, further work and progress is needed for AM to outperform traditional manufacturing in terms of material cost, equipment cost and overhead cost, as described in detail in [12]. Another critical issue is the fact that despite AM's physical metallurgy commonalities to phenomena observed during casting, welding, powder metallurgy and thermo-mechanical processing, many of the established textbook theories for traditional manufacturing might fail in AM [13]. A full understanding of microstructure and property evolution during $\mathrm{AM}$ to achieve reproducibility and to improve the technology to the point of gaining industry acceptance is, therefore, the current scope for AM researchers. AM of steel looks to be still in its middle stages of maturity and adoption, where new grades of steel more suitable for AM and with better performances are expected to be designed in the future. An overview of how current AM steels compete with conventionally processed steels in terms of performance would, therefore, provide invaluable insight for the ongoing research in AM of steels.

\section{Aim and structure of this review}

Overall, an extensive effort has been made on investigating the mechanical and corrosion properties of AM metals and alloys. There have been a number of papers reviewing the processing-microstructure-properties in AM including mechanical properties [14-16] and corrosion behaviour [17, 18] of additively manufactured metals. The two most comprehensive currently available reviews on AM of steels are by Fayazfar et al. [14] and Bajaj et al. [19]. Fayazfar et al. [14] comprehensively summarised the processing of steels through different powder-based AM technologies. These authors went through the basics of powder bed, powder-fed and binder jetting AM processes for steels and discussed the solidification microstructure of AM steels. Bajaj et al. [19] 
reviewed the evolution of steel microstructures during AM. These authors gave an overview over the different series of steels in use in AM processes and reviewed the microstructure- properties relationship in these steels. However, neither of these valuable reviews focused on how and where AM could enable manufacturing of steel parts with superior properties compared to conventional subtractive manufacturing. This is the focus of the current review.

Appreciating the unique microstructural characteristics of AM steels compared to the conventionally processed steels and despite considerable progress made in understanding these microstructural features, there is a lack of overview on how these will potentially result in advanced properties. The current review intends to fill this gap by providing a comprehensive summary of the unique properties of AM steels currently reported in the literature. We mainly concentrate on mechanical, corrosion and wear properties of steels where relevant data are available. Occasionally, other properties such as magnetic properties and hydrogen embrittlement are discussed if they are important properties of the corresponding steel grade. However, we do not include AM steel composites such as AM oxide dispersion strengthened (ODS) [20-22] and WC dispersed maraging steels $[23,24]$. We also do not discuss the details of different AM processes (for a detail overview on this please see [14]), and we intend to discuss the microstructural evolution during AM only briefly, if necessary, in order to explain differences in properties.

After a few necessary notes on typical AM microstructures, we will start with the two most popular steels in the AM context, i.e. austenitic stainless steels (with the vast body of literature on $316 \mathrm{~L})$ and maraging/precipitate hardening ( $\mathrm{PH})$ steels. Then we will continue to discuss a variety of other types of steels that have been processed by AM so far. These include duplex stainless steels, ferriticmartensitic steels, carbon-bearing tool steels and transformation-/twinning-induced plasticity (TRIP/ TWIP) steels.

\section{A few notes on typical AM microstructures}

With the ability to build material through successive adding of layers with thicknesses of a few tens of microns on top of each other, AM is capable of producing site-specific microstructures with tailored mechanical $[25,26]$ and corrosion properties [27] that are difficult/impossible to achieve through traditional manufacturing. In this regard, understanding the microstructural evolution during AM is essential. The thermal history to which a metal is exposed during AM is very different from that of conventional manufacturing. AM microstructures are formed through rapid solidification rates $\left(\mathrm{d} T / \mathrm{d} t: 10^{3}-10^{8} \mathrm{~K} /\right.$ $\mathrm{s})^{1}$ [28], high thermal gradients $\left(\mathrm{d} T / \mathrm{d} x: 10^{3}-10^{7} \mathrm{~K} /\right.$ $\mathrm{m})$, and significant thermal gyrations caused by the melting and deposition of several subsequent layers [29-31]. All of these processing parameters affect the evolution of key microstructural features including the solidification morphology, segregation, cells, grain structure (size and shape), crystallographic texture, microstructure stability, secondary phases, defects and inclusions. In AM microstructures, solidification cells are subgrains, very similar in orientation, delineated by segregation of alloying elements and dislocation accumulation at their boundaries [19]. Grains are defined by their distinct orientation separated by high angle grain boundaries.

AM microstructures exhibit a variety of grain morphologies. An example of this difference is presented in Fig. 1 for 316L stainless steel. In this regard, fine equiaxed grains at the melt pool boundaries are observed from the transverse direction (plane perpendicular to the building direction), where grains are columnar inside the individual melt pools (Fig. 1a). In contrast to the transverse plane, large columnar grains along the building direction are commonly reported for AM, as shown in Fig. 1b. This columnar grain morphology has been attributed to supercooling conditions inherent to AM that may change the solidification mode from planar to columnar and/or an epitaxial growth [32]. The cooling rate and extent of re-melting of the previous layer during LPBF are the main determining factors in controlling the grain size. For instance, very large, columnar grains with high aspect ratio for LPBF 316L stainless steel are formed as a result of epitaxial growth when using a high laser power (Fig. 1c) [33]. In general, if not epitaxially grown, grains in LPBF steels have been reported to be fine, a distinct feature compared to their conventional counterparts [15],

\footnotetext{
${ }^{1}$ Note that although being mentioned in several publications, these values mostly go back to simulation studies and not experiments. Even if experimentally achieved, values as high as $10^{8} \mathrm{~K} / \mathrm{s}$ are most probably valid for high-conductivity materials like $\mathrm{Al}$ and not for steels.
} 

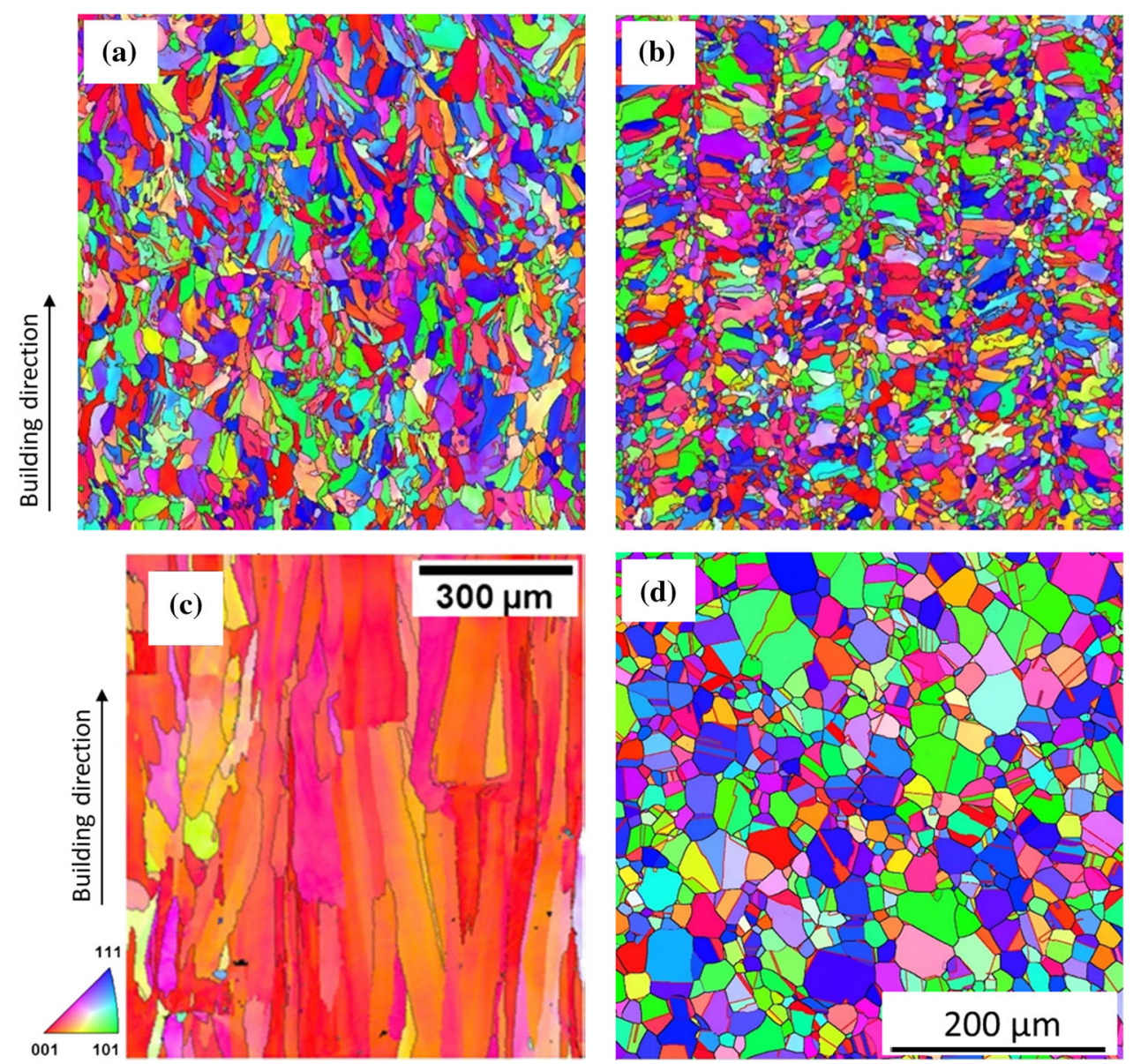

Figure 1 Typical grain structure of a LPBF 316L austenitic stainless steel acquired by electron back-scattered diffraction (EBSD) analysis. a An inverse pole figure (IPF) map of a LPBF $316 \mathrm{~L}$ austenitic stainless steel processed with a $150 \mathrm{~W}$ laser power along the building direction, $x-z$ plane. $b$ IPF map of the same specimen shown in (a) but from the transverse (perpendicular to the building) direction, $x-y$ plane. $c$ IPF map of another LPBF 316L austenitic stainless steel processed with a $1000 \mathrm{~W}$ laser

which is a result of the rapid solidification during LPBF. The as-built texture depends mostly on the melt pool size, direction of the local heat flow and competitive grain growth occurring during manufacturing [34]. One can control the texture in AM through imposing a change in the scanning strategy, for example rotations between different layers and/ or the so-called point heat source strategy in which the melted area is patterned in 'points', leaving some space between individual points [35].

AM has made great progress over the past years in terms of producing high-density parts; however, defect formation remains a challenge [37]. Porosities, delamination and balling are known as the most power along the building direction, indicating more elongated, columnar grains compared to those in the specimen processed with lower laser power in (a). IPF map of a conventionally processed 316L austenitic stainless steel is also presented in (d) for comparison purposes. $\mathbf{a}, \mathbf{b}$ and $\mathbf{d}$ have the same scale bars. $\mathbf{a}, \mathbf{b}$, $\mathbf{d}$ are adapted from Ref. [36] and $\mathbf{c}$ from Ref. [33], with permission.

common types of defects introduced during AM of metals. Two types of pores have been reported in the literature: (1) spherical or gas-induced pores and (2) non-spherical or process-induced pores. The former ones are believed to be due to the trapped gasses among the powder particles, which are released during melting and then locked-in during solidification. Another origin of spherical pores arises from gases being trapped inside the powder feedstock during the preparing process of the powder materials. This entrapped gas is then transferred into the part and leads to formation of gas-induced porosity [38]. On the other hand, non-spherical pores, also known as irregular-shaped, lack-of-fusion (LOF) or 
process-induced pores are generally formed when the applied laser energy density is not sufficient to completely melt the powder bed. This leads to formation of un-melted powder particles trapped inside of these pores. Furthermore, high laser energy densities have also been observed to induce irregularshaped pores during a process known as keyhole formation [39].

Delamination, which is defined as the separation of adjacent layers within an AM part, is mainly due to the incomplete melting of adjacent layers [40]. As opposed to LOF that is a microscopic internal defect and can be eliminated through post-processing processes, delamination is a macroscopic crack-like defect which cannot be repaired by post-processing [41]. Thus, careful adjusting of process parameters is necessary in order to avoid delamination. The balling phenomenon is another severe processing defect in AM parts [42]. Balling occurs when the melt pool loses its continuity owing to the Plateau-Rayleigh instability and then segregates into individual spherical islands [43, 44]. This can be mainly attributed to the high viscosity of the liquid, which in turn leads to significant suppression of liquid flow and insufficient wetting of the powder surface by the liquid. Powder particles then tend to agglomerate due to surface tension, and consequently the balling phenomenon occurs. Increasing the laser power or decreasing the scanning speed can help to reduce balling phenomena during AM [31].

Microstructures far from the equilibrium conditions are produced in AM parts due to the rapid solidification rates [31]. For instance, a very fine cellular microstructure with cell sizes of $1 \mu \mathrm{m}$ or less is usually obtained in AM austenitic stainless steels, as shown in Fig. 2a, b. Some elements like $\mathrm{Cr}$ and Mo have been reported to segregate at cell walls, as shown in the transmission electron microscopy (TEM) and energy-dispersive spectroscopy (EDS) maps in Fig. 2c. Inclusions are believed to play a prominent role in a range of properties of AM steels [45]. For example, oxide inclusions have been commonly reported in AM austenitic stainless steels and are shown to be spherical in shape with dimensions between a few tens of nanometres and a few microns and mainly enriched in $\mathrm{O}, \mathrm{Mn}$ and $\mathrm{Si}$ (Fig. 2c) [46-48]. This is in contrast to the larger $(>1 \mu \mathrm{m})$ and irregular-shaped oxide inclusions in conventional austenitic stainless steels [49].

\section{Austenitic stainless steels}

Austenitic stainless steels are one of the most widely used group of industrial alloys owing to their excellent corrosion resistance, biocompatibility and ductility, which make them suitable candidates for applications in various industries such as biomedical, aerospace, defence, oil \& gas, petrochemical and more. These steels are the most widely used class of steels in AM. Here, AM has been shown to provide some promising properties while many challenges remain. There are a large number of papers on AM of austenitic stainless steels in the literature. Going through all of them individually would make this section too lengthy. Therefore, we will review the trends with their advances and challenges in terms of mechanical and corrosion properties. It should be noted here that most of the literature on AM of austenitic stainless steels focuses on the grade of $316 \mathrm{~L}$, the most common material of choice for many industrial applications. However, other kinds of austenitic stainless steels like the $304 \mathrm{~L}$ grade will also be reviewed here if any achievements or challenges in different properties have been reported. The most important difference between $316 \mathrm{~L}$ and $304 \mathrm{~L}$ is in their chemical compositions, where almost $2 \mathrm{wt} \% \mathrm{Mo}$ is added to $316 \mathrm{~L}$ to improve its corrosion resistance.

\section{Mechanical properties}

Given their unique microstructures, AM austenitic stainless steels show interesting behaviour in tensile testing different from the conventionally produced parts. For instance, LPBF has shown to produce 316L stainless steel that is stronger than its wrought/cast counterpart (ultimate tensile strength (UTS) of 640-700 MPa for LPBF compared to 450-555 MPa for conventional; yield strength (YS) of 450-590 MPa for LPBF compared to 160-365 MPa for conventional) while still remaining ductile (elongation of $36-59 \%$ for LPBF compared to $30-43 \%$ for conventional) $[50,51]$. An example of such superior tensile properties for LPBF 316L stainless steel compared to its conventional counterpart is presented in Fig. 3a. This is mainly attributed to the presence of numerous nanoinclusions that hinder dislocation movements, and a large density of low angle grain boundaries. The exceptional combination of strength and ductility in 316L austenitic stainless steel is a great achievement for AM considering the limitation of conventional 

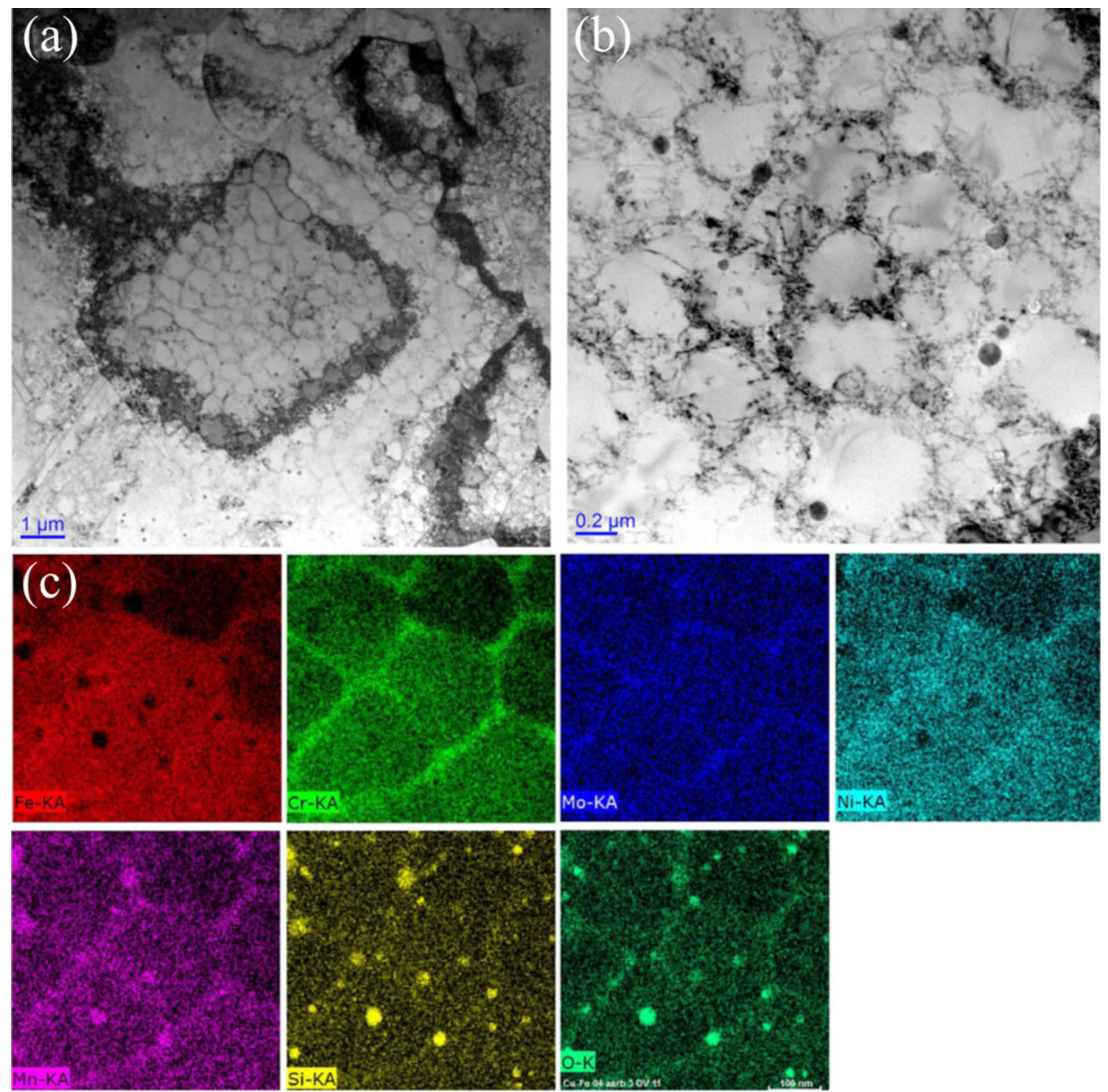

Figure 2 Non-equilibrium microstructure in LPBF 316L stainless steel. a, b Bright-field TEM images of the solidification cells within the grains at low and high magnification. c EDS analysis showing the segregation of alloying elements like $\mathrm{Mo}$ and $\mathrm{Cr}$ at

manufacturing in overcoming the strength-ductility dilemma [50, 51].

There are reports on LPBF 316L austenitic stainless steel showing a good fatigue performance, comparable to its conventionally processed counterpart [52]. LPBF 304 austenitic stainless steel also exhibits a comparable fatigue resistance in high-cycle regimes and an even slightly higher fatigue resistance in lowcycle-fatigue regimes [53], as presented in strain-life fatigue curves in Fig. 3b. AM 316L stainless steel has been shown to have a better wear resistance than its conventional counterpart at room temperature under

cell walls. Spherical dark regions in (c) are nano-inclusions that are enriched with Mn, Si and O. Images are adapted from Ref. [43] with permission.

dry sliding conditions and to even maintain this trend at high temperatures up to $400{ }^{\circ} \mathrm{C}$ [54], as depicted in the coefficient of friction versus sliding distance curves in Fig. 3c, d. This is attributed to the role of the cellular sub-grains within the microstructure of the AM 316L austenitic stainless steel in resisting against subsurface deformation through hindering dislocation movement. A similar conclusion has been made for better tribological behaviour of LPBF 316L austenitic stainless steel under wet wear test in a simulated body solution [28]. 
(a)

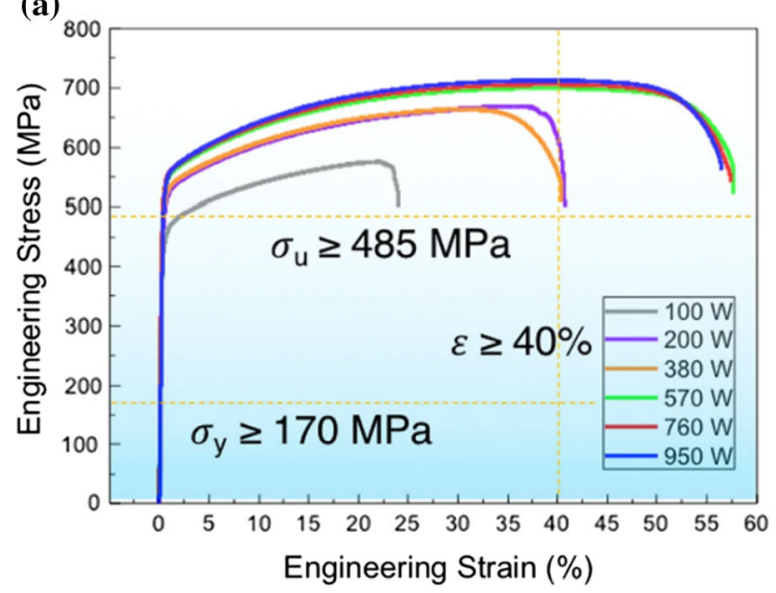

(c)

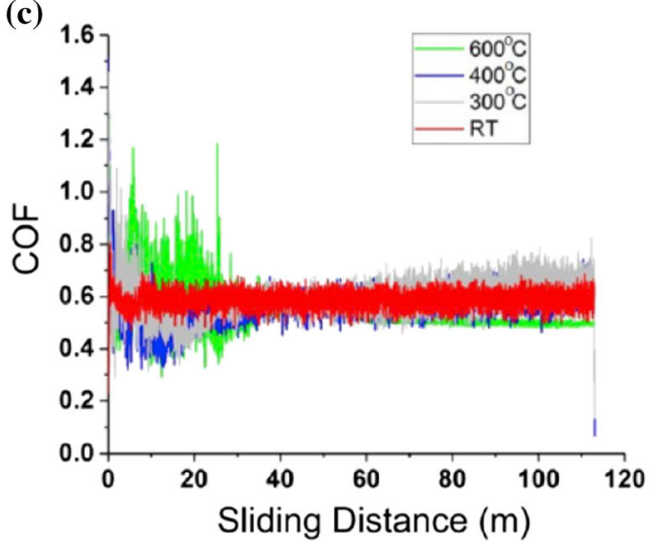

Figure 3 Representative unique mechanical properties of AM austenitic stainless steel. a Tensile engineering stress-strain curve for LPBF 316L austenitic stainless steel, indicating the capability of AM in producing stainless steel with simultaneously enhanced strength and ductility. The minimum requirements for tensile properties for 316L stainless steel are indicated by dashed yellow lines. b Comparison of strain-life fatigue behaviour of LPBF 304L

\section{Corrosion properties}

It is generally accepted that the corrosion properties of stainless steels are dependent on their microstructure and chemical composition. Phases such as $\delta$-ferrite, metallic/non-metallic inclusions and precipitates in the steel can all affect its corrosion resistance. The effects of microstructural features of AM stainless steel, which are in turn dependent upon the AM processing conditions, on their corrosion characteristics will be discussed in the following.

Sulphide inclusions, particularly manganese sulphide (MnS), are detrimental to pitting corrosion resistance of all grades of stainless steels [55-57]. Elimination of such harmful MnS inclusions is not practical in conventional subtractive manufacturing,
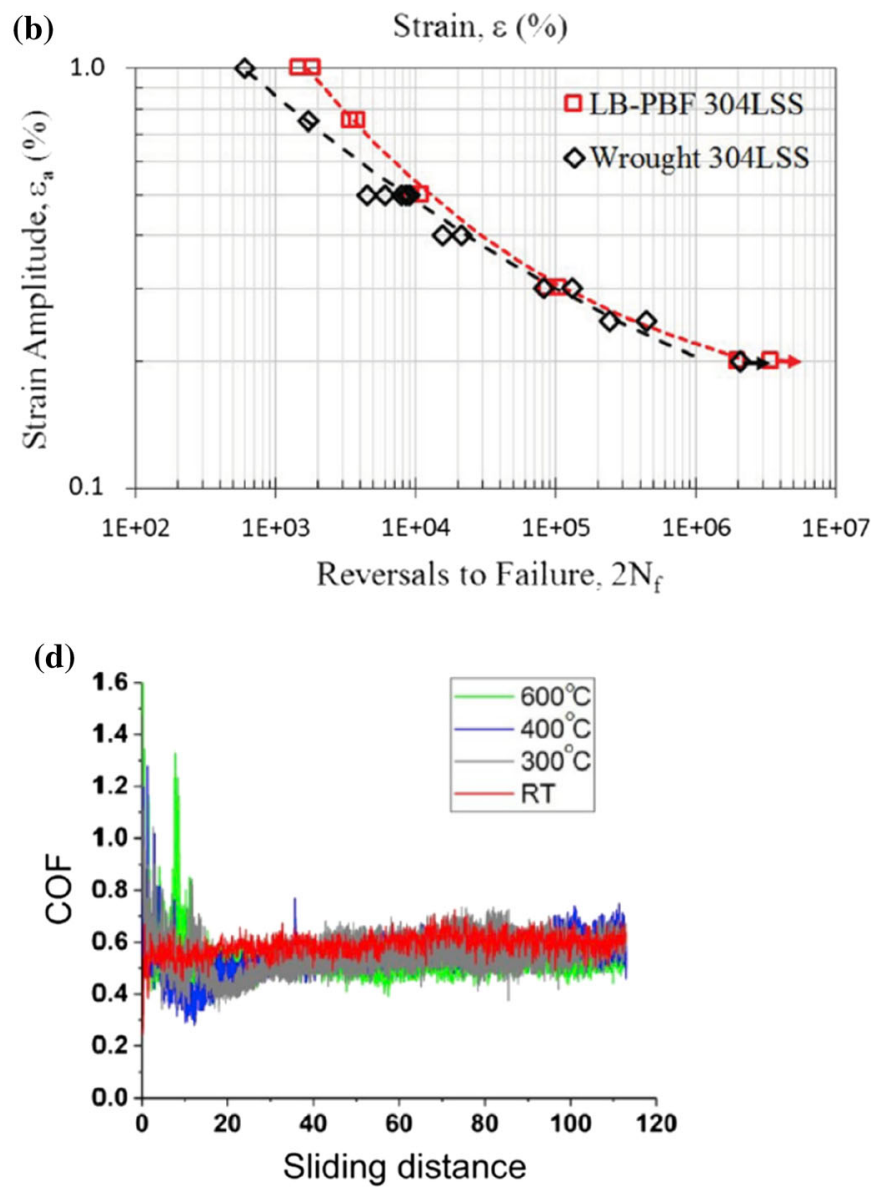

austenitic stainless steel with wrought 304L stainless steel. c Wear behaviour of LPBF $316 \mathrm{~L}$ austenitic stainless steel displayed as coefficient of friction (COF) versus sliding distance compared to (d) conventional $316 \mathrm{~L}$ stainless steel, showing a comparable wear resistance for LPBF 316L austenitic stainless steel at temperatures up to $400{ }^{\circ} \mathrm{C}$. $\mathbf{a}$ is adapted from Ref. [51], b from Ref. [53] and c, d from Ref. [54], with permission.

since $S$ is generally added to stainless steel as an alloying element with the aim of improving machinability [58]. Changing the chemical composition of MnS inclusions, e.g. by replacing $\mathrm{Mn}$ in the sulphide by $\mathrm{Cr}$, has been shown to be a useful method in enhancing the pitting corrosion resistance though not in severe corrosive environments like ferric chloride solutions [59]. Reducing the size of MnS inclusions through rapid solidification [60] or laser surface re-melting [61] has also been found to improve the pitting corrosion resistance. In this respect, AM has been shown to be capable of producing austenitic stainless steels with excellent pitting corrosion resistance [62, 63], as presented in Fig. 4a. This is mainly attributed to the rapid 
(a)

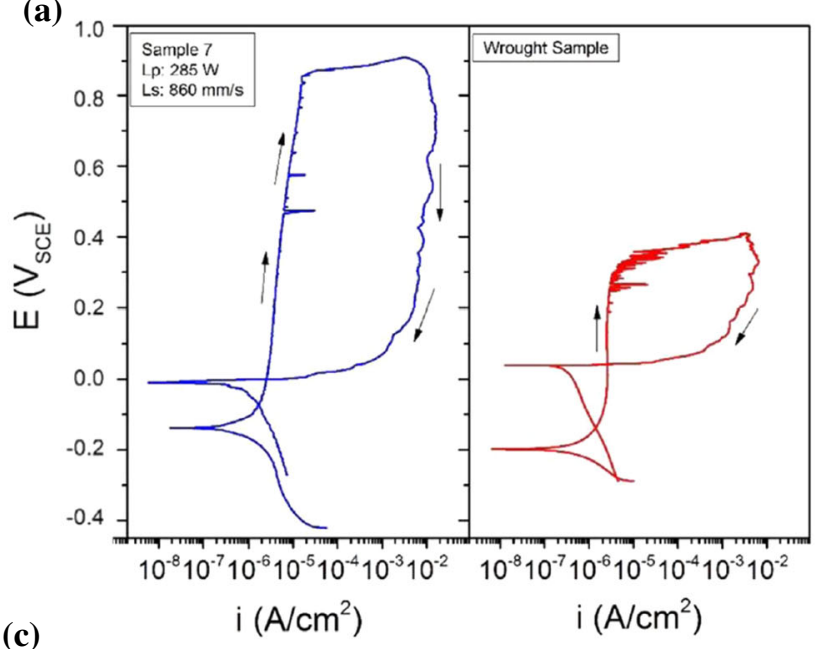

(c)

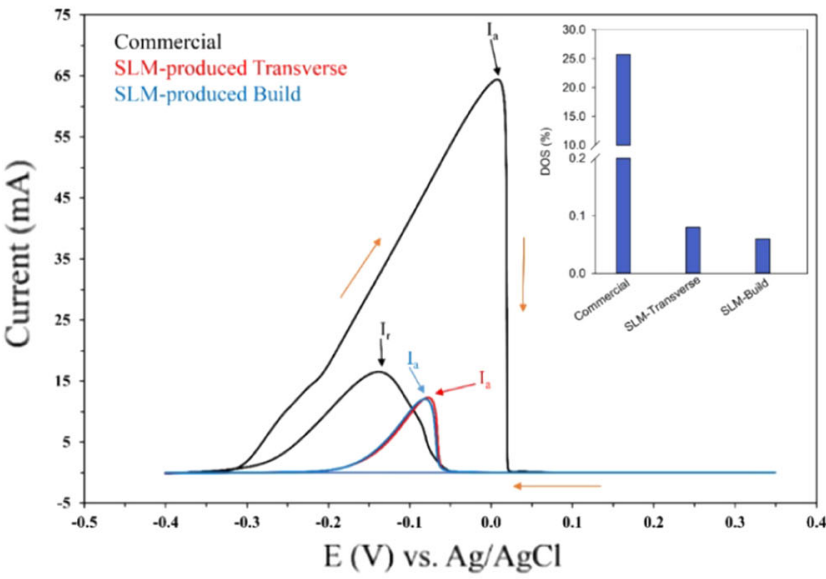

Figure 4 Representative unique corrosion characteristics of AM austenitic stainless steel. a Potentiodynamic polarisation curves recorded in $0.1 \mathrm{M} \mathrm{NaCl}$ solution, indicating an exceptionally higher pitting corrosion resistance for LPBF (= selective laser melting, SLM) 316L austenitic stainless steel compared to a wrought sample. b Potentiostatic polarisation curves recorded using a jet impingement setup in a $0.6 \mathrm{M} \mathrm{NaCl}$ solution containing $2.5 \mathrm{wt} \%$ sand particles, showing a lower erosion-corrosion resistance for LPBF 316L austenitic stainless steel compared to its conventional counterpart. c Double-loop electrochemical potentiokinetic reactivation (DL-EPR) test recorded in $0.5 \mathrm{M}$ $\mathrm{H}_{2} \mathrm{SO}_{4}+0.01 \mathrm{M} \mathrm{KSCN}$, along with the degree of sensitisation values (inset), showing a substantially higher IGC resistance for

solidification inherent to AM that limits the formation of MnS inclusions [64, 65].

Given the excellent pitting corrosion resistance and high hardness and wear resistance, as discussed previously, AM austenitic stainless steel is expected to exhibit an enhanced erosion-corrosion resistance compared to its conventional counterpart. However, (b)
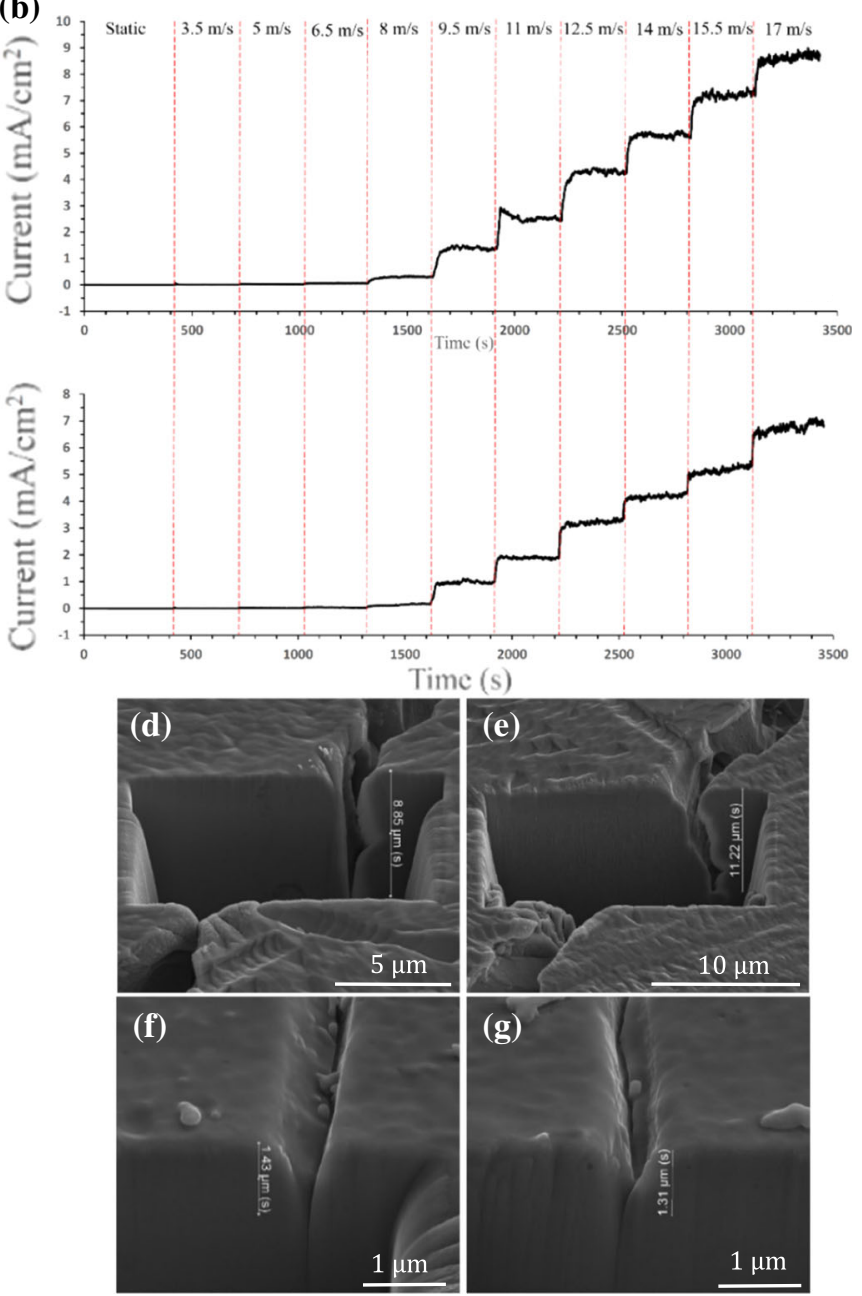

LPBF 316L austenitic stainless steel at both transverse and building planes relative to the conventional $316 \mathrm{~L}$ austenitic stainless steel. For sensitisation purpose, the specimens were heat-treated at $700{ }^{\circ} \mathrm{C}$ for $60 \mathrm{~h}$ followed by water quenching. $\mathbf{d}-$ g Post-DL-EPR images of the corroded grain boundaries acquired by focused ion beam SEM from $\mathbf{d}$, $\mathbf{e}$ conventional and $\mathbf{f}, \mathbf{g}$ LPBF 316L austenitic stainless steel specimens, indicating an extensive intergranular corrosion for conventional 316L austenitic stainless steel, while much shallower corrosion along grain boundaries is detected for LPBF $316 \mathrm{~L}$ austenitic stainless steel. a is adapted from Ref. [62], b from Ref. [63], c, $\mathbf{g}$ from Ref. [36], with permission.

Laleh et al. [63] report an unexpected lower erosioncorrosion resistance for LPBF 316L austenitic stainless steel (Fig. 4 b), which is due to the weaker repassivation ability in LPBF 316L austenitic stainless steel compared to its conventionally processed counterpart. This is in good agreement with other studies $[62,66,67]$. The mechanism behind this behaviour is 
still unclear; however, the presence of internal porosities and the inhomogeneous microstructure of AM steel are supposed to be the major factors. In this regard, a recent study by Kong et al. [68] shows a similar repassivation potential for LPBF 316L austenitic stainless steel to its conventional counterpart by eliminating the porosity content $(<0.03 \mathrm{vol} \%)$.

Intergranular corrosion (IGC) of stainless steel is a localised form of corrosion that proceeds along the grain boundaries and usually happens during exposure to high temperatures (between 500 and $800{ }^{\circ} \mathrm{C}$ ) or welding $[69,70]$. Formation of secondary precipitates like $\mathrm{Cr}$-rich carbides, $\sigma$ and $\chi$ phases along the grain boundaries leaves the adjacent areas more susceptible to corrosion during subsequent exposure to corrosive environments. IGC of AM stainless steel is still under dispute. Some studies report an accelerated interfacial corrosion in LPBF 316L [71, 72] while some others show an opposite behaviour [36]. The enhanced IGC resistance of the LPBF 316L austenitic stainless steel (Fig. $4 \mathrm{c}-\mathrm{g}$ ) is attributed to the presence of a large volume of low angle grain boundaries and twin boundaries [36], which are believed to be not susceptible to IGC. The existing disagreement in the IGC behaviour of AM stainless steels could be related to the sensitisation conditions (heat treatment temperature, cooling conditions) and/or IGC test method.

It has been shown that LPBF 316L austenitic stainless steel has a superior hydrogen damage resistance compared to its conventional counterpart [73], indicating that LPBF 316L austenitic stainless steel could be an option for using in hydrogen fuel cells. This behaviour is mainly attributed to the lower degree of austenite to martensite transformation and, thus, lower volume fraction of martensite in LPBF 316L austenitic stainless steel upon exposure to $4 \mathrm{~h}$ hydrogen charging, as the martensite phase has a poorer corrosion resistance than austenite in these steels. A similar conclusion has been made by Baek et al. [74] who report a higher resistance to hydrogen embrittlement under high-pressure $\mathrm{H}$ atmosphere for AM 304L austenitic stainless steel compared to its conventional counterpart, which is mainly discussed based on the stability of the austenite phase that does not transform to martensite phase under load stress. These results indicate an ability of the AM austenitic stainless steel to resist again phase transformation during $\mathrm{H}$ charging; however, the mechanism behind this phenomenon is still not clear in the literature and needs to be clarified in future work.

\section{Challenges}

Despite the above-mentioned promising properties offered by AM, there are still many important challenges inherent to AM of austenitic stainless steels that hinder their widespread industrial application. The most important challenges that AM currently encounters in austenitic stainless steels manufacturing will be reviewed in the following. They include residual stresses, anisotropy, formation of pores and post-processing via heat treatments.

The sharp thermal gradients associated with AM generate large residual stresses that cause part distortion [75, 76]. This will subsequently affect mechanical properties, decrease the stress corrosion cracking resistance [77-79] or even deteriorate final geometry [80] of the parts. Preheating the build substrate or feedstock material is the most common way to decrease temperature gradients and, thus, reduce residual stresses [81]. Controlling the scanning strategy is another approach to reduce residual stresses [82-84]. Other than these 'in situ' methods for controlling residual stresses, heat treatment postprocessing has also been reported to be beneficial in terms of releasing residual stresses [85].

Anisotropy in AM is a critical issue and can be categorised into two types: first, anisotropy that arises from building a part in different directions and second, anisotropy that arises from property measurements along different axes. It has been well understood that the building direction (the acute angle between the long axis of the fabricating part and the horizontal plane) can cause anisotropy in the microstructure and mechanical properties of AM austenitic stainless steel parts [86-88]. The columnar grain structure and strong crystallographic texture along the building direction have been known as major contributing factors to anisotropy in the mechanical properties of AM austenitic stainless steel parts [89]. For instance, it has been shown that the UTS in horizontally built specimens (loading direction parallel to the layers in the microstructure) is almost $20 \%$ higher compared to that of the vertically built specimens [88]. This behaviour is related to the preferential formation of defects between the successive layers during AM fabrication, which thereafter results in a decreased strength when the loading 
direction is perpendicular to the layers. Anisotropy has not been reported as a critical issue in corrosion properties of AM austenitic stainless steel as long as high-density specimens are produced. The focus in the literature is on the response of the different planes (i.e. transverse and building planes) against various kinds of corrosion, and most of the studies report similar corrosion characteristics in terms of pitting [27, 67, 90] and intergranular [36] corrosion resistances at all planes. It has also been shown that the building direction does not have a significant influence on the tribological performance of the LPBF 316L austenitic stainless steel under dry sliding wear test [91].

Different types of pores have been reported in AM austenitic stainless steels [41, 67-73]. LOF pores are shown to be more detrimental to wear properties [66, 92, 93], fatigue resistance [94, 95] and corrosion resistance [96-98] than spherical gas pores, since they act as the crack initiation site during tensile testing and pit formation site upon immersion in a corrosive environment. Examples of pit development at the sites of LOF pores in AM austenitic stainless steels when subjected to corrosive environments are presented in Fig. 5, indicated by potentiodynamic polarisation tests and three-dimensional computed tomography analysis. They show that the pitting corrosion resistance will decrease in the presence of LOF pores because of their susceptibility to act as the pit formation sites. Spherical gas pores have also been classified as open and covered pores based on their geometry at the top external surface. Open spherical gas pores are found to be less susceptible to stable pit formation compared to the semi-covered ones, which is attributed to the differences in the ions diffusion rates upon exposure to corrosive environments [99].

Interaction between the heat source and feedstock material during AM leads to a large number of rapid heating and cooling cycles, which might result in a microstructure far from the equilibrium conditions. In this regard, post-processing treatments including stress relief heat treatment and hot isostatic pressing (HIP) have been commonly used to eliminate these issues. Current standards for the heat treatment of austenitic stainless steels have all been developed for the cast and wrought materials and not optimised for AM parts. Examining the effect of such heat treatments on the properties of the AM parts and optimising heat treatment routes for AM products is therefore essential.
As an example, in terms of corrosion properties, solution annealing heat treatment at a temperature range between 1010 and $1120^{\circ} \mathrm{C}$ has generally been used for conventional austenitic stainless steel to increase corrosion resistance through dissolving carbides into the solid solution of the $\gamma$ matrix $[100,101]$. A summary of dependence of pitting potential for LPBF 316L austenitic stainless steel on the post-processing heat treatment is presented in Table 1. This table summarises a wide range of post-processing heat treatments (temperature, holding time and cooling conditions) used in the literature. In most of cases, heat treatment above $1000{ }^{\circ} \mathrm{C}$ leads to a decrease in the pitting corrosion resistance, suggesting that the commonly used solution annealing heat treatment for conventional austenitic stainless steels may not be applicable for AM 316L austenitic stainless steel.

It has been shown that heat treatments at temperatures above $1000{ }^{\circ} \mathrm{C}$ drastically decrease the pitting corrosion resistance $[64,68,102]$, indicating that such heat treatments are not practical for AM austenitic stainless steel in applications where high resistance to pitting corrosion is required. There is still no agreement on the mechanism behind the drastic decline in pitting corrosion resistance after subjecting to temperatures above $1000{ }^{\circ} \mathrm{C}$, although some authors believe that formation of detrimental MnS inclusions is responsible for this phenomenon [64] while others propose that release of compressive residual stresses leads to such behaviour [102]. Apparently, a heat treatment at high temperatures leads to the partial/complete transformation of some existing inclusions to inclusions with different chemical compositions, and even the formation of some new inclusions that were not present in the as-built condition $[48,64]$. The mechanism behind the inclusion transformation under such high-temperature heat treatments remains unclear.

\section{Maraging and precipitate hardening stainless steels}

\section{Introduction}

A number of steels have been developed which can undergo age hardening through the precipitation of phases other than carbides. Two such classes of alloys that have been extensively analysed for their 
(a)

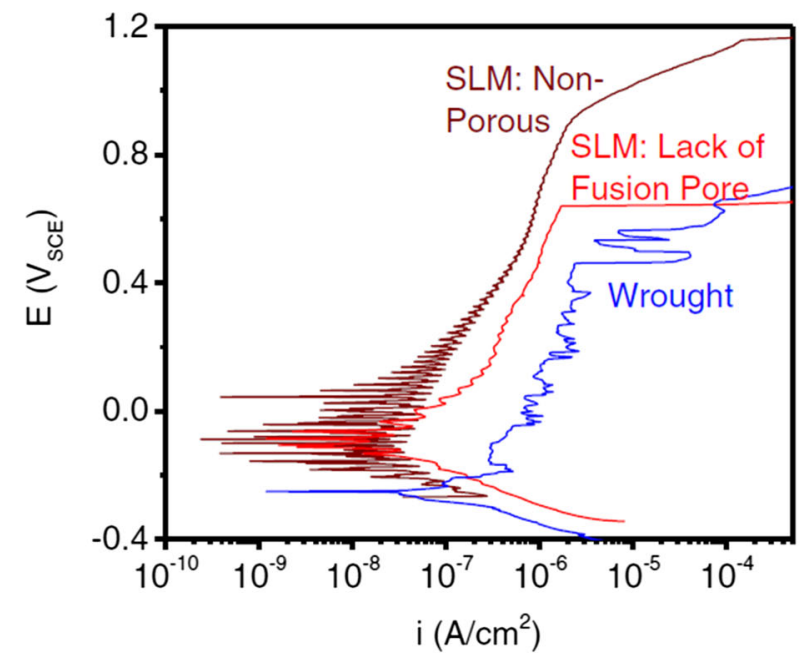

(b)

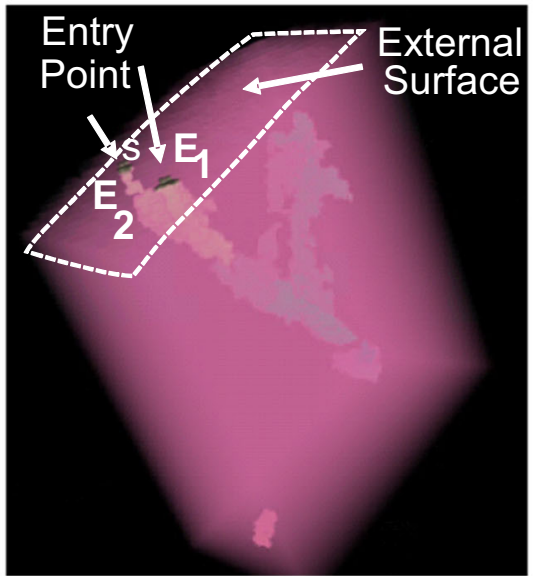

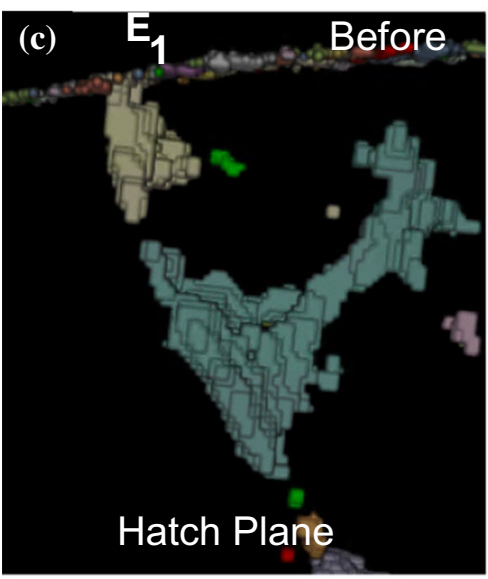

(d)

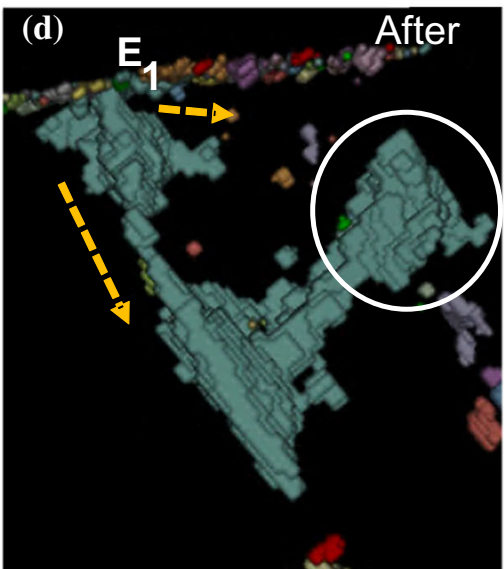

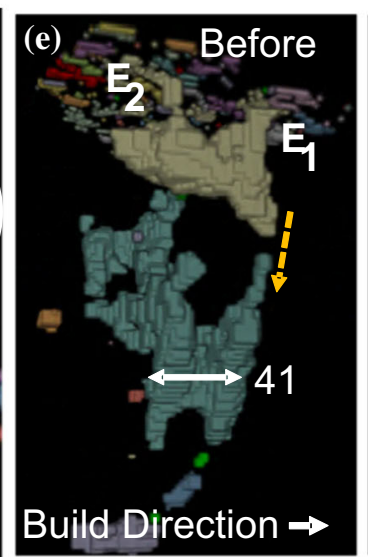

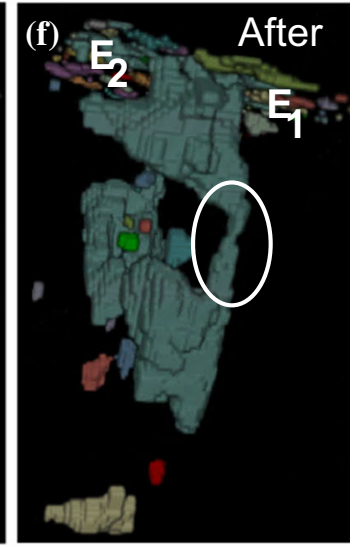

Figure 5 The role of LOF pores in pitting corrosion of AM austenitic stainless steels. a Potentiodynamic polarisation curves obtained using a micro-electrochemical cell in $0.6 \mathrm{M} \mathrm{NaCl}$ solution for LPBF 304L stainless steels, showing that the testing areas containing LOF pores have lower pitting corrosion resistance than the areas with no pores. $\mathbf{b}-\mathbf{f}$ Three-dimensional computed tomography imaging of an LPBF $316 \mathrm{~L}$ austenitic stainless steel specimen before and after one-week immersion into $6 \mathrm{wt} \%$ ferric chloride solution, indicating the development of corrosion within a LOF pore. $b$ General overview of the target LOF pore. The external surface is indicated by the dashed white line. The entry points into the LOF structure are also indicated by the labels E1 and E2. c, d LOF pore before and after corrosion, respectively;

suitability for production through AM are precipitation hardening $(\mathrm{PH})$ stainless steels and maraging (i.e. martensitic and aging) steels. Although $\mathrm{PH}$ stainless steels may also have matrix phases that are austenitic or semi-austenitic [105], the only PH stainless steels discussed in this section are classified as martensitic, as these are the most widely researched in the field of AM. Both alloy classes exhibit similar precipitate strengthening behaviour. They only entry point E1 can be seen from this perspective. c Shows two major LOF structures in off-white and cyan. $\mathbf{d}$ Shows that after corrosion these structures are connected via the LOF pores indicating propagation of corrosion within the structure. e, f Shows the LOF structure within the powder bed plane before and after corrosion, respectively. The spacing between two linear features is around $40 \mu \mathrm{m}$ which is slightly larger than the powder bed thickness of $30 \mu \mathrm{m}$. Entry points E1 and E2 are also shown. f After corrosion, all these independent features have the same colour indicating that they are joined. The white ellipse indicates where the corrosion has propagated from the off-white LOF structure to the cyan LOF structure. a is adapted from Ref. [97] and $\mathbf{b}-\mathbf{f}$ from Ref. [96], with permission.

have a low $\mathrm{C}$ content, in order to suppress carbide precipitation [7], which is particularly detrimental to corrosion resistance in stainless steels [105]. Martensitic PH stainless steels have moderate $\mathrm{Ni}$ content (4-11 wt\%) [105] whilst maraging steels have higher Ni content (17-25 wt\%) [7]. After quenching from the austenite phase field, the room temperature microstructure of these alloys is mainly martensitic but may contain some retained austenite depending 
Table 1 Influence of post-processing heat treatment on the pitting corrosion resistance of LPBF $316 \mathrm{~L}$ austenitic stainless steel

\begin{tabular}{|c|c|c|c|c|c|c|}
\hline Material & $\begin{array}{l}\text { Temperature } \\
\left({ }^{\circ} \mathrm{C}\right)\end{array}$ & $\begin{array}{l}\text { Holding time } \\
\text { (min) }\end{array}$ & $\begin{array}{l}\text { Cooling } \\
\text { condition }\end{array}$ & $\begin{array}{l}\text { Pitting potential } \\
\text { (V) }\end{array}$ & Testing solution & Refs. \\
\hline \multirow[t]{3}{*}{ LPBF $316 \mathrm{~L}$} & 400 & 240 & \multirow[t]{3}{*}{-} & $0.83 \pm 0.05$ & \multirow[t]{3}{*}{$0.58 \% \mathrm{w} / \mathrm{V} \mathrm{NaCl}$} & \multirow[t]{3}{*}{ [102] } \\
\hline & 650 & 120 & & $0.9 \pm 0.15$ & & \\
\hline & 1100 & 5 & & $0.67 \pm 0.1$ & & \\
\hline $\begin{array}{c}\text { As-built } \\
\text { 316L }\end{array}$ & - & - & & $0.85 \pm 0.01$ & & \\
\hline LPBF 316L & 1200 & 120 & Water & 0.9 & $0.04 \mathrm{M} \mathrm{H}_{3} \mathrm{BO}_{3}$ and $0.04 \mathrm{M}$ & {$[68]$} \\
\hline $\begin{array}{l}\text { As-built } \\
\text { 316L }\end{array}$ & - & - & - & 0.9 & $\mathrm{Na}_{2} \mathrm{~B}_{4} \mathrm{O}_{7} \cdot 10 \mathrm{H}_{2} \mathrm{O}$ & \\
\hline \multirow[t]{2}{*}{ LPBF $316 \mathrm{~L}$} & 950 & 240 & \multirow[t]{2}{*}{ Furnace } & $0.794 \pm 0.010$ & \multirow[t]{2}{*}{$3.5 \mathrm{wt} \% \mathrm{NaCl}$} & \multirow[t]{2}{*}{ [103] } \\
\hline & 1100 & 60 & & $0.337 \pm 0.004$ & & \\
\hline $\begin{array}{l}\text { As-built } \\
316 \mathrm{~L}\end{array}$ & - & - & - & $0.122 \pm 0.002$ & & \\
\hline LPBF 316L & 1100 & 5 & - & $0.56 \pm 0.07$ & $0.6 \mathrm{M} \mathrm{NaCl}$ & {$[65]$} \\
\hline $\begin{array}{l}\text { As-built } \\
\text { 316L }\end{array}$ & - & - & & $0.74 \pm 0.02$ & & \\
\hline \multirow[t]{6}{*}{ LPBF 316L } & 1050 & 30 & \multirow[t]{6}{*}{ Water } & $0.70 \pm 0.05$ & \multirow[t]{6}{*}{$3.5 \mathrm{wt} \% \mathrm{NaCl}$} & \multirow[t]{6}{*}{ [104] } \\
\hline & 1050 & 240 & & $0.61 \pm 0.02$ & & \\
\hline & 1050 & 120 & & $0.60 \pm 0.02$ & & \\
\hline & 1200 & 30 & & $0.40 \pm 0.00$ & & \\
\hline & 1200 & 240 & & $0.30 \pm 0.02$ & & \\
\hline & 1200 & 120 & & $0.30 \pm 0.05$ & & \\
\hline $\begin{array}{c}\text { As-built } \\
\text { 316L }\end{array}$ & - & - & - & $0.98 \pm 0.1$ & & \\
\hline \multirow[t]{8}{*}{ LPBF 316L } & 900 & 15 & \multirow[t]{8}{*}{ Water } & $0.70 \pm 0.12$ & \multirow[t]{8}{*}{$0.6 \mathrm{M} \mathrm{NaCl}$} & \multirow[t]{8}{*}[64]{} \\
\hline & 900 & 60 & & $0.65 \pm 0.1$ & & \\
\hline & 1000 & 15 & & $0.65 \pm 0.1$ & & \\
\hline & 1000 & 60 & & $0.75 \pm 0.1$ & & \\
\hline & 1100 & 15 & & $0.45 \pm 0.12$ & & \\
\hline & 1100 & 60 & & $0.45 \pm 0.0 .07$ & & \\
\hline & 1200 & 15 & & $0.45 \pm 0.1$ & & \\
\hline & 1200 & 60 & & $0.35 \pm 0.13$ & & \\
\hline $\begin{array}{c}\text { As-built } \\
\text { 316L }\end{array}$ & - & - & - & $0.72 \pm 0.1$ & & \\
\hline
\end{tabular}

on the composition of the steel in question and the temperature to which it is quenched [7]. The high strength of these precipitation hardening steel classes has led to their use as tools. Furthermore, the high strength-to-weight ratio and decent toughness of maraging steels are particularly desirable for applications in the aerospace (from landing gear components to aircraft fittings), automotive and defence [106, 107].

The most commonly used PH stainless steel in AM research so far has been 17-4 PH stainless steel due to its good printability and diverse range of applications, owing to its combination of high strength and corrosion resistance. In conventional processing, after being cast, 17-4 $\mathrm{PH}$ parts are subjected to a solution annealing heat treatment. This is typically at $1040{ }^{\circ} \mathrm{C}$ for $1 \mathrm{~h}$, although longer solution annealing times are required for thicker samples [108]. After solution annealing and quenching to room temperature, the martensitic microstructure is supersaturated in $\mathrm{Cu}$. From this condition, referred to as condition A, the part undergoes a thermal aging treatment to induce precipitation of $\mathrm{Cu}$-rich precipitates on the nanoscale. The most commonly applied aging treatment to 17-4 $\mathrm{PH}$ is at $482{ }^{\circ} \mathrm{C}$ for $1 \mathrm{~h}$, as this has been shown to generate the highest strength in such parts [108]. This 
is referred to as the $\mathrm{H} 900$ condition. In this condition, the UTS of parts is typically around $1380 \mathrm{MPa}$ [109].

$15-5 \mathrm{PH}$ stainless steel is a similar alloy to $17-4 \mathrm{PH}$. Although much less commonly used, this alloy has also been assessed for applicability for AM in a number of studies. Whilst it is still a martensitic precipitate hardening stainless steel, changes to the alloy composition allow it to have a greater wrought toughness than 17-4 PH due to the diminished levels of $\delta$-ferrite within the microstructure [110]. The kinetics of $\mathrm{Cu}$ precipitation are very similar to $17-4$ $\mathrm{PH}$, resulting in both alloys reaching peak age hardening after the $\mathrm{H} 900$ heat treatment [111].

A maraging steel that has been widely discussed for its applicability for $\mathrm{AM}$ is the $18 \mathrm{Ni} 300$ maraging steel. After quenching from the austenite phase field to form a martensitic microstructure, aging at temperatures between 400 and $500{ }^{\circ} \mathrm{C}$ causes the precipitation of $\mathrm{Ni}_{3}(\mathrm{Ti}, \mathrm{Mo})$ and then $\mathrm{Fe}_{7} \mathrm{Mo}_{6}$ phases [112-114]. After aging at $482{ }^{\circ} \mathrm{C}$ for $6 \mathrm{~h}$, the UTS of $18 \mathrm{Ni} 300$ maraging steel parts can exceed $2200 \mathrm{MPa}$ [115]. This high strength has allowed this alloy to be used in a range of military and aerospace applications.

Another important precipitate hardening stainless steel, identified in recent research for its applicability to additive manufacturing, is CX stainless steel. This material was recently developed and commercially produced as a powder by EOS GmbH [116]. CX stainless steel parts produced using LPBF can exhibit superior toughness to LPBF 17-4 PH and 316L steels in the as-built condition, perhaps paving the way for the replacement of these steels with CX in certain applications [117]. Thermal aging treatments performed at $530{ }^{\circ} \mathrm{C}$ for $3 \mathrm{~h}$ result in the formation of rod-/needle-shaped NiAl-based nanoprecipitates within the martensitic matrix both with and without a preceding solutionising heat treatment [118, 119]. With these heat treatments, LPBF-produced CX stainless steel can be fabricated with UTS of up to $1601 \mathrm{MPa}$ [118]. Due to the relative lack of literature discussing it, CX steel will not be discussed further in the following section.

This section will summarise the literature assessing the influence of the production of $\mathrm{PH}$ stainless steels and maraging steels by AM on their properties. Most of this literature has focused on 17-4 $\mathrm{PH}$ for $\mathrm{PH}$ stainless steels and $18 \mathrm{Ni} 300$ for maraging steels.

\section{Mechanical properties}

For simplicity, the American Society for Metals (ASM) standard wrought tensile properties for the alloys discussed in this section are presented in Table 2 for comparison to the properties exhibited by AM produced parts of these steels.

\section{5-5 PH stainless steel}

AM is able to generate improvements upon the mechanical properties of conventionally processed 15-5 PH stainless steel. Comparing LPBF and conventionally manufactured $15-5 \mathrm{PH}$, distinct differences of the martensitic microstructure are observed, with the AM material showing shorter and narrower martensitic laths [121]. AM material has been shown to have $\sim 34 \%$ greater UTS of $830 \mathrm{MPa}$ at $593{ }^{\circ} \mathrm{C}$ but over $50 \%$ lower ductility, at $9 \%$ elongation to failure, than the wrought material [121, 122]. In another study on 15-5 PH samples produced by LPBF after an age hardening heat treatment, it has been shown that, compared to the ASM wrought properties of 15-5 PH (listed in Table 2), horizontally built samples show $\mathrm{a} \sim 10 \%$ increase in YS with vertically built samples showing a $\sim 6 \%$ decrease in YS. Regardless of build orientation, the UTS increases by a similar margin compared to wrought values ( $\sim 11 \%$ for horizontal builds, $\sim 12 \%$ for vertical builds). These samples have been shown to fail predominantly by cleavage fracture [122, 123]. The fracture toughness from a Charpy impact test for LPBF 15-5 PH stainless steel has been measured to be $10.85 \pm 1.20 \mathrm{~J} / \mathrm{cm}^{2}$, well within the standards for wrought samples $\left(9.4-18.6 \mathrm{~J} / \mathrm{cm}^{2}\right)[123,121]$. It has also been found that the microhardness of LPBF 15-5 PH stainless steel is greater than that of the wrought material, with the hardness in transverse direction of the AM samples being $500 \mathrm{HV} 0.5$ [121]. This is 56\% greater than the wrought material.

Cyclic loading is inherent in many desired applications for PH stainless steels. Therefore, a component's fatigue performance is one of the most important concerns in the AM of these steels. Fatigue tests have shown 15-5 PH samples fabricated by LPBF to have a $20 \%$ reduced fatigue endurance limit as compared to wrought samples [122, 124]. This is attributed to the poor surface finish resultant from the LPBF process [125]. Significant improvement in fatigue life can be achieved by surface machining of 
Table 2 Standard tensile properties (YS, UTS and elongation to failure) for the steels discussed in this section when manufactured by conventional methods as stated in the ASM handbook

\begin{tabular}{lllll}
\hline Alloy & YS/MPa & UTS/MPa & Elongation to failure & Source \\
\hline 17-4 PH (H900) minimum properties & 1170 & 1310 & 10 & {$[120]$} \\
$17-4$ PH (H900) & 1055 & 1380 & 15 & {$[108]$} \\
$15-5$ PH (H900) & 1170 & 1310 & $6-10$ & {$[120]$} \\
18Ni 300 (solution annealed) & $760-895$ & $1000-1170$ & $6-15$ & {$[108]$} \\
18Ni 300 (peak age-hardened) & 2000 & 2050 & 7 & {$[108]$} \\
\hline
\end{tabular}

the AM samples to remove surface defects $[125,126]$, but not to the point of improving upon wrought properties. This supports the observation that surface defects are the most detrimental to the fatigue performance of AM 15-5 PH stainless steel [110]. However, an optimisation of process parameters combined with surface machining has produced 15-5 PH samples with fatigue performances well comparable to those of wrought components [110].

The high-temperature creep performance of additively manufactured PH stainless steels has not been extensively studied. An improvement in creep life of $\sim 17 \%$ in LPBF $15-5 \mathrm{PH}$ samples compared to wrought samples at $530^{\circ} \mathrm{C}$ has been shown [121]. The reason for this difference is not yet fully understood.

\section{7-4 PH stainless steel}

A reduced ductility as compared to wrought parts is an issue for AM 17-4 PH stainless steel. In both condition A and the $\mathrm{H} 900$ condition, the strength of AM produced 17-4 $\mathrm{PH}$ samples has been found to be superior to conventionally produced samples but the elongation to failure is inferior [127]. This result persists in both low strain rate (quasi-static) and high strain rate (dynamic) tensile testing, which can be seen in the strain curves in Fig. 6 [127]. Many studies into AM 17-4 $\mathrm{PH}$ stainless steel parts have also shown increased strength [128-132] and reduced ductility [129, 130, 133-135] as compared to wrought parts. Increased strength is cited to be due to the refined microstructure of AM parts [127] and reduced ductility is generally attributed to porosity resultant from the AM process [129, 136].

A study by Lass et al. [134] analyses the tensile properties of a number of LPBF-fabricated 17-4 PH samples with differing post-processing heat treatments and compares the results to data for wrought samples in condition A $(\mathrm{YS}=824 \mathrm{MPa}$, UTS $=1121 \mathrm{MPa}$, Elongation to failure $=10 \%)$. An alternative post-build solution annealing treatment developed by these researchers results in a YS > 90\% of wrought samples. For comparison, the AM samples in the as-built and condition A states show YS of $\sim 55 \%$ that of wrought samples. Samples treated with this new processing route also show a greater UTS and a diminished ductility as compared to wrought samples. The general effect of post-build heat treatments on the microstructure is illustrated in Fig. 7, showing several different morphologies obtained in 17-4 PH stainless steel. The melt pool boundaries and cellular solidification structure are clearly visible in the as-built microstructure (Fig. 7a), but after homogenising and solution annealing (i.e. being treated to condition A), this solidification structure is removed. The resultant microstructure (Fig. $7 \mathrm{~b}$ ) is comparable to the wrought microstructure (Fig. 7c). Other studies have also shown these distinct microstructural changes in AM 17-4 with heat treatment [137, 138], with these changes generating increases in strength for AM 17-4 parts [127, 139].

The characteristics of the powder feedstock used to produce additively manufactured parts also have an impact on the mechanical performance [140]. It has been found that by changing the 17-4 $\mathrm{PH}$ powder and/or adjusting the laser energy density, tensile properties comparable to or greater than wrought samples can be produced [140]. Pasebani et al. [131] show a significant effect of producing 17-4 $\mathrm{PH}$ parts by LPBF from gas-atomised or water-atomised powder to conventional part production and different post-production heat treatments on the mechanical properties. Using a suitable energy density during part production, LPBF parts produced from the gasatomised powders, solution annealed at $1051{ }^{\circ} \mathrm{C}$ for 


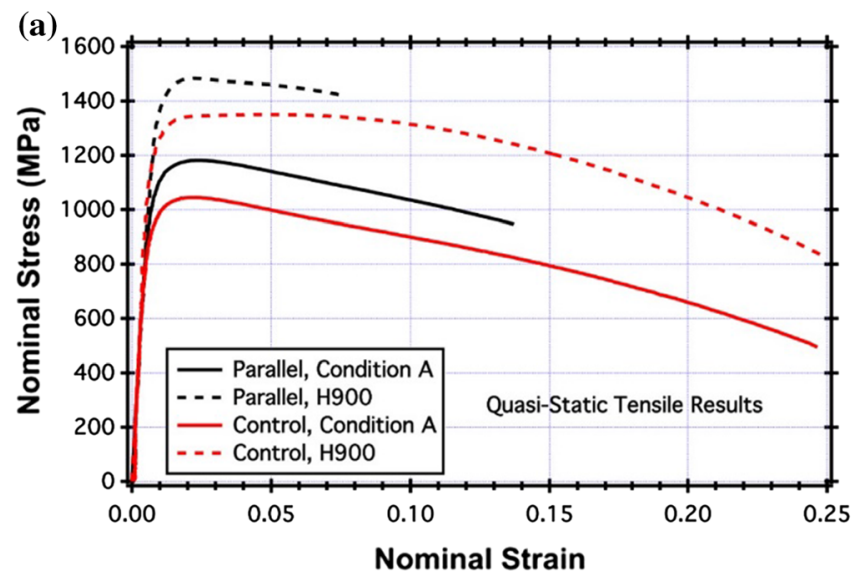

Figure 6 Stress vs strain curves for LPBF (with loading direction parallel to the $\mathrm{X}-\mathrm{Y}$ plane, normal to the building direction), shown in black, and conventionally produced, shown in red, 17-4 $\mathrm{PH}$ (b)

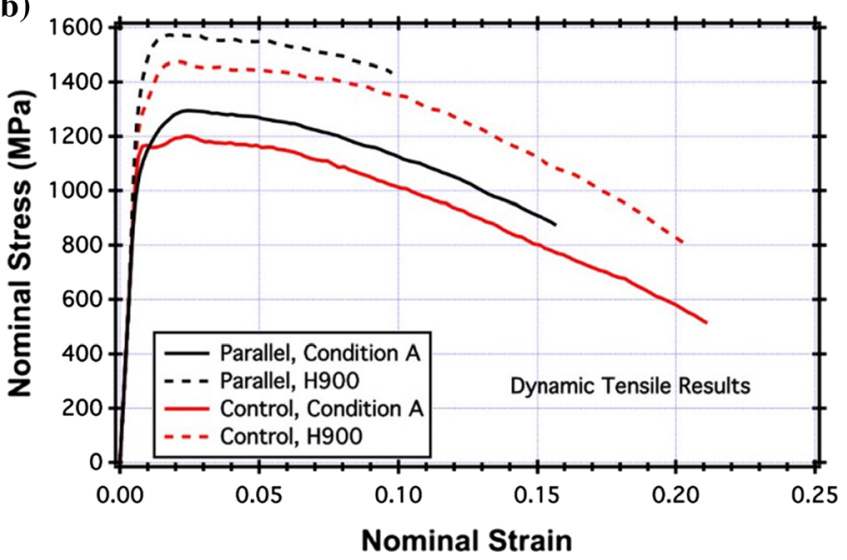

stainless steel. a Low strain rate, quasi-static tensile test results. b High strain rate dynamic tensile test results. Adapted from Ref. [127] with permission. (a)

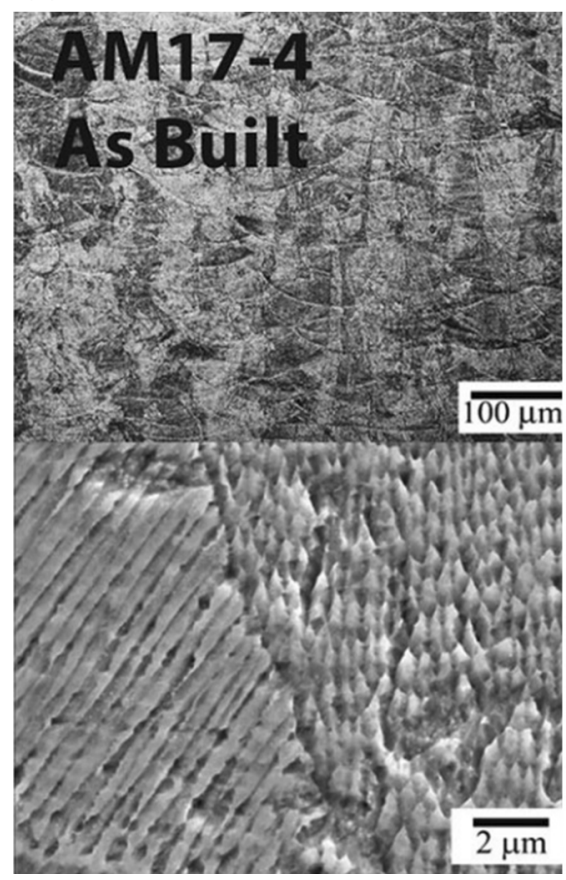

(b)

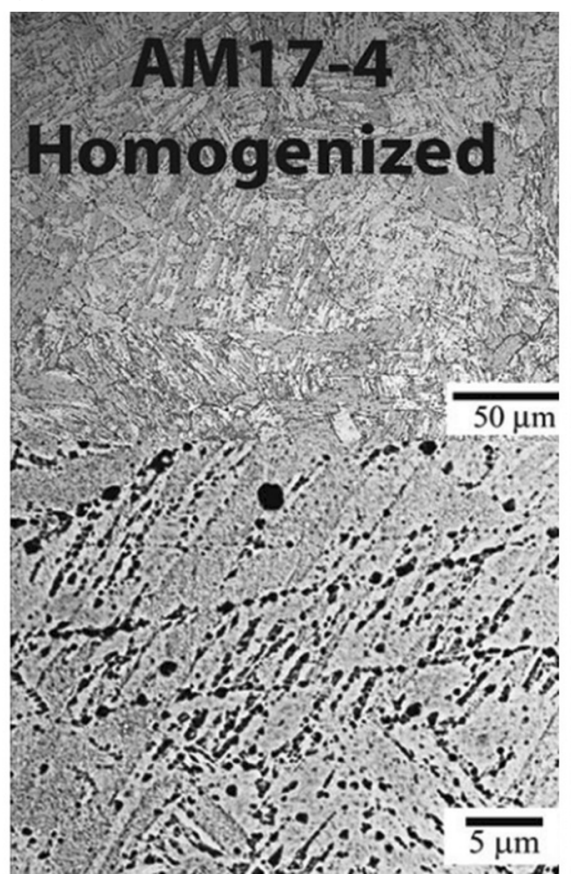

(c)

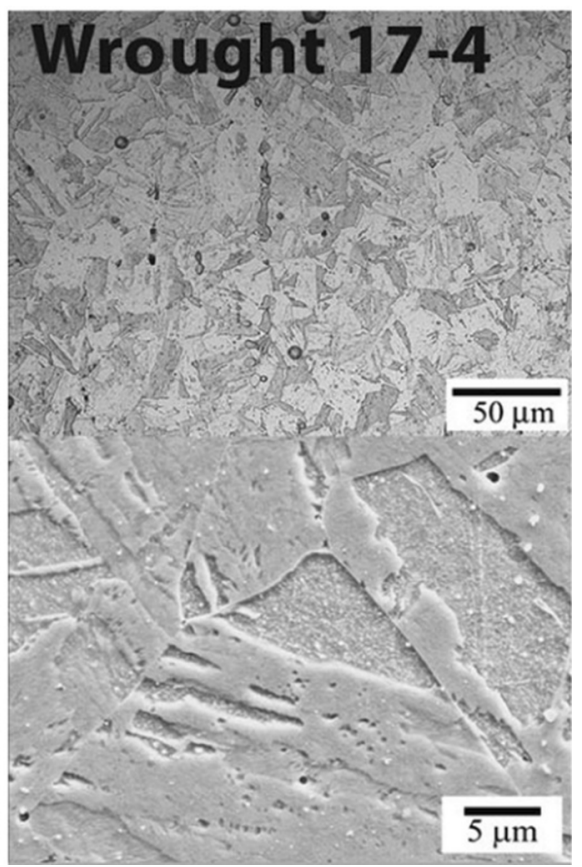

Figure 7 Optical micrographs of 17-4 PH stainless steel microstructures. (a) As-built by LPBF. (b) After a post-build homogenisation treatment. (c) Wrought. These micrographs were

$45 \mathrm{~min}$ and aged at $482{ }^{\circ} \mathrm{C}$ for $1 \mathrm{~h}$, show the greatest strength; comparable YS (consistently within 5\%) and superior UTS (up to 4.4\%) than the ASM reported data for wrought samples (from [120] in Table 2). Solution annealing at $1315{ }^{\circ} \mathrm{C}$ for $1 \mathrm{~h}$ before aging results in significantly improved YS and UTS for parts produced from water atomised powder. This is attributed to refinement in the martensitic lath taken parallel to the building direction and the rolling direction for the LPBF and wrought samples, respectively. Adapted from Ref. [141] with permission.

structure. The properties of the parts produced from water atomised powder, although still inferior ( $\sim 15 \%$ reduced YS and $\sim 4 \%$ reduced UTS) are comparable to the wrought properties. This is significant due to the relatively low cost of production of water atomised powder compared to gas atomised powder [131]. 
The presence of austenite within the microstructure has been observed to greatly affect the mechanical properties of 17-4 PH due to the transformation of austenite to martensite during mechanical testing [142-144]. AM samples of 17-4 PH with a greater austenite content exhibit greater ductility and capacities for work hardening in the same way as TRIP-assisted steels [139, 145]. 17-4 PH parts with the greatest levels of austenite in the microstructure are generally in the AM or directly aged (i.e. aged without a solution annealing treatment after fabrication) conditions [127, 143]. The results of Lebrun et al. [142] show that such samples give comparable ductility to wrought standards [108]. For instance, the as-built specimen in this study has a $36 \%$ volume fraction of retained austenite and a $16.2 \%$ elongation to failure, the expected ASM wrought elongation to failure being 15\% (Table 2). Austenite retention during LPBF in 17-4 $\mathrm{PH}$ has also shown increased ductility in compression as well as tension [146]. Figure 8a shows the AM microstructure of LPBF produced 17-4 PH, whilst Fig. $8 \mathrm{~b}$ shows the distribution of phases within microstructure, showing an increased presence of austenite along melt pool boundaries.

A comparison of the microstructure and mechanical properties of 17-4 $\mathrm{PH}$ when produced by LPBF as well as by conventional methods shows significant variation between the tensile properties achieved in all cases [136]. However, none of the results from
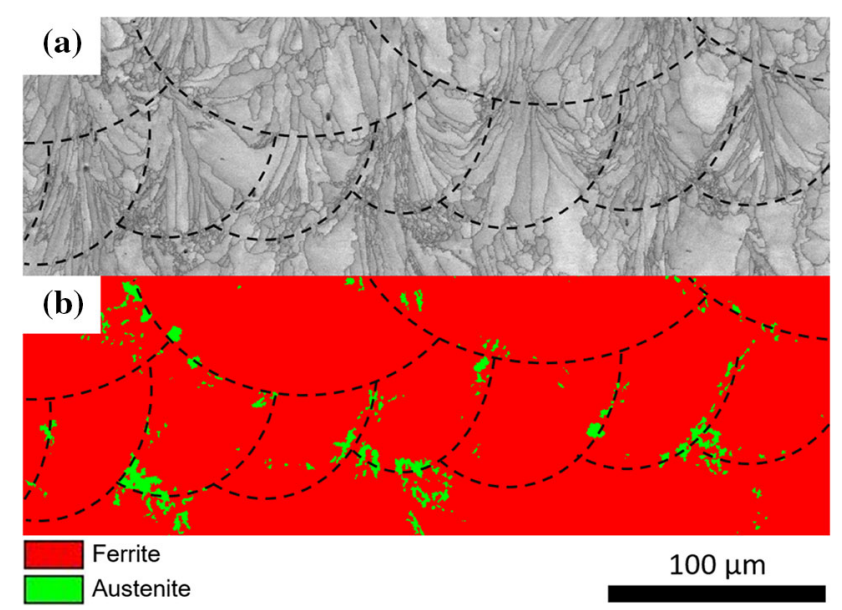

Figure 8 EBSD maps for 17-4 PH stainless steel manufactured by LPBF. a Image quality map and $\mathbf{b}$ Phase Map. Approximate locations of melt pool boundaries are shown by dashed black lines. The apparent difference in melt pool shape between layers is due to a $90^{\circ}$ rotation in the scanning strategy. Image courtesy of Maxwell Moyle and Sophie Primig (UNSW Sydney).
LPBF produced samples in this comparison are able to produce YS or UTS comparable to those of the wrought samples in the H900 condition. The variation in mechanical properties is attributed to the fact that LPBF samples show a greater level of retained austenite as well as porosity within the microstructure [136]. It is important to note that the presence of austenite in precipitate hardening steels affects their hardenability as solute atoms may be more soluble in austenite than in either ferrite or martensite, which inhibits their ability to form precipitates upon aging [142]. Absence of precipitation in austenitic regions of the microstructure has been observed both in 17-4 $\mathrm{PH}$ [142] and 18Ni 300 maraging steels [147]. Atom probe analysis of $18 \mathrm{Ni} 300$ maraging steel given in Fig. 9 shows this effect. Figure 9a, b shows martensitic areas of microstructures, each after some form of thermal aging. Intermetallic precipitates form as shown by the enclosed iso-concentration surfaces. Contrastingly, the atom probe dataset shown in Fig. 9c exhibits an interface between an austenitic and a martensitic area of the microstructure in an AM produced sample. The total absence of precipitation in the austenite as compared to the martensite is apparent.

The atmosphere in which AM is carried out has also been shown to affect the properties of AM 17-4 PH stainless steel. A study into the effect of building atmosphere on mechanical properties of 17-4 $\mathrm{PH}$ stainless steel when produced by directed energy deposition (DED), an AM technique where the metal powder is fed directly into the melt pool without the need to form a powder bed, has been conducted by Wang et al. [148]. Two chamber atmospheres have been considered in this study, Ar and air. Whilst the UTS of all the samples produced by AM are lower than that of conventionally produced samples [108], an increase in strength is noted for the samples processed in air, namely the UTS of air processed samples after heat treatment reaches $1145 \mathrm{MPa}$. This represents a 7\% increase in the Ar processed sample in the same condition. Further analysis of the microstructure led the authors to conclude that this is due to dispersion strengthening effect of amorphous oxides and solution strengthening of $\mathrm{N}$ resultant from processing in air. Furthermore, it has been shown that [149] printing in an $\mathrm{N}_{2}$ atmosphere, producing an austenitic microstructure, leads to $17-4 \mathrm{PH}$ parts with comparable UTS and ductility to wrought 
(a) LMD

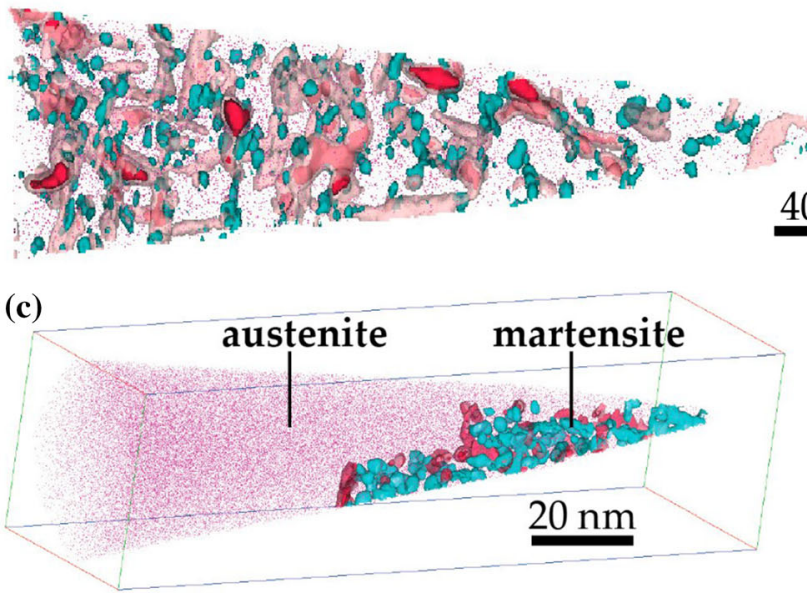

(b) conventional

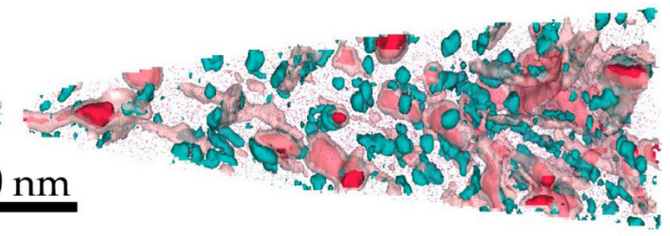

(c)

Figure 9 Atom probe tomography conducted on $18 \mathrm{Ni} 300$ maraging steel. a DED (= LMD) produced material versus b conventionally produced material. (c) Another data set from

parts due to significant strain hardening during plastic deformation in tensile testing [149].

The scatter graph in Fig. 10 shows a number of different combinations of UTS and ductility for additively manufactured 17-4 $\mathrm{PH}$ stainless steel reported. This figure also shows the properties for conventionally manufactured 17-4 $\mathrm{PH}$ samples to which the AM properties are compared in the literature. It should be noted when viewing this figure that the parameters of the AM process, surface treatments and post-build aging treatments vary between each study and between samples in the same study. From this figure, it can be seen that there is both a wide range of properties that have been achieved in the AM of this alloy and a wide range of reported wrought properties. It can also be seen that without optimisation of the AM process as well as post-build treatments, the resulting material can have very poor strength and/or ductility. However, this plot does highlight that with the optimisation, comparable or even enhanced properties compared to wrought values are possible. The combination of excellent UTS and ductility achieved by Facchini et al. [145] is partly due to the high levels of austenite within the microstructure of the material produced, which undergoes a strain induced transformation to martensite during tensile testing. Rafi et al. [139] also attribute the large ductility of their as-built sample to this effect. It is to be noted that the results by Dobson et al. [149] are presented in engineering stress.
DED-produced material showing the difference in precipitation behaviour between austenite and martensite. Adapted from Ref. [147] with permission.

Figures 11 and 12 show scatter plots composed of data from literature showing the UTS and elongation until failure, respectively, against the measured austenite volume fraction of additively manufactured 17-4 PH stainless steel. Figure 11 shows no strong dependence of UTS on the austenite volume fraction, with a UTS range of around $700 \mathrm{MPa}$ displayed across the austenite content range. Considering the datapoints taken from individual sources, both positive (Hsu, 2019 [143]) and negative (Lass, 2019 [134]) correlations between UTS and austenite volume fraction can be seen. This demonstrates that the UTS is dependent on factors other than the austenite content. The large variation in UTS is caused, in part, by the difference in printing parameters as well as the differing post-build thermal treatments. This results in differing levels of $\mathrm{Cu}$ precipitation within the microstructure. Examining individual datasets in Fig. 12, it can be seen that many show clear correlations between elongation to failure and austenite volume fraction, which is in agreement with observations of the presence of austenite increasing the ductility due to the TRIP effect [139, 145].

Comparable microhardness to wrought samples ( $\sim 450 \mathrm{HV} 0.5$ ) can be achieved during the LPBF of 17-4 PH with appropriate process parameters optimisation and heat treatment [129] as well as chamber gas [150]. 17-4 PH samples produced by atomic diffusion AM have also been investigated [151]. In the as-printed state and following any heat treatment investigated, atomic diffusion additively 

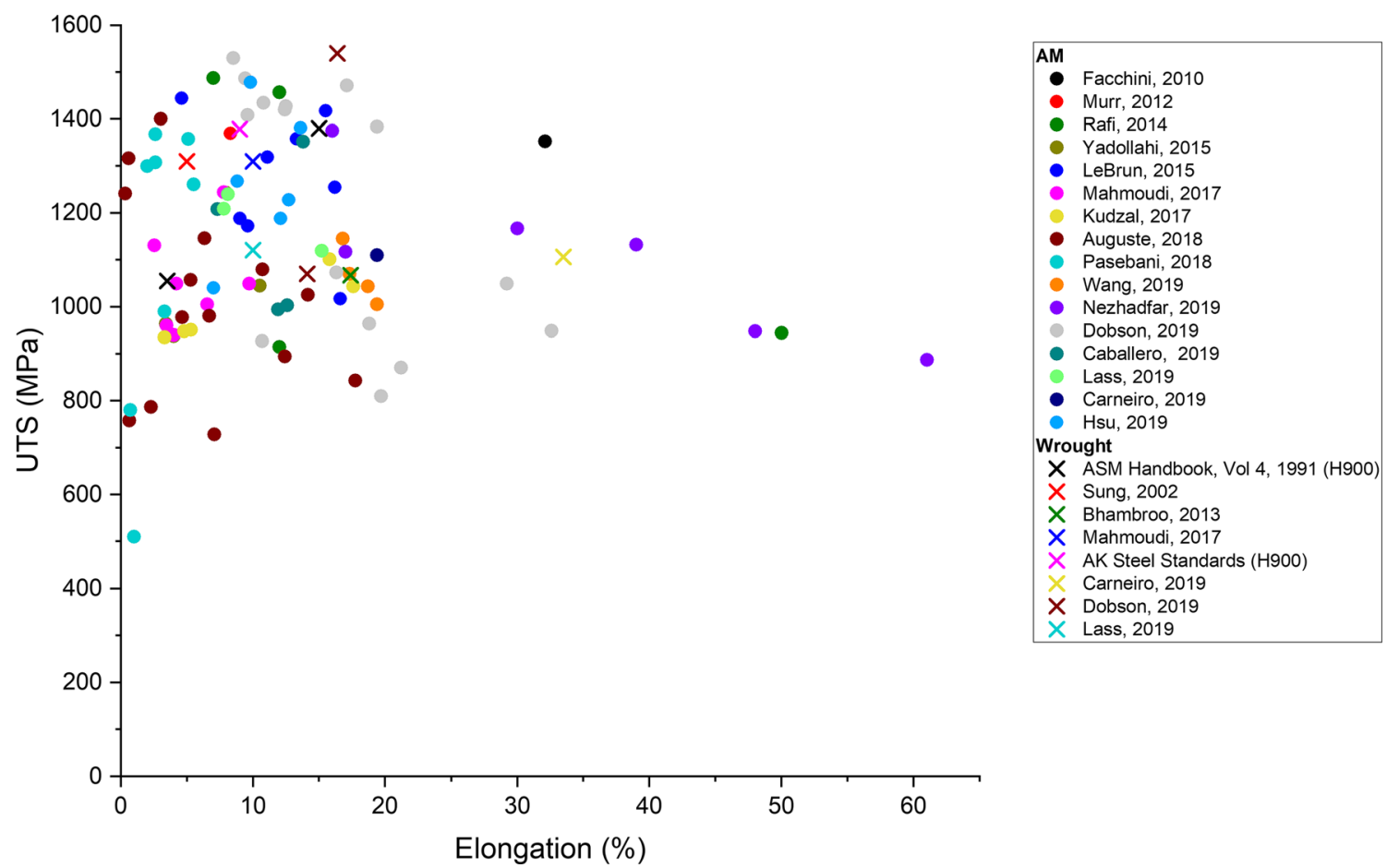

Figure 10 Scatter plot showing ranges of ultimate tensile stress and elongation to failure reported in literature for 17-4 PH stainless steel samples made by additive manufacturing, along with the properties of wrought samples to which they were compared [108, 109, 129-131, 134-136, 139, 142, 143, 145, 148, 149, 152-157].

manufactured samples have shown inferior hardness to cast samples.

The wear performance of LPBF 17-4 PH stainless steel parts relative to wrought parts has been shown to be dependent on the dominant wear mechanism. When tested dry, conventionally manufactured specimens show a greater wear rate than LPBF produced samples. This is a result of the finer microstructure and greater hardness of LPBF samples. However, in the lubricated condition, LPBF samples show a higher wear rate. This has been attributed to the fact that lubrication changes the dominant wear mechanisms from adhesion to surface fatigue and abrasion [144, 154].

As is also the case for monotonic mechanical properties, the most widely investigated precipitation hardening steel for its resistance for failure under cyclic loading after production by AM has been 17-4 PH. A study by Carneiro et al. [135] compares the fatigue behaviour of LPBF 17-4 PH to conventionally manufactured samples. The conventionally manufactured samples have a fatigue endurance limit (greatest stress amplitude of cyclic loading at which the sample will never fail) of $640 \mathrm{MPa}$ whilst for the
AM samples only show fatigue limits of $300 \mathrm{MPa}$. This reduction in fatigue strength is attributed to defects and poor surface finish [109, 158]. LPBF 17-4 $\mathrm{PH}$ samples exhibit a lower fatigue strength than wrought samples even after solution quenching as AM samples have a lower resistance to crack initiation due to the presence of defects [158]. However, LPBF samples interestingly show a lower rate of crack growth than conventionally produced samples. This is attributed to the effect of crack deflection and crack branching observed in AM and not wrought samples [158].

Some studies into the fatigue behaviour of AM 17-4 PH stainless steel have analysed the effect of subsequent heat treatments on the fatigue performances of these samples [132]. It has been determined that after solution annealing and aging, 17-4 LPBF parts still show lower fatigue strengths than wrought samples following the same thermal treatment [132]. Yadollahi et al. [87] also report that the fatigue strength of their LPBF 17-4 PH samples is far lower than wrought material which is attributed to the defects resultant from the LPBF process. The authors report that solution heat treating and aging 


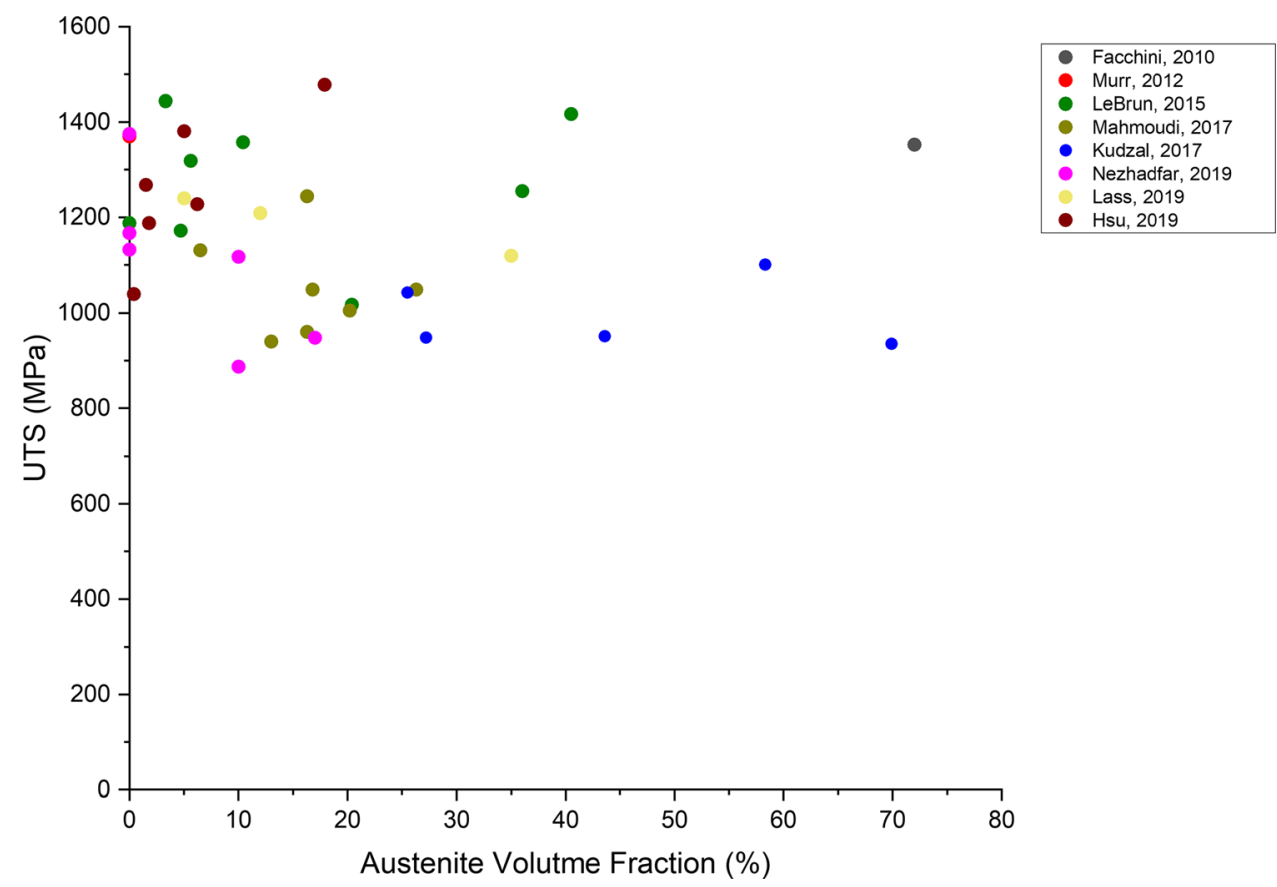

Figure 11 Scatter plot showing ranges of ultimate tensile stress against volume fractions of austenite reported in literature for 17-4 PH stainless steel samples made by additive manufacturing [129, 132, 134, 142, 143, 145, 152, 153].

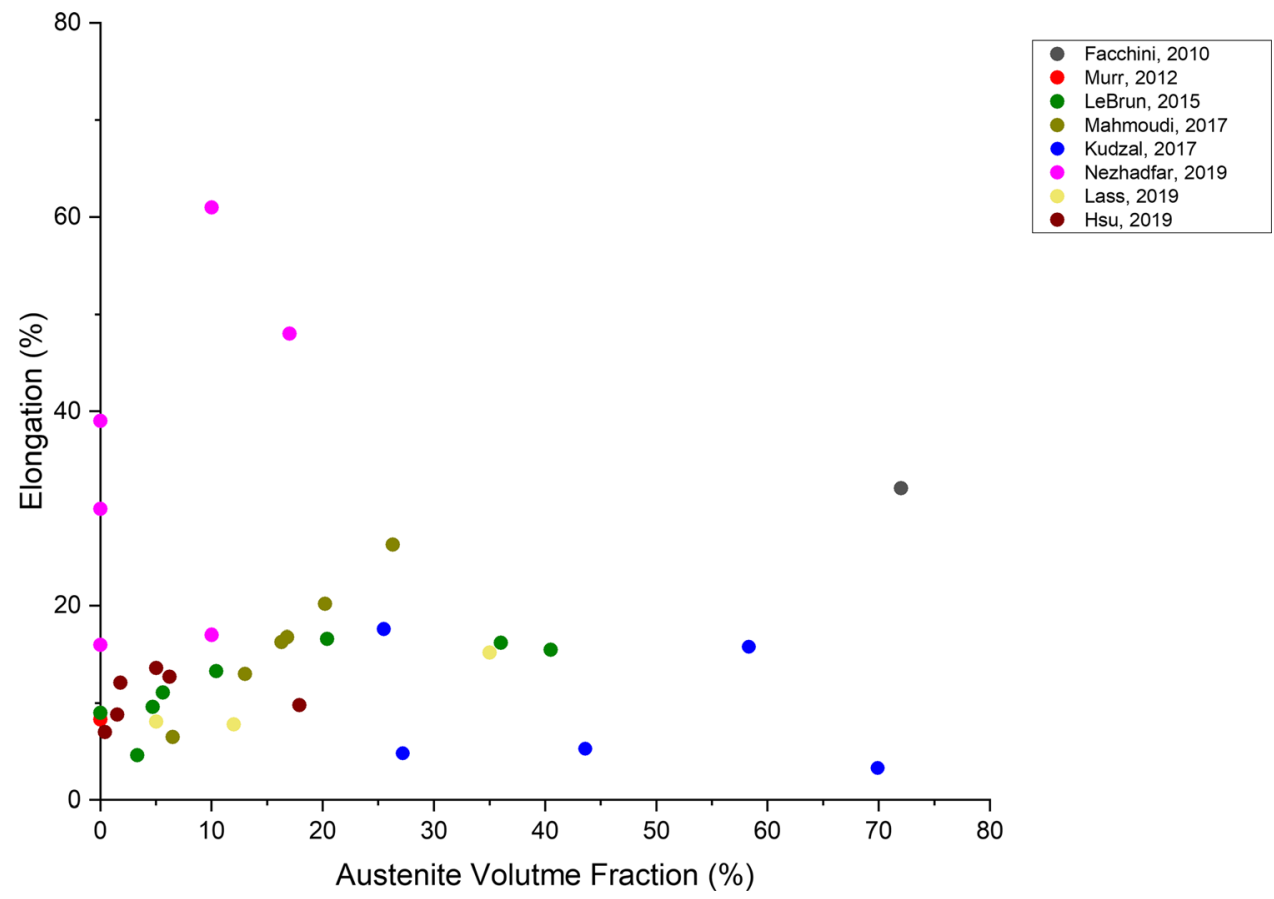

Figure 12 Scatter plot showing ranges of elongation to failure against volume fraction of austenite reported in literature for 17-4 PH stainless steel samples made by additive manufacturing [129, 132, 134, 142, 145, 152, 153].

the samples to the $\mathrm{H} 900$ condition results in improved fatigue resistance in 'low-cycle' fatigue but worsens the 'high cycle' fatigue lives. This is thought to be due to the hardening caused by the heat treatment resulting in an increased sensitivity to impurities. This sensitivity is less pronounced in the low- 
cycle regime. This effect is not seen in wrought samples [87, 159]. A similar effect is also observed in the analysis of the LPBF 15-5 PH alloy [126].

\section{Ni 300 maraging steel}

Changing the processing parameters towards achieving highest density has been an important means to achieve optimum properties in this grade of steel. A study by Casalino et al. [160] shows that optimisation of the density of the resultant parts from the LPBF processing of $18 \mathrm{Ni} 300$ maraging steel can result in advanced strength. The parts which have the maximum density $(\rho=99.7 \%)$ show a UTS of $1192 \mathrm{MPa}$ and an elongation to failure of $8 \%$, an improvement upon the typical solution annealed UTS of $18 \mathrm{Ni} 300$ maraging steel in the solution annealed condition and within the range of ductility (Table 2).

As with the 17-4 PH alloy system, post-build heat treatments have been shown to increase the mechanical properties of $18 \mathrm{Ni} 300$ maraging steel. Kempen et al. [161] have produced $18 \mathrm{Ni} 300$ maraging steel by LPBF with a UTS of $2217 \mathrm{MPa}$ following solution and aging heat treatments. This is even superior to the ATI datasheet reported values for the standard wrought UTS of this alloy in the same condition of $\sim 2210 \mathrm{MPa}$ [162]. It has been also found that the best tribological performance and UTS for LPBF $18 \mathrm{Ni} 300$ maraging steel both occur after the same thermal treatment [163]. With the appropriate selection of process parameters and building strategy [164, 165], it is feasible to produce $18 \mathrm{Ni} 300$ maraging steel samples with YS and UTS comparable and even superior to those of the ASM standard wrought properties (shown in Table 2) in both the solution treated and aged conditions [108, 164, 165]. It is generally the case that the ductility of LPBF samples is inferior to those exhibited by wrought samples, but in some cases they can be comparable. As is also the case for the 17-4 PH alloy system, many studies into the $\mathrm{AM}$ of $18 \mathrm{Ni} 300$ maraging steel have also shown comparable or increased strength but reduced ductility in comparison to wrought data from literature [106, 112, 161, 166-168]. The increase in strength is attributed to aging during the LPBF process due to cyclic reheating of the metal as well as the fine resultant solidification structure [106, 161]. The decrease in ductility is attributed to the presence of defects in AM parts [167].
Figure 13 is a scatter plot showing the combinations of UTS and ductility for additively manufactured $18 \mathrm{Ni} 300$ maraging steel samples from literature. As is the case with Fig. 10, it is important to consider that different process parameters and treatments have been used to produce each data point. It is particularly apparent from this figure, the difference in strength between samples that did or did not undergo an aging heat treatment, with those that did being grouped together on the scatter plot at a much higher UTS. This plot also shows the scale of improvement in mechanical properties that can be achieved by optimising the AM part production process.

In a study on the production of $18 \mathrm{Ni} 300$ maraging steel by LPBF and DED, Jägle et al. [147] compare the build hardness values as a function of build height to conventionally processed material in the solution annealed and quenched conditions (i.e. with little to no precipitation). The LPBF and conventionally produced material give similar hardness values, around $310 \mathrm{HV}$ 10. In the DED-produced material, however, the hardness is distinctly greater, around 360-420 HV 10 , except for the topmost layers. Atom probe analysis reveals that this is because early stages of precipitation already occur in the as-built DED sample. This is resultant from the cyclic reheating of already solidified layers of material as new layers are deposited during the DED process, which explains why the hardening effect is not observed in the topmost layers of the builds. This effect must also take place in LPBF, though it is clearly not as significant. This is likely due to the fact that the melt pool is smaller and the scan speed is higher in LPBF than in DED which led to a reduced thermal amplitude of cyclic reheating [147].

All materials tested by Jägle et al. [147] have been then aged to induce precipitate hardening. At the peak aged state, the conventionally produced material is the hardest due to the greater presence of retained austenite in the AM produced samples, which is cited to be due to chemical inhomogeneity from the AM processes [147]. Other studies which have observed large levels of retained austenite in AM produced steel attribute this to the large solidification undercooling [145] and microstructural refinement stabilising austenite [139] during the AM process.

AM produced $18 \mathrm{Ni} 300$ maraging steel has also been analysed for its fatigue properties [171]. LPBF 
Figure 13 Scatter plot showing ranges of ultimate tensile stress and elongation to failure reported in literature for $18 \mathrm{Ni} 300$ maraging steel samples made by additive manufacturing, along with the properties of wrought samples to which they were compared [108, 112, 161, 166-170].

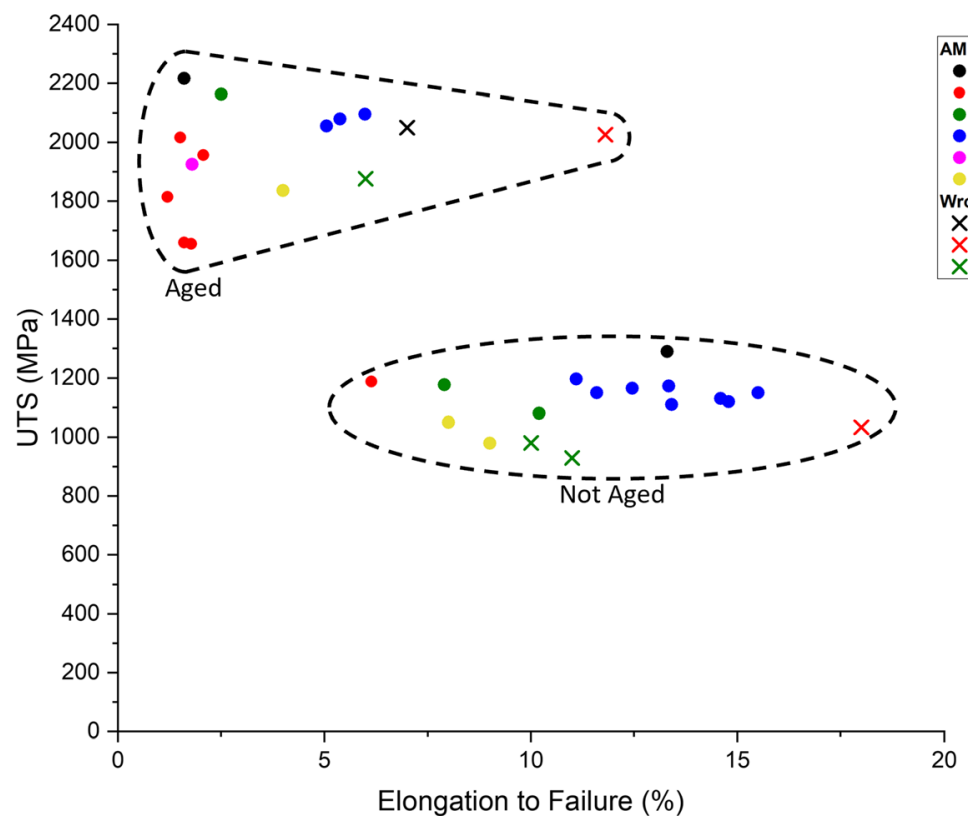

Elongation to Failure (\%) samples show lower fatigue lives than wrought ones [167] with fatigue cracks in these specimens initiating at subsurface lack-of-fusion defects or cluster defects $[167,171,172]$. It has also been found that the number of mechanical cycles until the elastic and plastic strains become equal, known as the transition life, of AM $18 \mathrm{Ni} 300$ maraging steel samples is extremely low as compared to wrought samples [172]. In summary, the main factor limiting the adoption of additively manufactured $\mathrm{PH}$ steels in applications which require high levels of fatigue performances is the presence of defects resultant from the AM process which act as favourable sites for crack initiation under cyclic loading, which have been widely observed in the published literature $[95,124,135,158,167,171]$.

\section{Corrosion resistance}

\section{5-5 PH stainless steel}

Due to its high $\mathrm{Cr}$ content, $15-5 \mathrm{PH}$ is expected to have high levels of corrosion resistance. In corrosive environments, a passive oxide layer $\left(\mathrm{Cr}_{2} \mathrm{O}_{3}\right)$ forms on the surface of the steel, protecting the bulk from further corrosion. It is, therefore, important to determine the effect of AM on the corrosion resistance of parts made of this alloy. A study by Li et al. [173] report a high volume fraction of austenite in the LPBF samples, especially after aging without a prior solution heat treatment, distributed strongly around the melt pool boundaries. Samples that undergo a solution heat treatment before aging exhibit fully martensitic microstructures, comparable to those of traditionally manufactured $15-5 \mathrm{PH}$ parts. The large austenite content in non-solution-treated samples leads to greater corrosion resistance than solutiontreated samples due to the greater surface potential of austenite than martensite.

\section{7-4 PH stainless steel}

As a stainless steel, corrosion resistance is an important property in 17-4 PH stainless steel. A study by Schaller et al. [174] shows that the LPBF 17-4 PH steel exhibits a reduced corrosion resistance compared to conventionally produced material. This is attributed to the greater level of porosity in the LPBF samples. In particular, the presence of pores $>50 \mu \mathrm{m}$ in diameter gives rise to active corrosion whilst passive behaviour persists around regions of pores $<10 \mu \mathrm{m}$ [174]. Contrastingly, the study by Stoudt et al. [141] notes that 17-4 PH samples produced by LPBF exhibit on average less negative pitting potentials than wrought samples which shows a greater level of corrosion resistance. This is attributed to two main factors. The first is that the AM process produces a more homogeneous distribution of elements within the microstructure, making the components more resistant to localised attack in corrosive environments. The second is that during the AM 
process (and subsequent heat treatments if applicable) $\mathrm{N}$ is absorbed which results in a more stable passive film.

The laser power during production as well as different 17-4 PH feedstock powders can also influence the corrosion resistance of the resulting parts. For instance, LPBF parts can have a lower corrosion current in $\mathrm{NaCl}$ (meaning a greater corrosion resistance) than wrought samples $(0.9 \pm 0.1 \mu \mathrm{A})$, with the lowest corrosion current exhibited by an LPBF part being $\sim 0.1 \mu \mathrm{A}$ [175]. However, parts that, as a result of their fabrication route, have lower than $\sim 97 \%$ density show significantly lower corrosion resistances than wrought parts, with further reductions in density leading to even more diminished corrosion resistances [175]. This is cited to be due to the stagnation of the $\mathrm{NaCl}$ within surface pores, leading to a breakdown of the passive $\mathrm{Cr}_{2} \mathrm{O}_{3}$ layer.

The effect of post-build thermal processing also affects the corrosion behaviour of LPBF 17-4 PH stainless steel [176]. Solution heat treatment has little effect on the general corrosion properties. Pitting potential is found to be higher in the as-built condition, which is attributed to the increased presence of higher angle grain boundaries and greater dislocation densities [175]. In the re-austenised condition, LPBF steel exhibits greater corrosion resistance than wrought samples. This is associated with the greater $\mathrm{Mn}$ and S content of the wrought material, as the formation and subsequent dissolution of $\mathrm{MnS}$ nanoparticles leads to localised $S$ enrichment on the sample surface leading to destabilisation of the passive film. However, re-austenised LPBF samples have a microstructure comprised of fine martensitic laths resulting in a high grain boundary density. This leads to a reduced resistance to pitting in comparison to the wrought material.

Overall, the corrosion resistance of $\mathrm{PH}$ stainless steels is still a matter of debate. Porosity has been found to play a detrimental role in the pitting corrosion resistance. In the case of high-density materials, it has generally been shown that AM PH stainless steels exhibit an improved pitting corrosion resistance compared to their conventional counterparts. However, the extents of this improvement reported in the open literature are inconclusive. There are a number of factors that must be considered when discussing the corrosion resistance, including the amount of retained austenite, size and content of secondary precipitates/inclusions, and grain size/grain boundary area. All of these parameters are highly dependent on the AM processing parameters as well as powder feedstock conditions (argon or nitrogen atomised), which make it difficult to reach a conclusion on what parameter is more important in evaluating the corrosion resistance.

\section{Other steels}

\section{Duplex stainless steels}

Duplex stainless steels (DSSs) have microstructures of essentially equal fractions of $\delta$-ferrite and austenite. This unlocks a wide range of attractive properties such as high strength, good ductility and excellent corrosion resistance for applications in oil \& gas, petrochemical, construction, marine, and desalination [177]. The current challenge with DSSs is their complex microstructural evolution where various further deleterious phases may be precipitated during multistep conventional processing, impacting the properties of these steels. AM can overcome the current challenges inherent to complex multistep traditional processing of DSSs. Most of the work published until now on AM of DSSs is on the microstructure evolution during AM and post-heat treatment of 2205 and 2507 grades. 2205 is the most common grade of duplex stainless steels, containing $22 \% \mathrm{Cr}, 3.2 \% \mathrm{Mo}$ and 5\% Ni (wt \%), offering high strength, good weldability and excellent pitting and crevice corrosion resistance. 2507 is a super-duplex stainless steel, containing $25 \% \mathrm{Cr}, 4 \% \mathrm{Mo}$ and $7 \% \mathrm{Ni}$ $(w t \%)$, that possesses an excellent combination of strength and corrosion resistance. This makes it an ideal candidate for aggressive environments such as warm seawater and acids for examples in offshore oil \& gas infrastructures [178]. Two types of the AM methods, i.e. LPBF and DED have mainly been employed for DSSs. The microstructures obtained through these techniques have been reported to be different. LPBF parts show mostly a ferritic microstructure with high strength but poor ductility, necessitating further heat treatments, while DEDproduced ones exhibit a considerable fraction of austenite offering higher ductility at the expense of strength. This is mainly due to the significant difference in the cooling rates between these two processing methods. 
2507 Alloy

It has been shown by Davidson et al. [179] that LPBF 2507 DSS offers higher hardness (380-440 HV) than that achieved in wrought alloy, particularly demonstrating an improvement in hardness with reducing the laser energy density. This is mainly due to a corresponding decrease in the austenite content. Similar improvements in strength can be achieved in a LPBF 2507 DSS using a bidirectional scanning pattern with a constant $45^{\circ}$ angle rotation between subsequent layers [180]. The observed superior YS and UTS of $1214 \mathrm{MPa}$ and $1321 \mathrm{MPa}$, respectively, might be due to several factors. One is the unique mosaictype microstructure (Fig. 14) in which grains in each 'tessera' have a different crystallographic orientation compared to the grains inside adjacent tesserae. Also, the high concentration of dislocations inside the material restricts further dislocation movement and imposes hardening effect. Moreover, nano-oxide inclusions and chromium nitride precipitates can inhibit free dislocation slip/glide and contribute to a hardening effect. Finally, the solubility of $\mathrm{N}$ in the ferrite structure steel leads to solid solution strengthening.

A post-heat treatment of LPBF 2507 DSS can impart UTS values (920 MPa) higher than that of as-cast and solution-treated ( 600-800 MPa) [181]. This is due to precipitation of $\mathrm{Mo}-/ \mathrm{Cr}$-rich intermetallic phases (mainly $\sigma$ and $\chi$ ). LPBF 2507 possesses a metastable ferritic microstructure that partially transforms to austenite during heat treatment. A promising sliding wear resistance of the heat-treated LPBF 2507 parts at $800{ }^{\circ} \mathrm{C}$ has been reported mainly due to the high hardness induced by the precipitation of intermetallics and formation of iron oxides acting as a third body lubricant.

Remarkably, magnetic properties of LPBF 2507 DSS are also promising, as reported by Davidson et al. [182], where a saturation magnetism (Ms) value of $110.9 \mathrm{Am}^{2} / \mathrm{kg}$, which is more than twice of that of the wrought specimen $\left(45.1 \mathrm{Am}^{2} / \mathrm{kg}\right)$, can be achieved. The anisotropy in grain structure of LPBF 2507 DSS, however, leads to a directional specific saturation magnetism. Super DSS deposited by LPBF enhances the corrosion of substrate [183]. An enhancement of the pitting corrosion resistance with decreasing the laser scan speed is observed which is related to a reduction in both surface roughness and the size of columnar grains in the deposited layer.
2205 Alloy

The challenge with AM of 2205 has been mostly around achieving desirable volume fraction of austenite and ferrite. For example, a work by Hengsbach et al. [184] demonstrates that an almost fully (99\%) ferritic structure is obtained for 2205 DSS through LPBF. Such structures offer a high strength of $\sim 940 \mathrm{MPa}$ and an elongation of $12 \%$. This enhanced strength compared to the wrought condition $(\sim 620 \mathrm{MPa})$ is attributed to the high density of dislocations and nitrides in the LPBF microstructure. It has been found that a post-heat treatment at 900-1200 ${ }^{\circ} \mathrm{C}$ is needed for austenite to precipitate out of the ferritic matrix, with the highest volume fraction of austenite (34\%) achievable at $1000{ }^{\circ} \mathrm{C}$ (Fig. 15). Annealing decreases the UTS to the range of 720-770 MPa, but significantly increases the elongation with the highest elongation value obtained at $1000{ }^{\circ} \mathrm{C}(28 \%)$. This implies that an increase in austenite volume fraction through adjusting the post$\mathrm{AM}$ heat treatment time/temperature might be a major means for enhanced ductility.

Similar observations have been seen in other works too, where for example, Papula et al. [185] show a post-annealing of LPBF 2205 DSS at $1050-1100{ }^{\circ} \mathrm{C}$ for 5-60 min is needed to bring its ductility back to the wrought level (i.e. elongation $>40 \%$ ). The pitting corrosion resistance substantially increases after annealing [185]. This is because annealing reduces the residual stresses within the build and changes the residual stress state of the surface layers from tensile to compressive, causing improvements in both ductility and pitting corrosion resistance.

It has been shown that in contrast to the LPBF, DED duplex stainless steel products show a mixture of austenite and ferrite in the as-built condition, with intragranular austenite particles preferentially nucleating on the inclusions [186]. Austenite content increases with the laser energy density. The volume fraction of austenite also increases with the $N$ level. The higher the $N$ content, the higher the hardness mostly due to the pronounced solid solution hardening effect by $N$.

\section{Ferritic/martensitic steels}

Different grades of low-carbon ferritic and martensitic steels can be processed by AM for applications where wear and corrosion resistance are needed. 
Figure 14 a Optical microscopy images of LPBF 2507 DSS and $\mathbf{b}$ EBSD Euler angle map of the same microstructure showing the single-phase ferritic structure with a mosaic-type macrostructure. Adapted from Ref. [180] with permission.
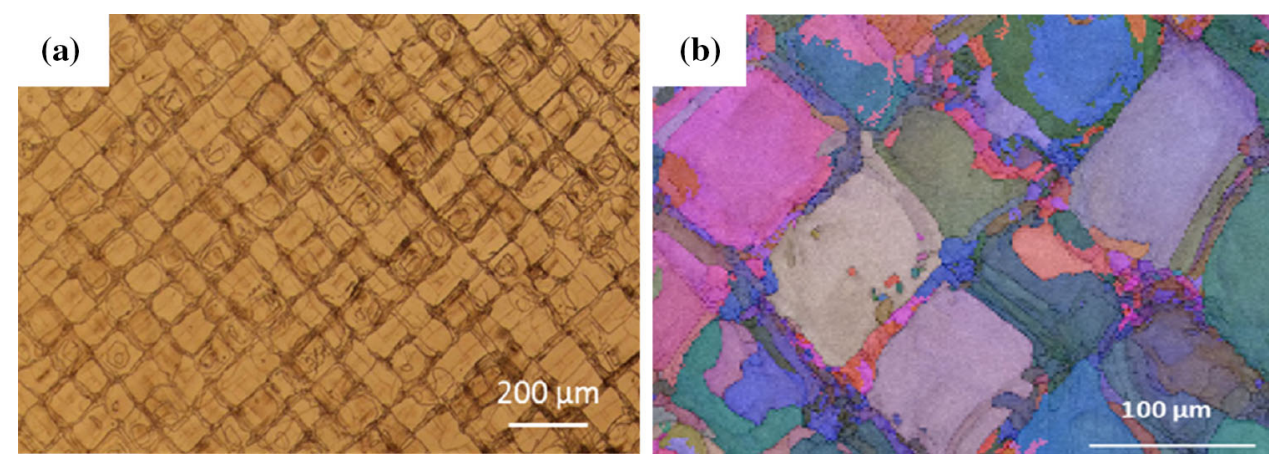

These include parts such as medical tools, bearings and blades as well as pumps, valves and shafts. It has been shown that AM products can achieve tensile strength, corrosion and magnetic properties equivalent or superior to those of wrought and conventionally processed samples. Poor ductility and toughness as well as anisotropy are, however, the remaining challenges with $\mathrm{AM}$ of these steels. One of these steels that has been studied in the context of AM is grade 420, a general-purpose medium C martensitic stainless steel with excellent hardenability and acceptable corrosion resistance. For example, an improvement in both tensile properties and corrosion resistance of 420 stainless steels in both AM and post-heat-treated conditions has been observed with the addition of $\mathrm{Nb}$ and $\mathrm{Mo}$ [187]. A summary of comparison of $\mathrm{Nb} / \mathrm{Mo}$ AM 420 steel with the AM 420 steel without $\mathrm{Nb} / \mathrm{Mo}$ and wrought 420 steel is given in Table 3. The enhancement of the mechanical properties is attributed to the formation of a martensitic microstructure containing nanoscale carbide such as $\mathrm{NbC}$. Such phases are not observed in the AM 420 stainless steel without $\mathrm{Nb} / \mathrm{Mo}$.

High strength is achievable also for 420 stainless steel via LPBF (UTS of $1670 \mathrm{MPa}$, YS of $600 \mathrm{MPa}$ and elongation of 3.5\%) [188]. The UTS achieved is much higher than the value reported for the wrought material (800 MPa). The elongation is, however, lower than wrought 420 stainless steel. A post-AM tempering heat treatment at $400{ }^{\circ} \mathrm{C}$ for $15 \mathrm{~min}$ can yield an extremely high UTS of $1800 \mathrm{MPa}$ and YS of $1400 \mathrm{MPa}$. Tempering also enhances the elongation to $\sim 25 \%$ that is about 5 times of elongation in the LPBF condition. The enhanced mechanical properties is attributed to the transformation of retained austenite to martensite during tensile testing. Similarly, there are also observations of higher YS and UTS in LPBF 4140 steel compared to the wrought steel in both building and normal to building directions without compromising ductility and impact toughness [189].

Post-AM heat treatment can significantly affect the mechanical performance of some other grades of martensitic/ferritic steels. For instance, as shown by Sridharan et al. [190] for both HT9 (a 12\%Cr-1\%Mo martensitic stainless steel widely used in turbines and boilers in fossil-fired power plants and nuclear energy systems) [191] and P91 ferritic-martensitic steel $(9 \% \mathrm{Cr}-1 \% \mathrm{Mo}$ steel mostly used in nuclear fission reactors) [192], a post-heat treatment reduces the YS and UTS but improves the ductility, at room and warm working temperatures (330 and $550{ }^{\circ} \mathrm{C}$ ). As another example, Liu et al. [193] reports that the impact toughness of an AM $300 \mathrm{M}$ ultra-high strength steel (a modified version of 4340 steel with $\mathrm{Si}$ added to enhance hot working) is extremely low (9 J/ $\mathrm{cm}^{2}$ ), while a post-deposition heat treatment can recover the toughness to $\sim 25 \mathrm{~J} / \mathrm{cm}^{2}$. The extremely low toughness in the as-built condition is attributed to the coarse size of 'effective microstructure unit' where coarse epitaxial primary austenite columnar grains result in coarse martensite packets in the asdeposited condition. In another study by Sridharan et al. [194], AM HT9 steel shows superior tensile properties $\quad(Y S=1043 \mathrm{MPa}, \quad$ UTS $=1168 \mathrm{MPa}$ and elongation at fracture $=14.2 \%$ ) compared to its wrought counterpart $\quad(\mathrm{YS}=800 \mathrm{MPa}, \quad \mathrm{UTS}=950$ $\mathrm{MPa}$ and elongation at fracture $=10-16 \%$ ). A postprocess heat treatment of the AM samples results in properties in the range of normalised and tempered HT9. This is mainly because a higher austenitising temperature and a lower tempering temperature results in a fine dispersion of the carbide structure and a fine-grained lath martensite, maximising tensile properties. 


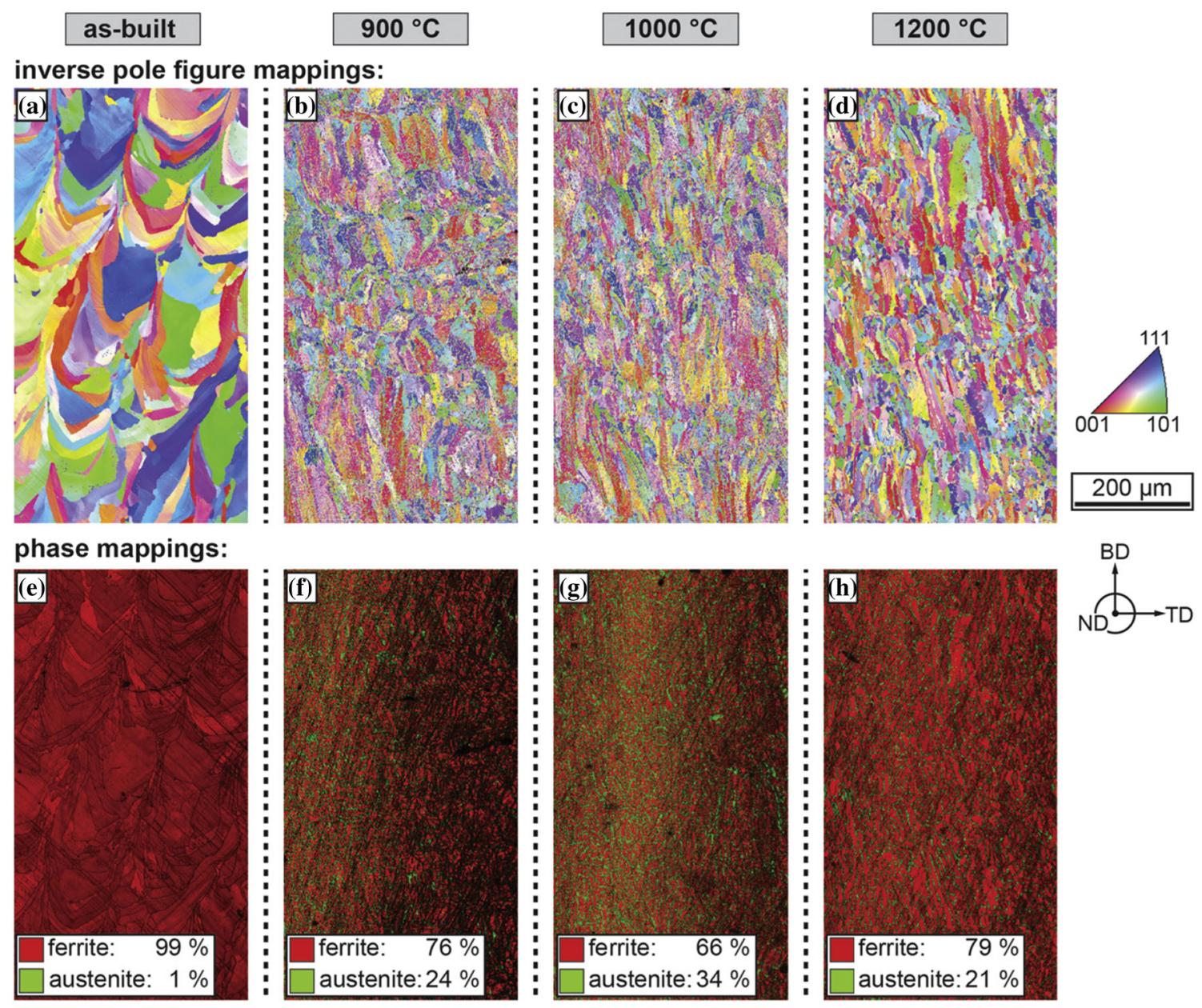

Figure 15 EBSD maps: a-d IPF maps, e-h phase maps of the LPBF 2205 steel in the as-built and post-AM heat-treated conditions (for 5 min). Adapted from Ref. [184] with permission.

Table 3 Mechanical and corrosion properties of 420 stainless steel with and without Nb/Mo. Data from Ref. [187] with permission

\begin{tabular}{|c|c|c|c|c|c|}
\hline \multirow{2}{*}{$\begin{array}{l}\text { Material } \\
\text { condition }\end{array}$} & \multicolumn{2}{|c|}{420 stainless steel with $\mathrm{Nb}$ and Mo } & \multicolumn{2}{|c|}{420 stainless steel } & \multirow{2}{*}{$\begin{array}{l}420 \text { stainless steel wrought } \\
\text { Hardened }\end{array}$} \\
\hline & As-printed & Heat-treated & As-printed & Heat-treated & \\
\hline Density $\left(\mathrm{g} / \mathrm{cm}^{3}\right)$ & 7.69 & 7.69 & 7.67 & 7.67 & N/A \\
\hline UTS (MPa) & 1320 & 1750 & 1050 & 1520 & $\sim 1600$ \\
\hline YS (MPa) & 1065 & 1280 & 850 & 950 & $\sim 1300$ \\
\hline Elongation (\%) & 4.0 & 9.0 & 2.5 & 6.3 & $\sim 14$ \\
\hline Hardness (Rc) & 52 & 51 & 55 & 53 & $\sim 50$ \\
\hline Corrosion current $\left(\mu \mathrm{A} / \mathrm{cm}^{2}\right)$ & 1.5 & 1.8 & 2.85 & 3.5 & 2.1 \\
\hline Corrosion potential (V) & -0.42 & -0.32 & -0.39 & -0.42 & -0.4 \\
\hline Breakdown potential $(\mathrm{V})$ & 0.03 & 0.2 & 0.05 & 0.22 & 0.15 \\
\hline Polarisation resistance $\left(\Omega / \mathrm{cm}^{2}\right)$ & 24200 & 23800 & 17100 & 16800 & 18700 \\
\hline Corrosion rate $(\mu \mathrm{m} / \mathrm{year})$ & 16 & 18 & 28 & 35 & 23 \\
\hline
\end{tabular}

Thermal cycles during AM may result in unexpected microstructures. For instance, in an LPBF
24CrNiMoY steel, with an increase in the number of thermal cycles, the microstructure changes from a 
martensitic one to a bainitic one [195]. For the bainitic microstructure, the laser energy density significantly affects the microstructure and mechanical properties. Decreasing the laser energy density from 210 to $140 \mathrm{~J} / \mathrm{mm}^{3}$ reduces the bainite lath width from 1.7 to $0.6 \mu \mathrm{m}$. A general Hall-Petch like trend of increasing the YS with decreasing bainite lath size is, in turn, observed. Promising tensile properties with about 5-10\% improvement compared to the as-cast material can be achieved in $24 \mathrm{CrNiMo}$ steel fabricated via DED, too [196]. Interestingly, the substrate temperature during DED can significantly change the microstructure constituents, texture and grain size. With the increase of substrate temperature from RT to $400{ }^{\circ} \mathrm{C}$, the microstructure changes from fully martensitic to a mixture of martensite and lower bainite. Correspondingly, grain size (texture intensity) decreases from $30 \mu \mathrm{m}$ (16.0) to $13 \mu \mathrm{m}$ (4.7).

Promising microstructure and tensile properties can be achieved in reduced activation fer$\mathrm{ritic} /$ martensitic (RAFM) steel (used mainly as structural material for fusion reactors [197]) produced by LPBF using two scanning strategies of (1) bidirectional scanning without and (2) with $45^{\circ}$ deviation from X/Y-axis and $90^{\circ}$ rotation [198]. Both strategies result in advanced tensile properties of YS = 893-911 MPa, UTS = 1008-1047 MPa and elongation $=15.0-18.7 \%$, which is a much higher combination compared to that in LPBF China low activation martensitic steel [199] and conventionally processed RAFM steels [200]. The enhanced strength is attributed to the grain refinement, and the acceptable ductility is ascribed to morphology of grains that change the fracture mode to transgranular ductile. A very interesting change in the grain morphology of the steel (from columnar-like to rhombus-shaped) is observed with the change of scanning strategy (Fig. 16), though these changes do not profoundly affect the strength.

The inhomogeneity and the in situ heat treatment inherited from the AM can be used as a means to enhance mechanical properties of martensitic/ferritic steels. For example, as reported by Jiang et al. [201], LPBF can be used to create a heterogeneous multi-/ bimodal microstructure in a RAFM S209 steel resulting in superior properties of YS of $1053 \mathrm{MPa}$ and elongation of $\sim 17 \%$. This is mainly attributed to the refined grains and fine martensite laths as a result of increasing the energy density during LPBF, which decreases the temperature gradient facilitating the formation of fine equiaxed grains.

AM can result in advanced properties in $24 \mathrm{CrNi}$ MoY steel, too [202]. The strength of AM 24CrNiMoY parts are mainly controlled by the size of the bainitic laths where the finer the bainitic ferrite lath bundle, the higher the YS [202]. The excellent hardness and tensile properties of this alloy in the LPBF condition is attributed to the dominance of supersaturated solid solution, dislocation and subgrain cell structures in the microstructure.

It is worth noting that there have also been reports showing poor mechanical properties of ferritic/martensitic steel AM products compared to the wrought samples. For example, ultra-high-strength martensitic stainless steel AerMet100 processed with DED shows lower tensile strength and ductility than its wrought counterpart [203]. There is also an anisotropy in tensile properties especially in elongation where longitude $(L)$ direction showed $12.3 \%$ elongation while transverse $(T)$ direction only showed $4.6 \%$. This is justified considering the applied tensile stress being perpendicular to the prior austenite grain boundary (locations prone to crack propagation) in $T$ direction. At the L-direction, however, the applied tensile stress was parallel to the grain boundary causing high crack propagation resistance through grain interior bainitic microstructures. An anisotropy has also been observed in the UTS and elongation of China Low Activation Martensitic steel processed by LPBF [199]. The tempering of the martensitic structure resulted from LPBF enhances ductility at the expense of strength. The LPBF steel shows a low impact toughness of $10 \mathrm{~J}$ which is less than $5 \%$ of that of the same steel in the wrought condition.

Silicon steels have also been processed by AM showing promising magnetic properties. While conventional processing is limited to electrical steels of less than $\sim 3.5 \mathrm{wt} \%$ Si due to workability limitations, Garibaldi et al. [204] report that a Fe-6.9 wt\% Si can be successfully produced by LPBF. This is outstanding as the electrical resistivity, and hence power losses, scale strongly with the Si content. Post-AM annealed parts can achieve excellent quasi-static magnetic properties (maximum relative permeability of 24,000 and coercivity of $16 \mathrm{~A} / \mathrm{m}$ ) which is as good as commercial high Si electrical steels such as JNEX Super Core developed by JFE Steel [204]. This has obvious benefits for processing novel core geometries, especially in applications where complex 

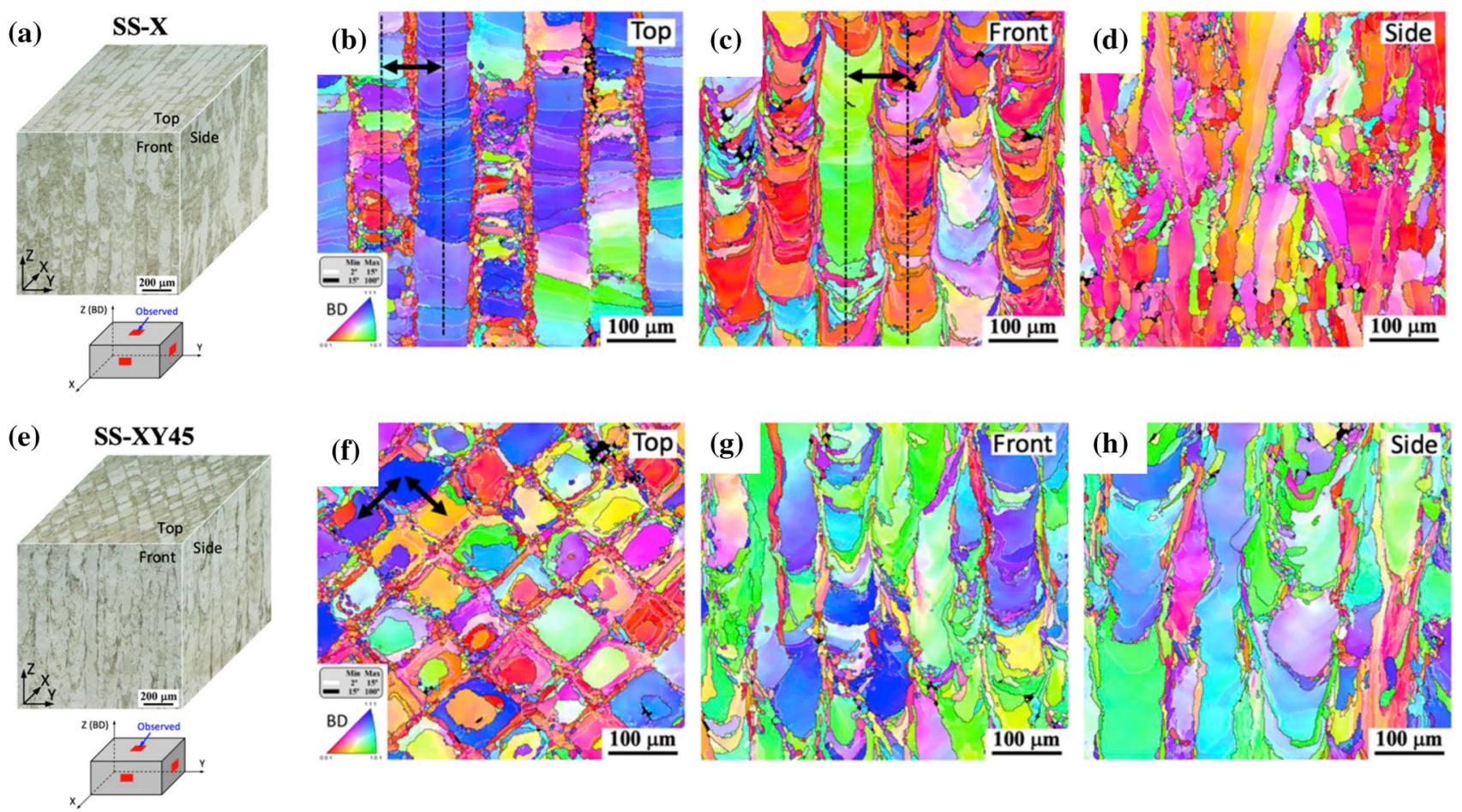

Figure 16 Microstructures of the LPBF RAFM steel processed by bidirectional scanning $\mathbf{a}-\mathbf{d}$ without and $\mathbf{e}-\mathbf{h}$ with $45^{\circ}$ deviation from $\mathrm{X} / \mathrm{Y}$-axis and $90^{\circ}$ rotation SS-XY45 examined at the central

geometrical core design is advantageous, while the employment of a laminated core is not viable due to structural integrity concerns or is not strictly necessary (e.g. in some synchronous rotor cores). This behaviour is attributed to stress relief (up to $900{ }^{\circ} \mathrm{C}$ ) and grain growth $\left(900-1150{ }^{\circ} \mathrm{C}\right)$ that reduce the density of lattice defects. Lattice defects are known to hinder magnetic domain wall motion through a pining effect [204].

\section{High-strength low-alloy (HSLA) steels}

HSLA steels have been successfully processed via AM for different applications such as tooling industries and defence. Their properties have been reported to be affected by the laser energy density and the distance from the substrate. For example, as shown by Jelis et al. [205], for AM HSLA steels used in defence applications, a desirable fine martensitic structure as a result of the rapid cooling of the melt pool can be achieved. The porosity increases and the morphology of the pores becomes more irregular as the energy density is decreased, which in turn increases the propensity to cracking. The brittle martensitic microstructure of the component may

region in each view: a, e three-dimensional view of optical microstructures, $\mathbf{b}-\mathbf{d}$ and $\mathbf{f}-\mathbf{h}$ EBSD IPF maps in different views. Adapted from Ref. [198] with permission.

also contribute to cracking as the components show a slightly higher brittleness at lower energy densities. Another example of successful AM of HSLA has been reported by Rodrigues et al. [206] who have processed HSLA steel with WAAM. This method of AM is, however, outside the scope of this review.

\section{Carbon bearing tool steels}

Tool steels are a family of high $C$ and alloy steels comprising carbide-forming elements such as $\mathrm{Cr}, \mathrm{V}$, Mo and $\mathrm{W}$ that are used to make tools such as drills, hobs, punches, dies, etc. These steels are of excellent hardness, wear resistance and resistance to hightemperature softening. They are usually heat treated to achieve a hard matrix with a dispersion of both coarse and fine carbides, providing improved wear resistance and hot hardness [207]. In general, AM processing of these steels is challenging. Firstly, these steels are of high strength and low toughness that makes them susceptible to cracking during cooling down. Furthermore, it has been reported that $C$ in these steels can segregate to the melt surface, reducing wettability [208]. This together with the severe thermal gradient during AM result in thermal 
stresses, that leads to cracking [209]. Despite such challenges, there are reports on successful AM of these steels in the literature.

During AM, due to the high cooling rate, these steels solidify as martensite supersaturated in $C$ and retained austenite. Every solidified layer is, however, affected by melting and heating of the neighbouring layers. In the case of an overlap, solidified layers can be remelted multiple times by the melting of adjacent tracks. If a layer is distant from the melt pool, it might be heated to temperatures above austenite transformation temperature, but not melting point. This will cause reaustenitisation of martensite. Distant further from the melt pool, the heat will be only enough for tempering of martensite, carbon partitioning and carbide precipitation. This implies that the retained austenite, martensite and carbide characteristics all depend on the heating/cooling cycle that each part of the build experiences during AM.

\section{H13}

Most of the studies on AM of C bearing tool steels have been focused on H13, the most common grade of hot working tool steels. This $\mathrm{Cr}$ steel with the nominal composition of $0.40 \mathrm{C}, 0.40 \mathrm{Mn}, 1.00 \mathrm{Si}, 5.25 \mathrm{Cr}$, $1.35 \mathrm{Mo}, 1.00 \mathrm{~V}$ (wt $\%$ ) offers excellent hot hardness and thermal fatigue resistance in wrought condition. The microstructure of AM H13 consists of cells and dendrites with retained austenite regions observed in the interdendritic areas [210, 211] (Fig. 17). Carbon enrichment results in retained austenite stabilisation at room temperature [210]. The size of the cells depends on the cooling rate with larger cells observed in DED samples compared to LPBF samples [211].

LPBF H13 steel shows hardness values higher than their as-quenched wrought counterparts [195]. For instance, Yan et al. [212] report in situ tempering of martensite during LPBF of $\mathrm{H} 13$ where the LPBF product exhibits higher hardness (57 HRC) compared to the conventionally processed H13 (45 HRC). In addition to the fine martensite and the tempering effect, the high compressive residual stress of the LPBF product also contributes to this high hardness. The YS and UTS of LPBF H13 is, however, in general lower than wrought $\mathrm{H} 13$ after conventional heat treatment. This is mainly due to the inherent brittleness of martensitic structure in thee alloys and the defect and porosities induced by AM [213, 214].
Similar to LPBF, DED-processed $\mathrm{H} 13$ possess a martensite plus retained austenite microstructure. H13 fabricated by DED, however, experiences an extensive intrinsic heat treatment (IHT) during deposition resulting in an in situ tempering of martensite. This is the reason why tensile strength and elongation of DED H13 is comparable to quenched and tempered H13 [215].

Preheating of the base plate is a critical step in successful AM of H13. The properties of AM H13 are, in turn, highly dependent on the base plate preheat temperature. Preheating above the martensite start temperature $\left(\mathrm{M}_{\mathrm{S}}\right)$, i.e. $\sim 300{ }^{\circ} \mathrm{C}$, is expected to change the microstructure to a bainitic one [214]. For example, preheating of building plate to $400{ }^{\circ} \mathrm{C}$ during LPBF of H13 steels can increase the UTS and hardness to the values higher than those in the wrought condition [214]. This implies that preheating might eliminate the need for the additional posttreatment. At preheating temperatures lower than Ms, an improvement in resistance to cracking is observed despite martensite still being formed. This is mostly attributed to the reduced residual stresses [216].

Other processing parameters also affect the microstructure properties of AM H13. For instance, Lee et al. [217] show an epitaxial growth in the building direction for the H13 tool steels where columnar grains mostly comprise of martensite with a low amount of retained austenite, together with $\mathrm{MC}$ (V-rich) and $\mathrm{M}_{2} \mathrm{C}$ (Mo-rich) carbides (Fig. 18). Supercooling of $\mathrm{H} 13$ with high laser scan speed increases the number of nucleation sites, resulting in a reduction in the diameter of columnar grains. No martensitic phase transformation is observed during tensile loading and porosity, pore size and pore types are the main parameters affecting the tensile properties. In AISI H13 and D2 tool steels fabricated by DED, as shown by Park et al. [218], hardness decreases with an increase in the energy input. This is in part due to higher secondary dendrite arm spacings with energy input due to decreased cooling rate. The other possible mechanism is decrement of $\mathrm{C}$ content with higher laser energy density as at higher laser energy densities, a longer time and a larger area is available for reaction of $\mathrm{C}$ with $\mathrm{O}$.

The processing parameters control the mechanical performance of H13 tool steels. As shown by Pellizzari et al. [219] in an LPBF H13, the fracture toughness increases with volume energy density. This is 
Figure 17 a Optical micrograph of LPBF H13 showing periodic layers in response to chemical etching. b Higher magnification SEM micrograph showing the cellular/dendritic structure, c, d EBSD band contrast and phase map of LPBF H13 showing the precipitation of austenite at the cellular boundaries. Adapted from Ref. [211] with permission.
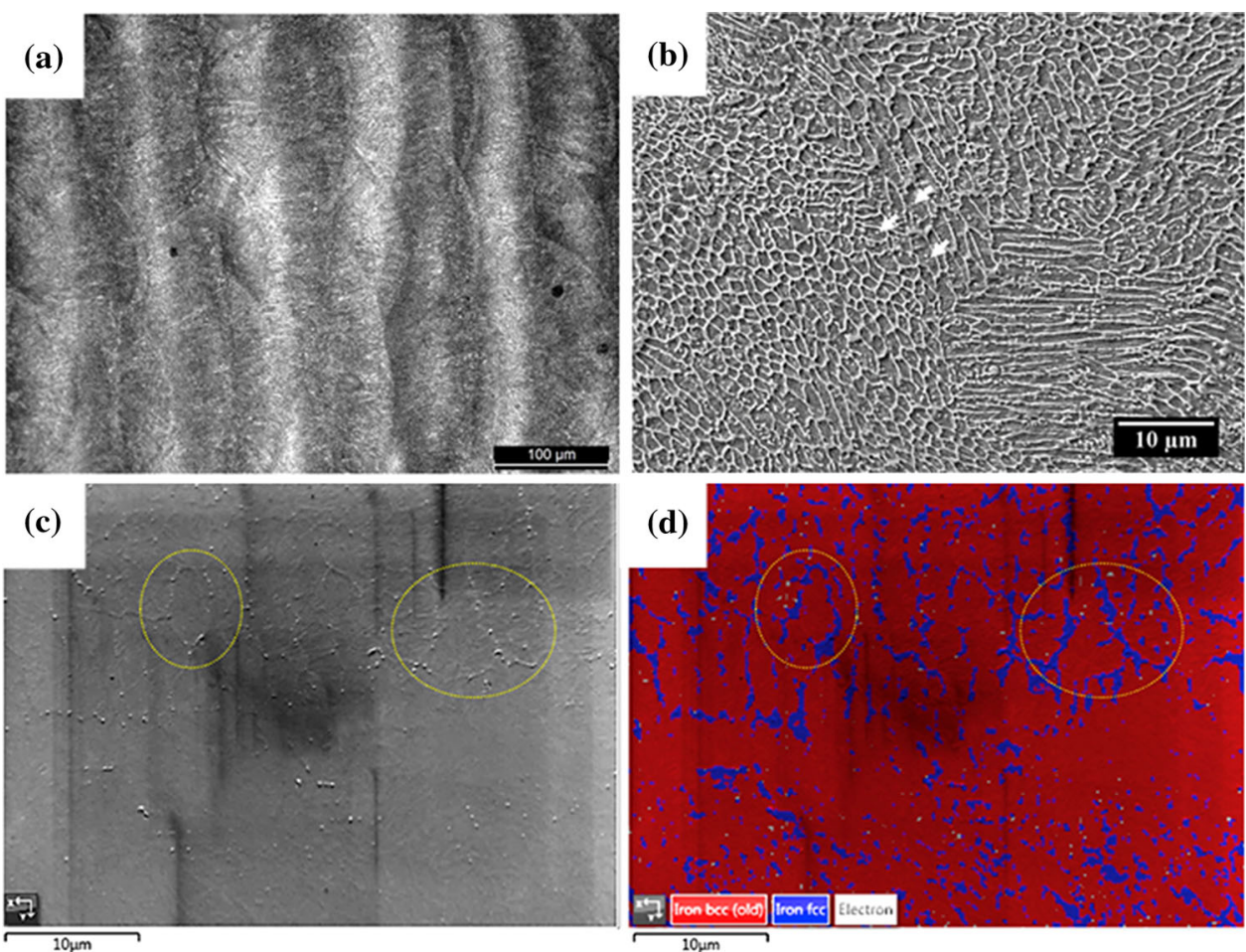

because higher energy densities reduce the porosity and unmelted particles, i.e. the flaws governing the crack propagation mechanisms. Other processing parameters such as building direction and different thermal cycles have a less pronounced effect compared to the energy density. An interesting point, mentioned in [219], is that the formation of secondary cracks perpendicular to the principal ones produces a decrease in the driving force for the main crack propagation, which results in improved fracture toughness. This effect is more pronounced in the tempered condition compared to the quench-tempered condition, due to more pronounced precipitation of carbides network at the prior melt boundaries which promotes the formation of secondary cracks, as well as due to the generally finer microstructures of tempered parts.

Wear and fatigue performance as well as inhomogeneity of the properties across the builds are the remaining challenges in AM of H13. Although Riza et al. [220] report a satisfactory wear behaviour for DED H13 tool steel, the wear resistance is still lower than the wrought counterpart. This is more critical in the context of fatigue performance. The LPBF H13 parts show inferior fatigue behaviour for a number of reasons [221]. The most important reason is the low surface quality due to the porosity and cavities at the surface resulted from insufficiently melted powder and insufficient layer connection. In addition to the surface effects, AM parts suffer from a higher density of volume defects such as pores and cavities, a lamellar structure and a higher $\mathrm{O}$ content compared to its wrought counterpart, all of which limit the fatigue resistance. The other challenge with the LPBF of $\mathrm{H} 13$ is the inhomogeneity throughout the built. As shown by Deirmina et al. [211] in the LPBF H13, the as-built microstructure consists of a partially tempered martensite and a much higher amount (up to $19 \mathrm{vol} \%$ ) of retained austenite compared to the quenched steel (retained austenite $<2 \mathrm{vol} \%$ ), leading to a much stronger secondary hardening during tempering. These authors report that LPBF produces a heterogeneous cellular/dendritic microstructure showing segregation of the heavy alloying elements at the melt pool boundaries and micro-segregation at the cellular boundaries as a result of rapid solidification. A partial non-uniform tempering is observed mostly due to the heat transfer from the solidifying layer to the previous layers, resulting in a heterogeneous hardness distribution. 

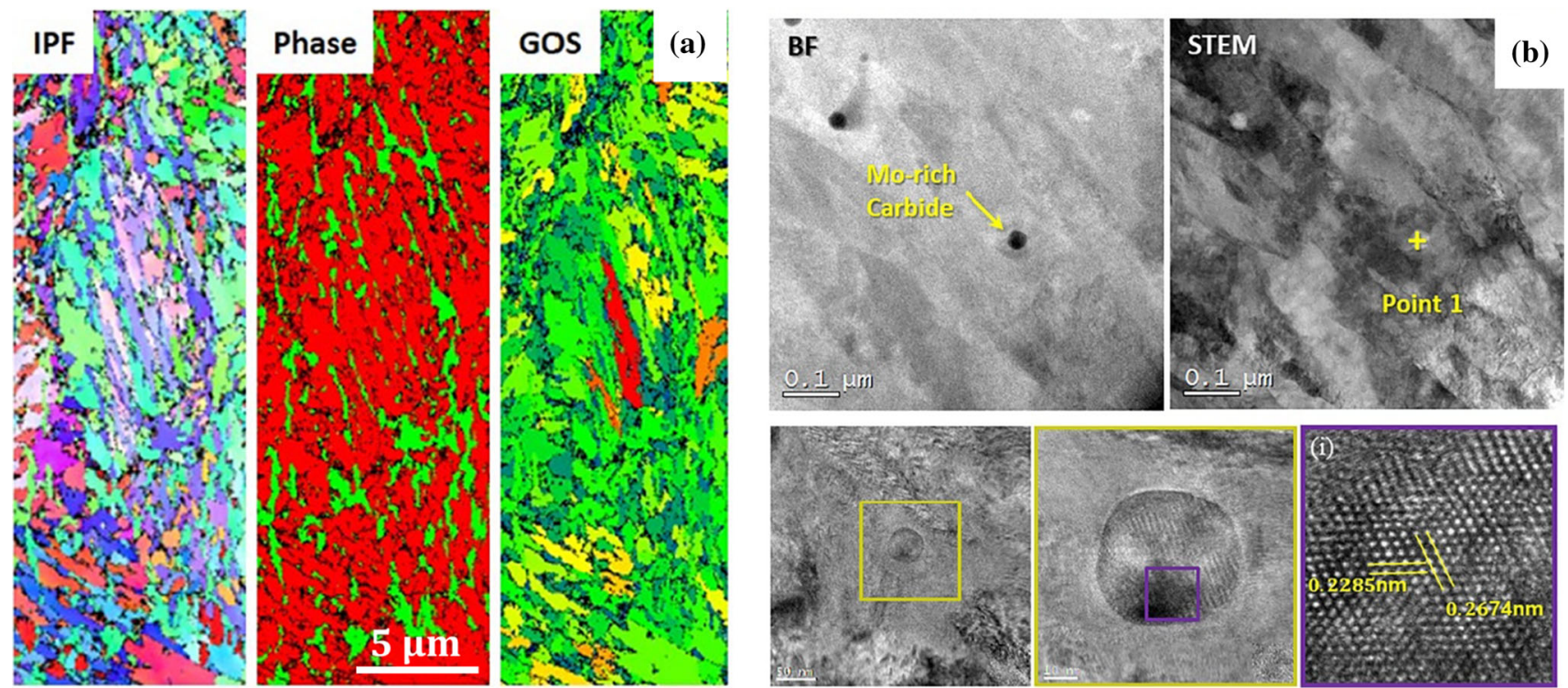

(c)
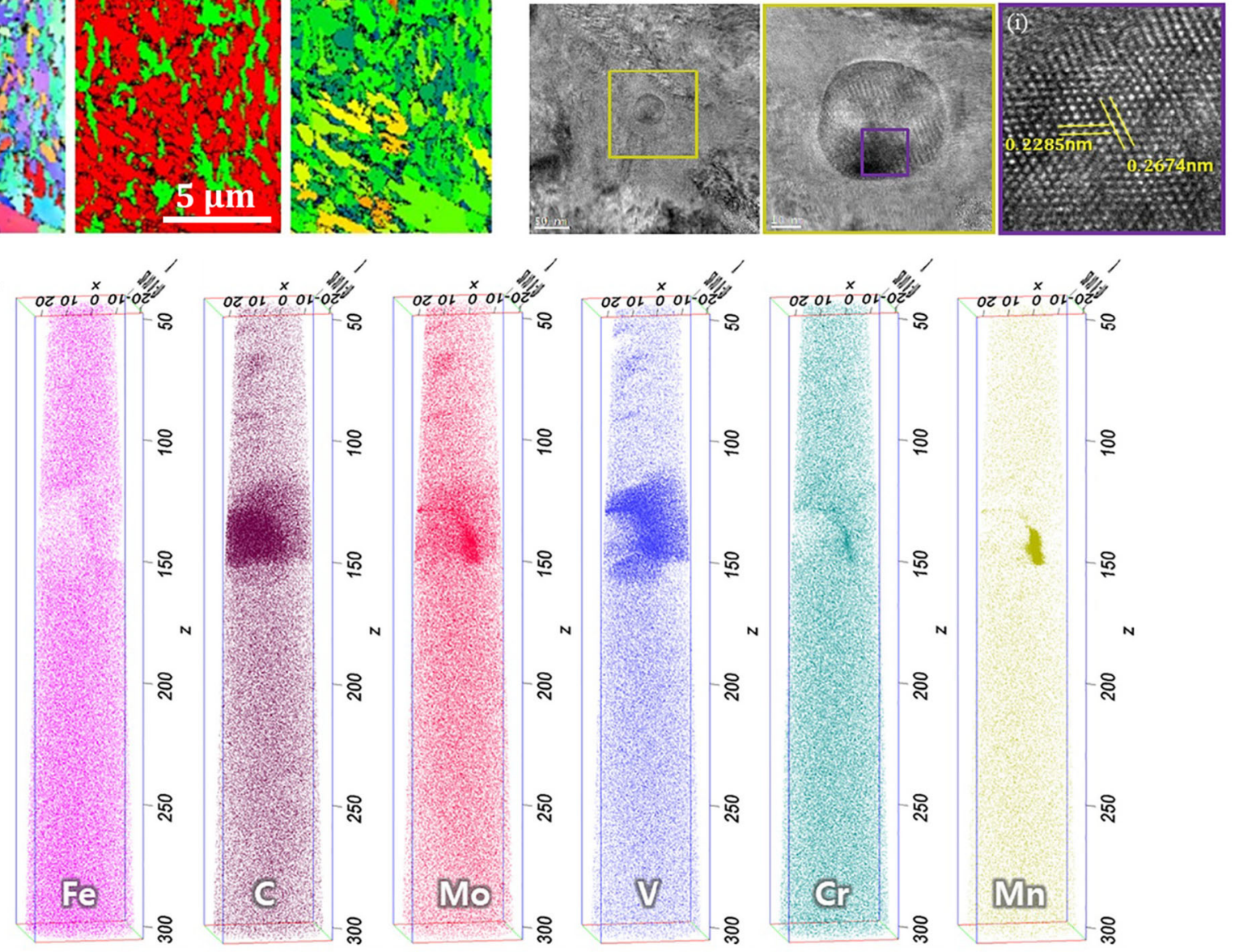

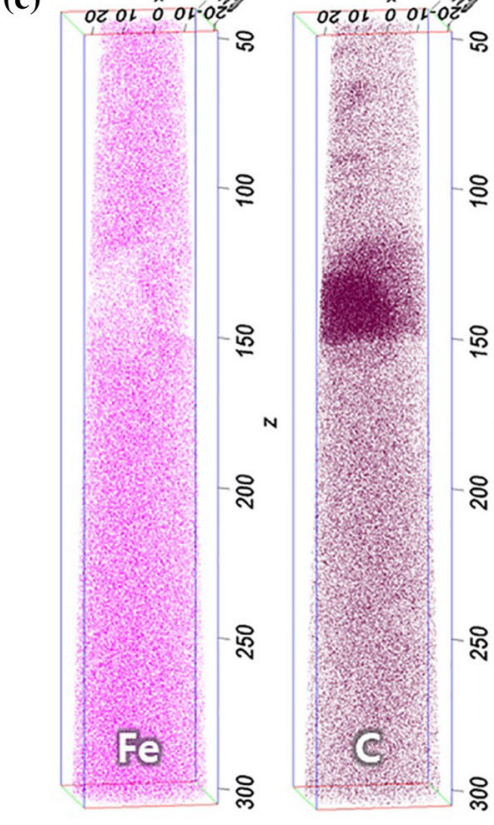

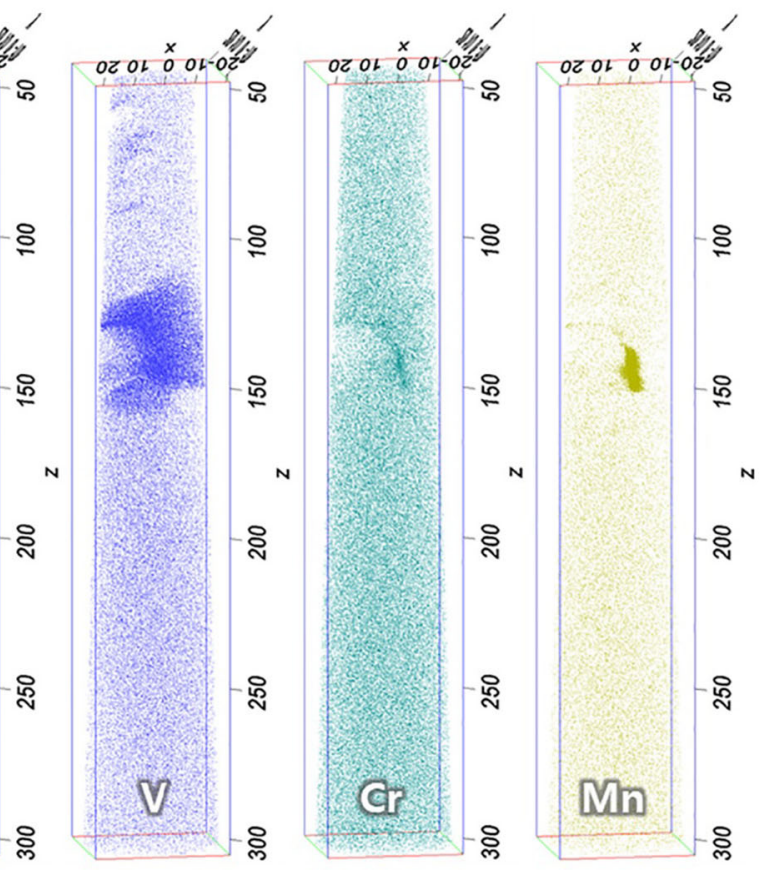

Figure 18 EBSD IPF, phase (red: martensite and green: austenite) and grain orientation spread (GOS) maps, b TEM, STEM and high-resolution TEM images and $\mathbf{c}$ atom probe tomography-

reconstructed maps showing V- and Mo-rich carbides in the LPBF H13 steel. Adapted from Ref. [217] with permission.

\section{H11}

H11 is another popular type of tool steel with less V than the H13 grade. Lower V contents increase the toughness at the expense of wear resistance [207]. Applying post-build heat treatment and modification of the composition of H11 steel can result in highperformance AM products. As reported by Huber et al. [222], LPBF of $\mathrm{H} 11$ tool steel results in a

presumably bainitic microstructure evidenced by a hardness of $\sim 642$ HV1. Post-process annealing at $550{ }^{\circ} \mathrm{C}$ for $2 \mathrm{~h}$ increases the hardness to $\sim 678 \mathrm{HV} 1$ because of the decomposition of residual austenite and precipitation of secondary carbides. Interestingly, the tensile properties in the direction parallel to the building direction does not change after postprocess heat treatment showing that LPBF material does not require a quench-hardening step to reach 
tensile properties needed for tooling applications. The wear resistance of lean H11 (L-H11) in the LPBF condition is much higher than the conventionally quench-tempered L-H11 steel [223]. Such improvement of the wear resistance is, however, not observed for the H11 steel after LPBF. This might imply that the leaner compositions could be suitable for the LPBF manufacturing of complex and large tool steel parts owing to their high toughness and high damage tolerance to residual stresses and processing defects.

The compressive performance of AM processed H11 can be comparable to the wrought condition [224]. A compressive strength (1770 MPa) comparable to that of conventionally processed parts (1810 MPa) is obtained, which shows that material undergoes an in situ hardening during AM followed by natural tempering. A further tempering of $\mathrm{AM}$ parts can result in YS of $\sim 1630 \mathrm{MPa}$ and UTS of $\sim 2130 \mathrm{MPa}$, showing a considerably better performance compared to the conventionally processed samples. This implies that AM might potentially eliminate the pre-austenitisation step of hardening. By tempering of the AM parts only, the mechanical properties could outperform those of conventionally processed material.

\section{Other C bearing tool steels}

Further efforts have been taken to apply post-AM heat treatments to achieve mechanical properties superior to that in wrought conditions in other tool steels. M2 high-speed steel sample processed by LPBF consist of supersaturated martensite, retained austenite and $\mathrm{M}_{2} \mathrm{C}$-type carbides [225]. Heat treatment at $560{ }^{\circ} \mathrm{C}$ causes tempering of the martensite and precipitation of further carbides. In both AM and heat-treated conditions, adhesive wear is the main sliding wear mechanism.

In some of the studies in the literature, the in situ heat treatment that tool steels experience during AM has been considered as the reason behind their acceptable mechanical properties without any need for further heat treatments. One example is the highstrength Fe85Cr4Mo8V2C1 (element contents in wt\%) tool steel processed by LPBF [209], where an excellent combination of mechanical properties including a

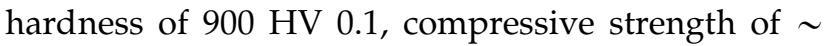
$3800 \mathrm{MPa}$ and fracture strain of $\sim 15 \%$ can be achieved. This is due to a fine, homogeneous microstructure composed of martensite, austenite and carbides. Compared to the as-cast state, the martensite content in the LPBF specimens is lower while the carbide content is higher. A lower ductility compared to the as-cast condition is achieved due to a higher fraction of brittle carbides, rough surface of the LPBF products and internal stresses caused by the rapid cooling during the LPBF process.

A significant enhancement of wear resistance in LPBF samples is achievable compared to the cast alloy in FeCrMoVC alloy [226]. This is in line with their higher hardness and compressive strength compared to the cast samples. The intrinsic heat treatment has been observed in some other tool steels too. For example, LPBF can create a heterogenous microstructure of fresh martensite and tempered martensite in X65MoCrWV3-2 tool steel [227]. The tempering is a result of the moderate heat produced during the melting of the subsequent layers, while fresh martensite is formed as a result of partial reaustenitisation of the already-solidified material. Such tempering effect could potentially eliminate the need for further tempering treatment, although such claim might be too optimistic. This can be, however, seen in LPBF M2 steel for example in the work by Kempen et al. [228] where a high hardness is achieved in situ without a need for any further aging heat treatment.

A TRIP effect can enhance the mechanical properties of AM tool steels. As AM might result in a significant volume fraction of retained austenite in these steels, the transformation-induced plasticity resulted from austenite to martensite transformation can open new pathways for obtaining a desirable combination of strength and ductility in these steels. As an example, FeCrMoVWC steel processed by LPBF shows higher compressive and tensile strength as well as higher fracture strain [229] compared to its cast counterpart [230]. This enhanced mechanical performance is due to several factors such as nanosized carbides $\left(\mathrm{M}_{2} \mathrm{C}\right)$, solid solution effect and above these, TRIP effect of the retained austenite.

\section{Transformation/twinning induced plasticity (TRIP/TWIP) steels}

TRIP/TWIP steels are attractive due to their high work hardening rates, making them ideal candidates for applications such as automotive and defence where a high post-yield plasticity and energy absorption capacity is desired. These steels are 
basically austenitic and go through twinning and/or a martensitic phase transformation during deformation. There are only few papers focusing on the TRIP and TWIP effects in AM-processed austenitic base steels. Most of these works show enhanced tensile properties mainly due to the opportunities existing in AM to locally change the chemistry and in turn stacking fault energy that controls the deformation mechanism.

Heterogenous (location dependent) TRIP and TWIP effects can be observed in DED high Mn steel due to the heterogeneity in the chemical composition that affects the stacking fault energy and the dominant deformation mechanism (Fig. 19) [231]. This is in contrast to what is observed in the same alloy produced via conventional processing or LPBF. Notably, such heterogeneity does not affect the macroscopic deformation behaviour. It has also been found that increasing the $\mathrm{Al}$ content during DED decreases the work hardening rate. This is mainly due to an increase in the stacking fault energy with $\mathrm{Al}$ content that shifts the deformation mechanism from twinning to the cross-slip. Through site-specific change in the chemical composition during AM, one can induce site-specific deformation mechanisms. For example, $\mathrm{X} 30 \mathrm{MnAl} 23-1$ is of a chemical composition that yields a stacking fault energy value low enough to activate the TWIP effect only while avoiding the TRIP effect. This results in high specific energy absorption and predictable compressive deformation behaviour as no brittle martensite is formed during straining. Such capabilities to design microstructures and in turn micro-deformation mechanisms are promising for high $\mathrm{Mn}$ steel, considering the difficulties associated with their conventional processing.

Other studies show that high Mn steels processed with LPBF possess strength levels higher than the conventionally processed steels at the expense of elongation [232]. The presence of $\varepsilon$ - and $\alpha^{\prime}$-martensite as well as the high density of dislocations provide high strength while porosities and impurities typical of AM deteriorate the formability. The same work hardening rate is achieved for these steels irrespective of their fabrication route, with both TWIP and TRIP effects. An anisotropy in the tensile properties of these AM steels is, however, observed which is mainly due to the anisotropic texture and elongated grain morphology. The TRIP effect can impart a surprisingly high elongation to a LPBF 304L steel despite the observation of porosities [233]. Such

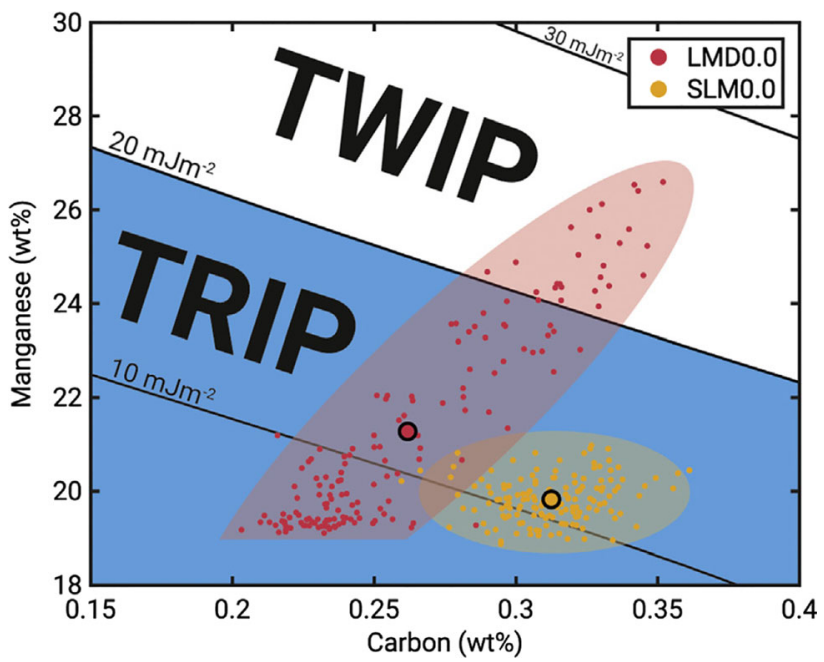

Figure 19 A schematic showing how the variation in local chemical composition during LPBF (= SLM) and DED (= LMD) of the same steel changes the stacking fault energy and, in turn, the activation of TRIP/TWIP effects. The point cloud covers both intra- and interdendritic regions, while the bold dot represents the mean chemical composition. Adapted from Ref. [231] with permission.

excellent ductility is due to a secondary hardening effect by the martensite formed during tensile deformation, as martensite can accommodate more load compared to austenite, resulting in an increased plasticity.

The TWIP effect can be activated in LPBF 316L austenitic stainless steel [234]. This has been attributed to the role of $\mathrm{N}$ that decreases the stacking fault energy of 316L steel into the TWIP region. Twinninginduced plasticity can override the detrimental effect of porosity and other defects on ductility of AM samples. The synergy between the TWIP effect and the high strength resulting from hierarchical fine subgrains can offer new windows for AM austenitic stainless steels. Generally, the TRIP effect is a main factor in advanced properties of AM tool steels and $\mathrm{PH} /$ maraging steels with significant volume of retained austenite. This has been discussed in sections on tool steels and $\mathrm{PH} /$ maraging steels.

\section{Concluding remarks}

This review highlights that AM is capable of fabricating parts made of various common grades of steels that can have properties comparable and superior to their conventionally processed counterparts. These 
achievements, together with the geometrical flexibility, rapid production and the possibility to design the microstructure via targeted optimisation of printing parameters, pave the way towards much more widespread application of AM techniques in the future of steel production. A wide range of steels can nowadays be processed by AM with near-to- $100 \%$ density. The main conclusions from the existing literature on AM steels can be summarised as follows: Austenitic stainless steels

- Austenitic stainless steels are the most widely used class of steels in AM. They offer an exceptional combination of strength and ductility due to nano-inclusions and low angle grain (cell) boundaries that hinder dislocation movements. These microstructural features also result in good wear and fatigue properties as well as resistance to $\mathrm{H}$ embrittlement, comparable to wrought conditions.

- AM enhances the pitting corrosion resistance of these steels mainly due to the rapid solidification inherent to AM that limits the formation of MnS inclusions. Erosion-corrosion and intergranular corrosion behaviour of these steels in AM conditions are still a matter of debate.

- Residual stresses, anisotropy and formation of pores are the current challenges of AM of austenitic stainless steels. Moreover, most of the current standard heat treatments might not be applicable to the AM stainless steels, and optimising heat treatment routes for AM products seems essential.

Maraging/PH stainless steels

- The most commonly used PH stainless steel in AM so far is 17-4 PH stainless steel, due to its high printability and diverse range of applications.

- AM 17-4 and 15-5 PH stainless steels as well as $18 \mathrm{Ni} 300$ maraging steels offer high strength due to their refined microstructures, while ductility is reduced due to porosity resultant from the AM process.

- Fatigue resistance of both 15-5 and 17-4 PH steels in AM conditions is poor compared to the wrought conditions, mostly due to the poor surface finish resulting from the AM process.

- AM 17-4 PH steels can show promising strength/ductility combinations due to the presence of austenite that transforms to martensite during mechanical testing (a TRIP-assisted effect).

- The wear performance of AM 17-4 PH stainless steel depends on the wear mechanism. When tested dry, AM products show better wear properties due to the finer microstructure and higher hardness. However, in the lubricated condition, the AM samples show a higher wear rate as lubrication changes the dominant wear mechanisms from adhesion to surface fatigue and abrasion.

- The high austenite content in non-solution-treated AM PH steels causes greater corrosion resistance than solution treated samples, due to the greater surface potential of austenite than martensite.

- LPBF PH steels exhibit a reduced corrosion resistance compared to conventionally produced materials due to their greater level of porosity. In particular, the presence of pores $>50 \mu \mathrm{m}$ in diameter trigger active corrosion whilst passive behaviour persists around regions of pores $<10 \mu \mathrm{m}$.

- $\mathrm{AM}$ can act as intrinsic heat treatment, triggering 'in situ' phase transformations including tempering and other precipitation phenomena. This offers potential to eliminate some of the traditional heat treatments needed for certain grades of steels such as PH stainless steels and tool steels.

Other steels

- Two types of the AM methods, i.e. LPBF and DED have mainly been employed for duplex stainless steels, and the microstructures obtained through these techniques are different. LPBF parts show mostly a ferritic microstructure with high strength but poor ductility, necessitating further heat treatments, while DED-produced parts exhibit a considerable fraction of austenite offering higher ductility at the expense of strength.

- Annealing of AM duplex stainless steel decreases the UTS, but increases the elongation and pitting corrosion resistance. The volume fraction of austenite and hardness both increase with the $N$ level.

- Different grades of ferritic/martensitic steels can be successfully processed via AM. The processing parameters such as substrate temperature as well as post-AM heat treatment significantly change the microstructure and properties of these steels. 
- Silicon steels of up to $6.9 \mathrm{wt} \% \mathrm{Si}$ have been successfully processed by AM showing promising magnetic properties. In order to achieve excellent quasi-static magnetic properties, annealing of AM products is necessitated to reduce the density of lattice defects.

- AM processing of carbon bearing tool steels is challenging due to their susceptibility to cracking. This is due to low toughness, segregation of $C$ to the melt surface that reduces wettability and severe thermal gradients during AM.

- H13 is the most common tool steel in the AM context. LPBF and DED-processed H13 possess a martensite plus retained austenite microstructure. H13 fabricated by DED experiences an extensive intrinsic heat treatment during deposition resulting in an in situ tempering of martensite.

- Preheating of the base plate is a critical step in successful AM of tool steels. The properties of AM H13 are, in turn, highly dependent on the base plate preheat temperature.

- Wear and fatigue performance as well as inhomogeneity of the properties across the builds is the main challenges in AM of tool steels. The most important reason is the low surface quality due to the porosity and cavities at the surface resulted from insufficiently melted powder and insufficient layer connection. AM parts also suffer from a higher density of volume defects such as pores and cavities, lamellar structures and higher $\mathrm{O}$ contents compared to their wrought counterparts.

- AM can potentially eliminate the pre-austenitisation step of hardening for C-bearing tool steels. By tempering of the AM parts only, the mechanical properties can outperform those of conventionally processed materials.

- Generally, the TRIP effect is a major reason behind the advanced properties of AM tool steels and $\mathrm{PH} /$ maraging steels as a significantly higher volume of retained austenite is achieved in AM of these steels compared to conventional processing.

- TRIP and TWIP effects can be induced in AM steels resulting in enhanced tensile properties. This is mainly due to the opportunities existing in AM to locally change the chemistry and, in turn stacking fault energy, that determines the predominant deformation mechanism.

- Heterogenous (location dependent) TRIP and TWIP effects can be observed in DED high Mn steels due to the heterogeneity in the chemical composition that affects the stacking fault energy.

Steels are the most prominent structural engineering materials used by mankind, owing to their countless design opportunities on offer via systematic control of allotropic transformations during thermal treatments. This implies that severe temperature gradients and exceptionally high cooling rates as well as the inherent chemical heterogeneities in AM unlock the potential to generate unique microstructures in steels. Further, the unique microstructural evolution during AM will necessitate the development of new post-processing heat treatment schedules that might be different from the ones developed for conventional processing routes. There are still some downsides and limitations with AM of steels such as residual stresses, poor surface quality, microstructural inhomogeneity and anisotropy. Some properties of the AM steel parts remain puzzling, and more research needs to be done.

While the future of steel AM is bright, more work is needed in order for AM to replace conventional processing of steels in more areas. Perhaps the most promising observation in steel AM is that unique microstructures can be engineered that have not yet been achieved through conventional processing routes. This highlights the potential of developing AM-specific steels that profit from the typical thermal cycles associated with AM.

\section{Acknowledgements}

Funding by the AUSMURI program, Department of Industry, Innovation and Science, Australia, is acknowledged. A/Prof Sophie Primig is supported under the Australian Research Council's DECRA (project number DE180100440) and the UNSW Scientia Fellowship schemes.

\section{Funding}

This study was funded by Department of Industry, Innovation and Science, Australia, and Australian Research Council. 


\section{Compliance with ethical standards}

Conflict of interest The authors declare that they have no conflict of interest.

Open Access This article is licensed under a Creative Commons Attribution 4.0 International License, which permits use, sharing, adaptation, distribution and reproduction in any medium or format, as long as you give appropriate credit to the original author(s) and the source, provide a link to the Creative Commons licence, and indicate if changes were made. The images or other third party material in this article are included in the article's Creative Commons licence, unless indicated otherwise in a credit line to the material. If material is not included in the article's Creative Commons licence and your intended use is not permitted by statutory regulation or exceeds the permitted use, you will need to obtain permission directly from the copyright holder. To view a copy of this licence, visit http://creativecommons.org/licen ses/by $/ 4.0 /$.

\section{References}

[1] Niaki MK, Nonino F (2018) The management of additive manufacturing. Springer, Berlin, pp 973-978

[2] Gibson I, Rosen DW, Stucker B (2014) Additive manufacturing technologies. Springer, Berlin

[3] Ciraud L (1973) A method and apparatus for making any belongings from any fusible material. German patent application DE 19722263777A1

[4] Meiners W, Wissenbach K, Gasser A (1996) Shaped body especially prototype or replacement part production. DE Patent 19649865

[5] Deckard C (1986) Part generation by layer-wise selective laser sintering, MS. Univeristy of Texas-Austin, Austin

[6] Yap CY, Chua CK, Dong ZL, Liu ZH, Zhang DQ, Loh LE, Sing SL (2015) Review of selective laser melting: materials and applications. Appl Phys Rev 2(4):041101

[7] Bhadeshia H, Honeycombe R (2017) Steels: microstructure and properties. Butterworth-Heinemann, Oxford

[8] Peng T, Kellens K, Tang R, Chen C, Chen G (2018) Sustainability of additive manufacturing: an overview on its energy demand and environmental impact. Addit Manuf 21:694-704

[9] Sreenivasan R, Goel A, Bourell DL (2010) Sustainability issues in laser-based additive manufacturing. Phys Procedia $5: 81-90$
[10] Huang R, Riddle M, Graziano D, Warren J, Das S, Nimbalkar S, Cresko J, Masanet E (2016) Energy and emissions saving potential of additive manufacturing: the case of lightweight aircraft components. J Clean Prod 135:1559-1570

[11] Fitzsimons L, McNamara G, Obeidi M, Brabazon D (2020) The circular economy: additive manufacturing and impacts for materials processing. Encyclopedia of Renewable and Sustainable Materials 1:81-92

[12] Bourell DL (2016) Perspectives on additive manufacturing. Annu Rev Mater Res 46:1-18

[13] Plotkowski A, Rios O, Sridharan N, Sims Z, Unocic K, Ott R, Dehoff R, Babu S (2017) Evaluation of an Al-Ce alloy for laser additive manufacturing. Acta Mater 126:507-519

[14] Fayazfar H, Salarian M, Rogalsky A, Sarker D, Russo P, Paserin V, Toyserkani E (2018) A critical review of powder-based additive manufacturing of ferrous alloys: process parameters, microstructure and mechanical properties. Mater Des 144:98-128

[15] Herzog D, Seyda V, Wycisk E, Emmelmann C (2016) Additive manufacturing of metals. Acta Mater 117:371-392

[16] Lewandowski JJ, Seifi M (2016) Metal additive manufacturing: a review of mechanical properties. Annu Rev Mater Res 46:151-186

[17] Sander G, Tan J, Balan P, Gharbi O, Feenstra D, Singer L, Thomas S, Kelly R, Scully J, Birbilis N (2018) Corrosion of additively manufactured alloys: a review. Corrosion 74(12):1318-1350

[18] Kong D, Dong C, Ni X, Li X (2019) Corrosion of metallic materials fabricated by selective laser melting. NPJ Mater Degrad 3(1):1-14

[19] Bajaj P, Hariharan A, Kini A, Kürnsteiner P, Raabe D, Jägle EA (2019) Steels in additive manufacturing: a review of their microstructure and properties. Mater Sci Eng A $772: 138633$

[20] Boegelein T, Dryepondt SN, Pandey A, Dawson K, Tatlock GJ (2015) Mechanical response and deformation mechanisms of ferritic oxide dispersion strengthened steel structures produced by selective laser melting. Acta Mater 87:201-215

[21] Shi Y, Lu Z, Yu L, Xie R, Ren Y, Yang G (2020) Microstructure and tensile properties of $\mathrm{Zr}$-containing ODS-FeCrAl alloy fabricated by laser additive manufacturing. Mater Sci Eng A 774:138937

[22] Shi Y, Lu Z, Xu H, Xie R, Ren Y, Yang G (2019) Microstructure characterization and mechanical properties of laser additive manufactured oxide dispersion strengthened Fe-9Cr alloy. J Alloys Compd 791:121-133 
[23] Yan X, Huang C, Chen C, Bolot R, Dembinski L, Huang R, Ma W, Liao H, Liu M (2019) Additive manufacturing of WC reinforced maraging steel 300 composites by cold spraying and selective laser melting. Surf Coat Technol 371:161-171

[24] Yan X, Chen C, Zhao R, Ma W, Bolot R, Wang J, Ren Z, Liao H, Liu M (2019) Selective laser melting of WC reinforced maraging steel 300: microstructure characterization and tribological performance. Surf Coat Technol 371:355-365

[25] Shi R, Khairallah SA, Roehling TT, Heo TW, McKeown JT, Matthews MJ (2020) Microstructural control in metal laser powder bed fusion additive manufacturing using laser beam shaping strategy. Acta Mater 184:284-305

[26] Xu W, Lui E, Pateras A, Qian M, Brandt M (2017) In situ tailoring microstructure in additively manufactured $\mathrm{Ti}-$ $6 \mathrm{Al}-4 \mathrm{~V}$ for superior mechanical performance. Acta Mater 125:390-400

[27] Sun S-H, Ishimoto T, Hagihara K, Tsutsumi Y, Hanawa T, Nakano T (2019) Excellent mechanical and corrosion properties of austenitic stainless steel with a unique crystallographic lamellar microstructure via selective laser melting. Scr Mater 159:89-93

[28] Bartolomeu F, Buciumeanu M, Pinto E, Alves N, Carvalho O, Silva F, Miranda G (2017) 316L stainless steel mechanical and tribological behavior - a comparison between selective laser melting, hot pressing and conventional casting. Addit Manuf 16:81-89

[29] Ma M, Wang Z, Zeng X (2017) A comparison on metallurgical behaviors of $316 \mathrm{~L}$ stainless steel by selective laser melting and laser cladding deposition. Mater Sci Eng A 685:265-273

[30] Hooper PA (2018) Melt pool temperature and cooling rates in laser powder bed fusion. Addit Manuf 22:548-559

[31] Sun S, Brandt M, Easton M (2017) Powder bed fusion processes: an overview, laser additive manufacturing. Elsevier, Amsterdam, pp 55-77

[32] Farshidianfar MH, Khajepour A, Gerlich AP (2016) Effect of real-time cooling rate on microstructure in laser additive manufacturing. J Mater Process Technol 231:468-478

[33] Niendorf T, Leuders S, Riemer A, Richard HA, Tröster T, Schwarze D (2013) Highly anisotropic steel processed by selective laser melting. Metall Mater Trans B 44(4):794-796

[34] Liu J, To AC (2017) Quantitative texture prediction of epitaxial columnar grains in additive manufacturing using selective laser melting. Addit Manuf 16:58-64

[35] Kirka MM, Lee Y, Greeley DA, Okello A, Goin MJ, Pearce MT, Dehoff RR (2017) Strategy for texture management in metals additive manufacturing. JOM 69(3):523-531
[36] Laleh M, Hughes AE, Xu W, Haghdadi N, Wang K, Cizek P, Gibson I, Tan MY (2019) On the unusual intergranular corrosion resistance of $316 \mathrm{~L}$ stainless steel additively manufactured by selective laser melting. Corros Sci 161:108189

[37] Zhang B, Li Y, Bai Q (2017) Defect formation mechanisms in selective laser melting: a review. Chin J Mech Eng 30(3):515-527

[38] Zhao X, Chen J, Lin X, Huang W (2008) Study on microstructure and mechanical properties of laser rapid forming Inconel 718. Mater Sci Eng A 478(1-2):119-124

[39] Cunningham R, Zhao C, Parab N, Kantzos C, Pauza J, Fezzaa K, Sun T, Rollett AD (2019) Keyhole threshold and morphology in laser melting revealed by ultrahigh-speed X-ray imaging. Science 363(6429):849-852

[40] Li R, Liu J, Shi Y, Wang L, Jiang W (2012) Balling behavior of stainless steel and nickel powder during selective laser melting process. Int $\mathrm{J}$ Adv Manuf Technol 59(9-12):1025-1035

[41] Khairallah SA, Anderson A (2014) Mesoscopic simulation model of selective laser melting of stainless steel powder. J Mater Process Technol 214(11):2627-2636

[42] Khairallah SA, Anderson AT, Rubenchik A, King WE (2016) Laser powder-bed fusion additive manufacturing: physics of complex melt flow and formation mechanisms of pores, spatter, and denudation zones. Acta Mater 108:36-45

[43] Gorsse S, Hutchinson C, Gouné M, Banerjee R (2017) Additive manufacturing of metals: a brief review of the characteristic microstructures and properties of steels, Ti$6 \mathrm{Al}-4 \mathrm{~V}$ and high-entropy alloys. Sci Technol Adv Mater 18(1):584-610

[44] Godec M, Zaefferer S, Podgornik B, Šinko M, Tchernychova E (2020) Quantitative multiscale correlative microstructure analysis of additive manufacturing of stainless steel 316L processed by selective laser melting. Mater Charact 160:110074

[45] Park JH, Kang Y (2017) Inclusions in stainless steels - a review. Steel Res Int 88(12):1700130

[46] Saeidi K, Kvetková L, Lofaj F, Shen Z (2015) Austenitic stainless steel strengthened by the in situ formation of oxide nanoinclusions. RSC Adv 5(27):20747-20750

[47] Saeidi K, Gao X, Zhong Y, Shen ZJ (2015) Hardened austenite steel with columnar sub-grain structure formed by laser melting. Mater Sci Eng A 625:221-229

[48] Yan F, Xiong W, Faierson E, Olson GB (2018) Characterization of nano-scale oxides in austenitic stainless steel processed by powder bed fusion. Scr Mater 155:104-108

[49] Costa e Silva A (2018) Non-metallic inclusions in steelsorigin and control. J Mater Res Technol 3:283-299 
[50] Wang YM, Voisin T, McKeown JT, Ye J, Calta NP, Li Z, Zeng Z, Zhang Y, Chen W, Roehling TT (2018) Additively manufactured hierarchical stainless steels with high strength and ductility. Nat Mater 17(1):63-70

[51] Sun Z, Tan X, Tor SB, Chua CK (2018) Simultaneously enhanced strength and ductility for 3D-printed stainless steel $316 \mathrm{~L}$ by selective laser melting. NPG Asia Mater 10(4):127-136

[52] Riemer A, Leuders S, Thöne M, Richard H, Tröster T, Niendorf T (2014) On the fatigue crack growth behavior in 316L stainless steel manufactured by selective laser melting. Eng Fract Mech 120:15-25

[53] Pegues JW, Roach MD, Shamsaei N (2020) Additive manufacturing of fatigue resistant austenitic stainless steels by understanding process-structure-property relationships. Mater Res Lett 8(1):8-15

[54] Alvi S, Saeidi K, Akhtar F (2020) High temperature tribology and wear of selective laser melted (SLM) 316L stainless steel. Wear 448:203228

[55] Ryan MP, Williams DE, Chater RJ, Hutton BM, McPhail DS (2002) Why stainless steel corrodes. Nature 415(6873):770

[56] Meng Q, Frankel G, Colijn H, Goss S (2003) Metallurgy (communication arising): stainless-steel corrosion and $\mathrm{MnS}$ inclusions. Nature 424(6947):389-390

[57] Frankel G (1998) Pitting corrosion of metals a review of the critical factors. J Electrochem Soc 145(6):2186-2198

[58] Newman RC (2002) Beyond the kitchen sink. Nature 415(6873):743-744

[59] Sedriks A (1983) Role of sulphide inclusions in pitting and crevice corrosion of stainless steels. Int Met Rev 28(1):295-307

[60] Searson P, Latanision R (1986) A comparison of the general and localized corrosion resistance of conventional and rapidly solidified AISI 303 stainless steel. Corrosion 42(3):161-168

[61] Stewart J, Williams D (1992) The initiation of pitting corrosion on austenitic stainless steel: on the role and importance of sulphide inclusions. Corros Sci 33(3):457-474

[62] Sander G, Thomas S, Cruz V, Jurg M, Birbilis N, Gao X, Brameld M, Hutchinson C (2017) On the corrosion and metastable pitting characteristics of 316L stainless steel produced by selective laser melting. J Electrochem Soc 164(6):C250-C257

[63] Laleh M, Hughes AE, Xu W, Gibson I, Tan MY (2019) Unexpected erosion-corrosion behaviour of $316 \mathrm{~L}$ stainless steel produced by selective laser melting. Corros Sci 155:67-74

[64] Laleh M, Hughes AE, Xu W, Cizek P, Tan MY (2019) Unanticipated drastic decline in pitting corrosion resistance of additively manufactured 316L stainless steel after hightemperature post-processing. Corros Sci 165:108412

[65] Chao Q, Cruz V, Thomas S, Birbilis N, Collins P, Taylor A, Hodgson PD, Fabijanic D (2017) On the enhanced corrosion resistance of a selective laser melted austenitic stainless steel. Scr Mater 141:94-98

[66] Sun Y, Moroz A, Alrbaey K (2014) Sliding wear characteristics and corrosion behaviour of selective laser melted 316L stainless steel. J Mater Eng Perform 23(2):518-526

[67] Kazemipour M, Mohammadi M, Mfoumou E, Nasiri A (2019) Microstructure and corrosion characteristics of selective laser-melted $316 \mathrm{~L}$ stainless steel: the impact of process-induced porosities. JOM 71(9):3230-3240

[68] Kong D, Dong C, Ni X, Zhang L, Luo H, Li R, Wang L, Man C, Li X (2020) The passivity of selective laser melted 316L stainless steel. Appl Surf Sci 504:144495

[69] Hopkinson B, Carroll K (1959) Chromium distribution around grain boundary carbides found in austenitic stainless steel. Nature 184(4697):1479-1480

[70] Cíhal V, Kašová I (1970) Relation between carbide precipitation and intercrystalline corrosion of stainless steels. Corros Sci 10(12):875-881

[71] Macatangay D, Thomas S, Birbilis N, Kelly R (2017) Unexpected interface corrosion and sensitization susceptibility in additively manufactured austenitic stainless steel. Corrosion 74(2):153-157

[72] Man C, Duan Z, Cui Z, Dong C, Kong D, Liu T, Chen S, Wang X (2019) The effect of sub-grain structure on intergranular corrosion of $316 \mathrm{~L}$ stainless steel fabricated via selective laser melting. Mater Lett 243:157-160

[73] Kong D, Dong C, Ni X, Zhang L, Luo H, Li R, Wang L, Man C, Li X (2020) Superior resistance to hydrogen damage for selective laser melted $316 \mathrm{~L}$ stainless steel in a proton exchange membrane fuel cell environment. Corros Sci 166:108425

[74] Baek S-W, Song EJ, Kim JH, Jung M, Baek UB, Nahm SH (2017) Hydrogen embrittlement of 3-D printing manufactured austenitic stainless steel part for hydrogen service. Scr Mater 130:87-90

[75] Shiomi M, Osakada K, Nakamura K, Yamashita T, Abe F (2004) Residual stress within metallic model made by selective laser melting process. CIRP Ann 53(1):195-198

[76] Mercelis P, Kruth JP (2006) Residual stresses in selective laser sintering and selective laser melting. Rapid Prototyp J 12(5):254-265

[77] De Bruycker E, Montero Sistiaga M, Thielemans F, Vanmeensel K (2017) Corrosion testing of a heat treated 3161 functional part produced by selective laser melting. Mater Sci Appl 8:223-233 
[78] Lou X, Song M, Emigh PW, Othon MA, Andresen PL (2017) On the stress corrosion crack growth behaviour in high temperature water of $316 \mathrm{~L}$ stainless steel made by laser powder bed fusion additive manufacturing. Corros Sci 128:140-153

[79] Lou X, Andresen PL, Rebak RB (2018) Oxide inclusions in laser additive manufactured stainless steel and their effects on impact toughness and stress corrosion cracking behavior. J Nucl Mater 499:182-190

[80] Zaeh MF, Branner G (2010) Investigations on residual stresses and deformations in selective laser melting. Prod Eng Res Devel 4(1):35-45

[81] Kruth J-P, Deckers J, Yasa E, Wauthlé R (2012) Assessing and comparing influencing factors of residual stresses in selective laser melting using a novel analysis method. Proc Inst Mech Eng Pt B J Eng Manuf 226(6):980-991

[82] Kruth J-P, Froyen L, Van Vaerenbergh J, Mercelis P, Rombouts M, Lauwers B (2004) Selective laser melting of iron-based powder. J Mater Process Technol 149(1-3):616-622

[83] Wu AS, Brown DW, Kumar M, Gallegos GF, King WE (2014) An experimental investigation into additive manufacturing-induced residual stresses in 316L stainless steel. Metall Mater Trans A 45(13):6260-6270

[84] Cheng B, Shrestha S, Chou K (2016) Stress and deformation evaluations of scanning strategy effect in selective laser melting. Addit Manuf 12:240-251

[85] Lou X, Othon MA, Rebak RB (2017) Corrosion fatigue crack growth of laser additively-manufactured $316 \mathrm{~L}$ stainless steel in high temperature water. Corros Sci 127:120-130

[86] Shamsaei N, Yadollahi A, Bian L, Thompson SM (2015) An overview of direct laser deposition for additive manufacturing; part II: mechanical behavior, process parameter optimization and control. Addit Manuf 8:12-35

[87] Yadollahi A, Shamsaei N, Thompson SM, Elwany A, Bian L (2017) Effects of building orientation and heat treatment on fatigue behavior of selective laser melted 17-4 PH stainless steel. Int J Fatigue 94:218-235

[88] Mertens A, Reginster S, Contrepois Q, Dormal T, Lemaire O, Lecomte-Beckers J (2014) Microstructures and mechanical properties of stainless steel AISI 316L processed by selective laser melting. Trans Tech Publ, Mater Sci Forum, pp 898-903

[89] Kok Y, Tan XP, Wang P, Nai M, Loh NH, Liu E, Tor SB (2018) Anisotropy and heterogeneity of microstructure and mechanical properties in metal additive manufacturing: a critical review. Mater Des 139:565-586

[90] Andreatta F, Lanzutti A, Vaglio E, Totis G, Sortino M, Fedrizzi L (2019) Corrosion behaviour of 316L stainless steel manufactured by selective laser melting. Mater Corros 70(9):1633-1645

[91] Li H, Ramezani M, Li M, Ma C, Wang J (2018) Tribological performance of selective laser melted $316 \mathrm{~L}$ stainless steel. Tribol Int 128:121-129

[92] Carlton HD, Haboub A, Gallegos GF, Parkinson DY, MacDowell AA (2016) Damage evolution and failure mechanisms in additively manufactured stainless steel. Mater Sci Eng A 651:406-414

[93] Zhu Y, Zou J, Chen X, Yang H (2016) Tribology of selective laser melting processed parts: stainless steel $316 \mathrm{~L}$ under lubricated conditions. Wear 350:46-55

[94] Shrestha R, Simsiriwong J, Shamsaei N (2019) Fatigue behavior of additive manufactured $316 \mathrm{~L}$ stainless steel parts: effects of layer orientation and surface roughness. Addit Manuf 28:23-38

[95] Yadollahi A, Shamsaei N (2017) Additive manufacturing of fatigue resistant materials: challenges and opportunities. Int J Fatigue 98:14-31

[96] Laleh M, Hughes AE, Yang S, Li J, Xu W, Gibson I, Tan MY (2019) Two and three-dimensional characterisation of localised corrosion affected by lack-of-fusion pores in $316 \mathrm{~L}$ stainless steel produced by selective laser melting. Corros Sci 165:108394

[97] Schaller RF, Mishra A, Rodelas JM, Taylor JM, Schindelholz EJ (2018) The role of microstructure and surface finish on the corrosion of selective laser melted 304L. J Electrochem Soc 165(5):C234-C242

[98] Melia MA, Nguyen H-DA, Rodelas JM, Schindelholz EJ (2019) Corrosion properties of 304L stainless steel made by directed energy deposition additive manufacturing. Corros Sci 152:20-30

[99] Duan Z, Man C, Dong C, Cui Z, Kong D, Wang X (2020) Pitting behavior of SLM 316L stainless steel exposed to chloride environments with different aggressiveness: pitting mechanism induced by gas pores. Corros Sci 167:108520

[100] Davis JR (1997) ASM specialty handbook: heat-resistant materials. ASM International, Cleveland

[101] Padilha AF, Plaut RL, Rios PR (2006) Stainless steel heat treatment, steel heat treatment. CRC Press, Boca Raton, pp 706-751

[102] Cruz V, Chao Q, Birbilis N, Fabijanic D, Hodgson P, Thomas S (2019) Electrochemical studies on the effect of residual stress on the corrosion of 316L manufactured by selective laser melting. Corros Sci 164:108314

[103] Zhou C, Hu S, Shi Q, Tao H, Song Y, Zheng J, Xu P, Zhang L (2020) Improvement of corrosion resistance of SS316L manufactured by selective laser melting through subcritical annealing. Corros Sci 164:108353 
[104] Kong D, Dong C, Ni X, Zhang L, Yao J, Man C, Cheng X, Xiao K, Li X (2019) Mechanical properties and corrosion behavior of selective laser melted $316 \mathrm{~L}$ stainless steel after different heat treatment processes. J Mater Sci Technol 35(7):1499-1507. https://doi.org/10.1016/j.jmst.2019.03. 003

[105] McGuire MF (2008) Stainless steels for design engineers. ASM International, Cleveland

[106] Yasa E, Kempen K, Kruth J, Thijs L, Van Humbeeck J (2010) Microstructure and mechanical properties of maraging steel 300 after selective laser melting. In: Solid freeform fabrication symposium proceedings, pp 383-396

[107] Malakondaiah G, Srinivas M, Rao PR (1995) Basic studies leading to the development of an ultrahigh strength, high fracture toughness low-alloy steel. Bull Mater Sci 18(4):325-341

[108] Committee AH (1991) ASM Handbook Volume 4 Heat Treating, ASM Standards. American Society for Metals, Materials Park

[109] https://www.aksteel.com/sites/default/files/2018-01/155ph2 01706.pdf

[110] Croccolo D, De Agostinis M, Fini S, Olmi G, Bogojevic N, Ciric-Kostic S (2018) Effects of build orientation and thickness of allowance on the fatigue behaviour of 15-5 PH stainless steel manufactured by DMLS. Fatigue Fract Eng Mater Struct 41(4):900-916

[111] Palanisamy D, Senthil P, Senthilkumar V (2016) The effect of aging on machinability of $15 \mathrm{Cr}-5 \mathrm{Ni}$ precipitation hardened stainless steel. Arch Civ Mech Eng 16(1):53-63

[112] Casati R, Lemke JN, Tuissi A, Vedani M (2016) Aging behaviour and mechanical performance of 18-Ni 300 steel processed by selective laser melting. Metals 6(9):218-230

[113] Jägle EA, Sheng Z, Wu L, Lu L, Risse J, Weisheit A, Raabe D (2016) Precipitation reactions in age-hardenable alloys during laser additive manufacturing. JOM 68(3):943-949

[114] Sha W, Cerezo A, Smith G (1993) Phase chemistry and precipitation reactions in maraging steels: part IV. Discussion and conclusions. Metall Mater Trans A 24(6):1251-1256

[115] www.aksteel.com/sites/default/files/2018-01/174ph201706. pdf

[116] https://cdn0.scrvt.com/eos/1801f2663ea474ba/efe087ff3ca d/StainlessSteel-CX-M280_Material_data_sheet_09-15_en. pdf

[117] Asgari H, Mohammadi M (2018) Microstructure and mechanical properties of stainless steel CX manufactured by direct metal laser sintering. Mater Sci Eng A 709:82-89

[118] Yan X, Chen C, Chang C, Dong D, Zhao R, Jenkins R, Wang J, Ren Z, Liu M, Liao H (2020) Study of the microstructure and mechanical performance of CX stainless steel processed by selective laser melting (SLM). Mater Sci Eng A 781:139227

[119] Chang C, Yan X, Bolot R, Gardan J, Gao S, Liu M, Liao H, Chemkhi M, Deng S (2020) Influence of post-heat treatments on the mechanical properties of CX stainless steel fabricated by selective laser melting. J Mater Sci 55:8303-8316. https://doi.org/10.1007/s10853-020-04566 $-\mathrm{x}$

[120] AH (1990) Volume, 1: properties and selection: irons, steels, and high-performance alloys; American Society for Metals; ASM International; The Materials Information Company: Almere, The Netherlands

[121] Roberts D, Zhang Y, Charit I, Zhang J (2018) A comparative study of microstructure and high-temperature mechanical properties of 15-5 $\mathrm{PH}$ stainless steel processed via additive manufacturing and traditional manufacturing. Prog Addit Manuf 3(3):183-190

[122] Rafi HK, Starr TL, Stucker BE (2013) A comparison of the tensile, fatigue, and fracture behavior of $\mathrm{Ti}-6 \mathrm{Al}-4 \mathrm{~V}$ and 15-5 PH stainless steel parts made by selective laser melting. Int J Adv Manuf Technol 69(5-8):1299-1309

[123] Sagar S, Zhang Y, Wu L, Park H-Y, Lee J-H, Jung Y-G, Zhang J (2018) Room-temperature charpy impact property of 3d-printed 15-5 stainless steel. J Mater Eng Perform 27(1):52-56

[124] Spierings AB, Starr TL, Wegener K (2013) Fatigue performance of additive manufactured metallic parts. Rapid Prototyp J 19:88-94

[125] Sarkar S, Kumar CS, Nath AK (2019) Effects of different surface modifications on the fatigue life of selective laser melted 15-5 PH stainless steel. Mater Sci Eng A 762:138109

[126] Sarkar S, Kumar CS, Nath AK (2019) Effects of heat treatment and build orientations on the fatigue life of selective laser melted 15-5 PH stainless steel. Mater Sci Eng A 755:235-245

[127] Lebrun T, Tanigaki K, Horikawa K, Kobayashi H (2014) Strain rate sensitivity and mechanical anisotropy of selective laser melted 17-4 PH stainless steel. Mech Eng J 1(5):SMM0049

[128] Kumpaty S, Kamara S, Tomlin B, Yoo J, Kumpaty H, Anderson D, Govindaraju M, Kanoongo N, Balasubramanian K (2013) Effect of heat treatment on mechanical/ metallurgical properties of direct metal laser sintered 17-4 precipitate hardened stainless steel. Advanced Materials Research, Trans Tech Publ, 2013, pp 795-801

[129] Mahmoudi M, Elwany A, Yadollahi A, Thompson SM, Bian L, Shamsaei N (2017) Mechanical properties and microstructural characterization of selective laser melted 17-4 PH stainless steel. Rapid Prototyp J 23:280-294 
[130] Auguste P, Mauduit A, Fouquet L, Pillot S (2018) Study on 17-4 PH stainless steel produced by selective laser melting. UPB Sci Bull Ser B-Chem Mater Sci 80:197-210

[131] Pasebani S, Ghayoor M, Badwe S, Irrinki H, Atre SV (2018) Effects of atomizing media and post processing on mechanical properties of 17-4 PH stainless steel manufactured via selective laser melting. Addit Manuf 22:127-137

[132] Nezhadfar P, Shrestha R, Phan N, Shamsaei N (2019) Fatigue behavior of additively manufactured 17-4 $\mathrm{PH}$ stainless steel: synergistic effects of surface roughness and heat treatment. Int J Fatigue 124:188-204

[133] Ghayoor M, Badwe SB, Irrinki H, Atre SV, Pasebani S (2018) Water atomized 17-4 PH stainless steel powder as a cheaper alternative powder feedstock for selective laser melting. Mater Sci Forum Trans Tech Publ, pp 698-703

[134] Lass EA, Stoudt MR, Williams ME (2019) Additively manufactured nitrogen-atomized 17-4 $\mathrm{PH}$ stainless steel with mechanical properties comparable to wrought. Metall Mater Trans A 50(4):1619-1624

[135] Carneiro L, Jalalahmadi B, Ashtekar A, Jiang Y (2019) Cyclic deformation and fatigue behavior of additively manufactured 17-4 PH stainless steel. Int J Fatigue 123:22-30

[136] Yadollahi A, Shamsaei N, Thompson SM, Elwany A, Bian L (2015) Mechanical and microstructural properties of selective laser melted 17-4 PH stainless steel. In: ASME 2015 international mechanical engineering congress and exposition, American Society of Mechanical Engineers Digital Collection

[137] Cheruvathur S, Lass EA, Campbell CE (2016) Additive manufacturing of 17-4 PH stainless steel: post-processing heat treatment to achieve uniform reproducible microstructure. JOM 68(3):930-942

[138] Sun Y, Hebert RJ, Aindow M (2018) Effect of heat treatments on microstructural evolution of additively manufactured and wrought $17-4 \mathrm{PH}$ stainless steel. Mater Des 156:429-440

[139] Rafi HK, Pal D, Patil N, Starr TL, Stucker BE (2014) Microstructure and mechanical behavior of 17-4 precipitation hardenable steel processed by selective laser melting. J Mater Eng Perform 23(12):4421-4428

[140] Irrinki H, Jangam JSD, Pasebani S, Badwe S, Stitzel J, Kate K, Gulsoy O, Atre SV (2018) Effects of particle characteristics on the microstructure and mechanical properties of 17-4 PH stainless steel fabricated by laser-powder bed fusion. Powder Technol 331:192-203

[141] Stoudt MR, Ricker RE, Lass E, Levine LE (2017) Influence of postbuild microstructure on the electrochemical behavior of additively manufactured 17-4 PH stainless steel. JOM 69(3):506-515

[142] LeBrun T, Nakamoto T, Horikawa K, Kobayashi H (2015) Effect of retained austenite on subsequent thermal processing and resultant mechanical properties of selective laser melted 17-4 PH stainless steel. Mater Des 81:44-53

[143] Hsu T-H, Chang Y-J, Huang C-Y, Yen H-W, Chen C-P, Jen K-K, Yeh A-C (2019) Microstructure and property of a selective laser melting process induced oxide dispersion strengthened 17-4 PH stainless steel. J Alloys Compd. 803:30-41

[144] AlMangour B, Yang J-M (2016) Improving the surface quality and mechanical properties by shot-peening of 17-4 stainless steel fabricated by additive manufacturing. Mater Des 110:914-924

[145] Facchini L, Vicente N Jr, Lonardelli I, Magalini E, Robotti P, Molinari A (2010) Metastable austenite in 17-4 precipitation-hardening stainless steel produced by selective laser melting. Adv Eng Mater 12(3):184-188

[146] Ponnusamy P, Masood S, Ruan D, Palanisamy S, Rashid RR, Mohamed OA (2017) Mechanical performance of selective laser melted 17-4 PH stainless steel under compressive loading. In: Solid freeform fabrication symosium proceedings, pp 321-331

[147] Jägle EA, Sheng Z, Kürnsteiner P, Ocylok S, Weisheit A, Raabe D (2017) Comparison of maraging steel micro-and nanostructure produced conventionally and by laser additive manufacturing. Materials 10(1):8-22

[148] Wang D, Chi C, Wang W, Li Y, Wang M, Chen X, Chen Z, Cheng X, Xie Y (2019) The effects of fabrication atmosphere condition on the microstructural and mechanical properties of laser direct manufactured stainless steel 17-4 PH. J Mater Sci Technol 35(7):1315-1322. https://doi.org/ 10.1016/j.jmst.2019.03.009

[149] Dobson S, Vunnam S, Frankel D, Sudbrack C, Starr T (2019) Powder variation and mechanical properties for slm 17-4 ph stainless steel. In: Solid freeform fabrication 2019: proceedings of the 30th annual international, pp 478-493

[150] Nezhadfar PD, Masoomi M, Thompson S, Phan N, Shamsaei N (2018) Mechanical properties of 17-4 PH stainless steel additively manufactured under Ar and N2 shielding gas. In: Proceedings of the 29th annual international solid freeform fabrication, Austin, TX, USA, 13-15

[151] Condruz MR, Paraschiv A, Puscasu C (2018) Heat treatment influence on hardness and microstructure of ADAM manufactured 17-4 PH, Turbo 1:39-45

[152] Murr LE, Martinez E, Hernandez J, Collins S, Amato KN, Gaytan SM, Shindo PW (2012) Microstructures and properties of 17-4 PH stainless steel fabricated by selective laser melting. J Mater Res Technol 1(3):167-177 
[153] Kudzal A, McWilliams B, Hofmeister C, Kellogg F, Yu J, Taggart-Scarff J, Liang J (2017) Effect of scan pattern on the microstructure and mechanical properties of powder bed fusion additive manufactured 17-4 stainless steel. Mater Des 133:205-215

[154] Sanjeev K, Nezhadfar P, Phillips C, Kennedy M, Shamsaei N, Jackson R (2019) Tribological behavior of 17-4 PH stainless steel fabricated by traditional manufacturing and laser-based additive manufacturing methods. Wear 440:203100

[155] Caballero A, Ding J, Ganguly S, Williams S (2019) Wire + Arc additive manufacture of 17-4 PH stainless steel: effect of different processing conditions on microstructure, hardness, and tensile strength. J Mater Process Technol 268:54-62

[156] Sung H-J, Ha TK, Ahn S, Chang YW (2002) Powder injection molding of a 17-4 PH stainless steel and the effect of sintering temperature on its microstructure and mechanical properties. J Mater Process Technol 130:321-327

[157] Bhambroo R, Roychowdhury S, Kain V, Raja V (2013) Effect of reverted austenite on mechanical properties of precipitation hardenable 17-4 stainlesssteel. Mater Sci Eng A 568:127-133

[158] Akita M, Uematsu Y, Kakiuchi T, Nakajima M, Kawaguchi R (2016) Defect-dominated fatigue behavior in type 630 stainless steel fabricated by selective laser melting. Mater Sci Eng A 666:19-26

[159] Yadollahi A, Shamsaei N, Thompson SM, Elwany A, Bian L, Mahmoudi M (2015) Fatigue behavior of selective laser melted 17-4 PH stainless steel. In: Proceedings of 26th international solid freeform fabrication symposium, Austin, TX

[160] Casalino G, Campanelli S, Contuzzi N, Ludovico A (2015) Experimental investigation and statistical optimisation of the selective laser melting process of a maraging steel. Opt Laser Technol 65:151-158

[161] Kempen K, Yasa E, Thijs L, Kruth J-P, Van Humbeeck J (2011) Microstructure and mechanical properties of selective laser melted 18Ni-300 steel. Phys Procedia 12:255-263

[162] https:/www.atimetals.com/Products/Documents/datasheet s/stainless-specialty-steel/specialtysteel/ati_c-200-250-300350_tds_en1_v1.pdf

[163] Yin S, Chen C, Yan X, Feng X, Jenkins R, O'Reilly P, Liu M, Li H, Lupoi R (2018) The influence of aging temperature and aging time on the mechanical and tribological properties of selective laser melted maraging $18 \mathrm{Ni}-300$ steel. Addit Manuf 22:592-600

[164] Tan C, Zhou K, Kuang M, Ma W, Kuang T (2018) Microstructural characterization and properties of selective laser melted maraging steel with different build directions. Sci Technol Adv Mater 19(1):746-758

[165] Tan C, Zhou K, Ma W, Zhang P, Liu M, Kuang T (2017) Microstructural evolution, nanoprecipitation behavior and mechanical properties of selective laser melted high-performance grade 300 maraging steel. Mater Des 134:23-34

[166] Monkova K, Zetkova I, Kučerová L, Zetek M, Monka P, Daňa M (2019) Study of 3D printing direction and effects of heat treatment on mechanical properties of MS1 maraging steel. Arch Appl Mech 89(5):791-804

[167] Damon J, Hanemann T, Dietrich S, Graf G, Lang K-H, Schulze V (2019) Orientation dependent fatigue performance and mechanisms of selective laser melted maraging steel X3NiCoMoTi18-9-5. Int J Fatigue 127:395-402

[168] Kučerová L, Zetková I, Jandová A, Bystrianský M (2019) Microstructural characterisation and in-situ straining of additive-manufactured $\mathrm{X} 3 \mathrm{NiCoMoTi}$ 18-9-5 maraging steel. Mater Sci Eng A 750:70-80

[169] Bai Y, Yang Y, Wang D, Zhang M (2017) Influence mechanism of parameters process and mechanical properties evolution mechanism of maraging steel 300 by selective laser melting. Mater Sci Eng A 703:116-123

[170] A.M.-p.P.d. bulletin, https://www.aksteel.com/sites/default/ files/2018-01/155ph201706.pdf

[171] Meneghetti G, Rigon D, Gennari C (2019) An analysis of defects influence on axial fatigue strength of maraging steel specimens produced by additive manufacturing. Int J Fatigue 118:54-64

[172] Branco R, Costa JD, Berto F, Razavi SMJ, Ferreira JAM, Capela C, Santos L, Antunes F (2018) Low-cycle fatigue behaviour of AISI $18 \mathrm{Ni} 300$ maraging steel produced by selective laser melting. Metals 8(1):32-46

[173] Wang L, Dong C, Man C, Kong D, Xiao K, Li X (2020) Enhancing the corrosion resistance of selective laser melted 15-5PH martensite stainless steel via heat treatment. Corros Sci 166:108427

[174] Schaller RF, Taylor JM, Rodelas J, Schindelholz EJ (2017) Corrosion properties of powder bed fusion additively manufactured 17-4 PH stainless steel. Corrosion 73(7):796-807

[175] Irrinki H, Harper T, Badwe S, Stitzel J, Gulsoy O, Gupta G, Atre SV (2018) Effects of powder characteristics and processing conditions on the corrosion performance of 17-4 PH stainless steel fabricated by laser-powder bed fusion. Progress Addit Manuf 3(1-2):39-49

[176] Alnajjar M, Christien F, Barnier V, Bosch C, Wolski K, Fortes AD, Telling M (2020) Influence of microstructure and manganese sulfides on corrosion resistance of selective laser melted 17-4 $\mathrm{PH}$ stainless steel in acidic chloride medium. Corros Sci 168:108585 
[177] Gunn R (1997) Duplex stainless steels: microstructure, properties and applications. Elsevier, Amsterdam

[178] https://www.materials.sandvik/en/

[179] Davidson K, Singamneni S (2016) Selective laser melting of duplex stainless steel powders: an investigation. Mater Manuf Process 31(12):1543-1555

[180] Saeidi K, Kevetkova L, Lofaj F, Shen Z (2016) Novel ferritic stainless steel formed by laser melting from duplex stainless steel powder with advanced mechanical properties and high ductility. Mater Sci Eng A 665:59-65

[181] Saeidi K, Alvi S, Lofaj F, Petkov VI, Akhtar F (2019) Advanced mechanical strength in post heat treated SLM 2507 at room and high temperature promoted by hard/ductile sigma precipitates. Metals 9(2):199-209

[182] Davidson KP, Singamneni S (2017) Magnetic characterization of selective laser-melted Saf 2507 duplex stainless steel. JOM 69(3):569-574

[183] Murkute P, Pasebani S, Isgor OB (2019) Electrochemical investigation of super duplex stainless steel cladded carbon steel manufactured via powder bed selective laser melting. In: CORROSION 2019, NACE international

[184] Hengsbach F, Koppa P, Duschik K, Holzweissig MJ, Burns M, Nellesen J, Tillmann W, Tröster T, Hoyer K-P, Schaper M (2017) Duplex stainless steel fabricated by selective laser melting-Microstructural and mechanical properties. Mater Des 133:136-142

[185] Liu H, Feng X (2013) Effect of post-processing heat treatment on microstructure and microhardness of watersubmerged friction stir processed 2219-T6 aluminum alloy. Mater Des 47:101-105

[186] Iams A, Keist J, Palmer T (2020) Formation of austenite in additively manufactured and post-processed duplex stainless steel alloys. Metall Mater Trans A 51(2):982-999

[187] Nath SD, Clinning E, Gupta G, Wuelfrath-Poirier V, L'Espérance G, Gulsoy O, Kearns M, Atre SV (2019) Effects of $\mathrm{Nb}$ and $\mathrm{Mo}$ on the microstructure and properties of 420 stainless steel processed by laser-powder bed fusion. Addit Manuf 28:682-691

[188] Saeidi K, Zapata DL, Lofaj F, Kvetkova L, Olsen J, Shen Z, Akhtar F (2019) Ultra-high strength martensitic 420 stainless steel with high ductility. Addit Manuf 29:100803

[189] Wang W, Kelly S (2016) A metallurgical evaluation of the powder-bed laser additive manufactured 4140 steel material. JOM 68(3):869-875

[190] Sridharan N, Field K (2019) A road map for the advanced manufacturing of ferritic-martensitic steels. Fusion Sci Technol 75(4):264-274

[191] Davis J, Michel D (1984) Proceedings of the topical conference on ferritic alloys for use in nuclear energy technologies, United States, The Metallurgical Society, Inc.
[192] Yvon P (2016) Structural materials for generation IV nuclear reactors. Woodhead Publishing, Sawston

[193] Liu F, Lin X, Shi J, Zhang Y, Bian P, Li X, Hu Y (2019) Effect of microstructure on the Charpy impact properties of directed energy deposition $300 \mathrm{M}$ steel. Addit Manuf 29:100795

[194] Sridharan N, Gussev MN, Field KG (2019) Performance of a ferritic/martensitic steel for nuclear reactor applications fabricated using additive manufacturing. J Nucl Mater 521:45-55

[195] Xi L, Chen S, Wei M, Liang J, Liu C, Wang M (2019) Microstructural evolution and properties of $24 \mathrm{CrNiMoY}$ alloy steel fabricated by selective laser melting. J Mater Eng Perform 28(9):5521-5532

[196] Kang X, Dong S, Wang H, Yan S, Liu X, Xu B (2020) Inhomogeneous microstructure and its evolution of laser melting deposited 24CrNiMo steel: from single-track to bulk sample. Mater Sci Eng A 772:138795

[197] Tanigawa H, Gaganidze E, Hirose T, Ando M, Zinkle S, Lindau R, Diegele E (2017) Development of benchmark reduced activation ferritic/martensitic steels for fusion energy applications. Nucl Fusion 57(9):092004

[198] Liu C, Tong J, Jiang M, Chen Z, Xu G, Liao H, Wang P, Wang X, Xu M, Lao C (2019) Effect of scanning strategy on microstructure and mechanical properties of selective laser melted reduced activation ferritic/martensitic steel. Mater Sci Eng A 766:138364

[199] Huang B, Zhai Y, Liu S, Mao X (2018) Microstructure anisotropy and its effect on mechanical properties of reduced activation ferritic/martensitic steel fabricated by selective laser melting. J Nucl Mater 500:33-41

[200] Mao C, Liu C, Yu L, Li H, Liu Y (2018) Mechanical properties and tensile deformation behavior of a reduced activated ferritic-martensitic (RAFM) steel at elevated temperatures. Mater Sci Eng A 725:283-289

[201] Jiang M, Chen Z, Tong J, Liu C, Xu G, Liao H, Wang P, Wang X, Xu M, Lao C (2019) Strong and ductile reduced activation ferritic/martensitic steel additively manufactured by selective laser melting. Mater Res Lett 7(10):426-432

[202] Zuo P, Chen S, Wei M, Zhou L, Liang J, Liu C, Wang M (2019) Microstructure evolution of 24CrNiMoY alloy steel parts by high power selective laser melting. J Manuf Process 44:28-37

[203] Ran X, Liu D, Li A, Wang H, Tang H, Cheng X (2016) Microstructure characterization and mechanical behavior of laser additive manufactured ultrahigh-strength AerMet100 steel. Mater Sci Eng A 663:69-77

[204] Garibaldi M, Ashcroft I, Lemke J, Simonelli M, Hague R (2018) Effect of annealing on the microstructure and 
magnetic properties of soft magnetic $\mathrm{Fe}-\mathrm{Si}$ produced via laser additive manufacturing. Scr Mater 142:121-125

[205] Jelis E, Kerwien S, Ravindra NM, Clemente M (2014) Development of low alloy high strength steel process parameters for direct metal laser sintering. Mater Sci Technol 1:2011-2018

[206] Rodrigues TA, Duarte V, Avila JA, Santos TG, Miranda R, Oliveira J (2019) Wire and arc additive manufacturing of HSLA steel: effect of thermal cycles on microstructure and mechanical properties. Addit Manuf 27:440-450

[207] Roberts GA, Kennedy R, Krauss G (1998) Tool steels. ASM International, Cleveland

[208] Wright CS, Youseffi M, Akhtar S, Childs T, Hauser C, Fox P (2006) Selective laser melting of prealloyed high alloy steel powder beds. Mater Sci Forum Trans Tech Publ, pp 516-523

[209] Sander J, Hufenbach J, Giebeler L, Wendrock H, Kühn U, Eckert J (2016) Microstructure and properties of FeCrMoVC tool steel produced by selective laser melting. Mater Des 89:335-341

[210] Ren B, Lu D, Zhou R, Li Z, Guan J (2019) Preparation and mechanical properties of selective laser melted H13 steel. J Mater Res 34(8):1415-1425

[211] Deirmina F, Peghini N, AlMangour B, Grzesiak D, Pellizzari M (2019) Heat treatment and properties of a hot work tool steel fabricated by additive manufacturing. Mater Sci Eng A 753:109-121

[212] Yan J, Zheng D, Li H, Jia X, Sun J, Li Y, Qian M, Yan M (2017) Selective laser melting of H13: microstructure and residual stress. J Mater Sci 52(20):12476-12485. https://d oi.org/10.1007/s10853-017-1380-3

[213] Holzweissig MJ, Taube A, Brenne F, Schaper M, Niendorf $\mathrm{T}$ (2015) Microstructural characterization and mechanical performance of hot work tool steel processed by selective laser melting. Metall Mater Trans B 46(2):545-549

[214] Mertens R, Vrancken B, Holmstock N, Kinds Y, Kruth J-P, Van Humbeeck J (2016) Influence of powder bed preheating on microstructure and mechanical properties of $\mathrm{H} 13$ tool steel SLM parts. Phys Procedia 83:882-890

[215] Xue L, Chen J, Wang S-H (2013) Freeform laser consolidated H13 and CPM 9V tool steels. Metallogr Microstruct Anal 2(2):67-78

[216] Krell J, Röttger A, Geenen K, Theisen W (2018) General investigations on processing tool steel X40CrMoV5-1 with selective laser melting. J Mater Process Technol 255:679-688

[217] Lee J, Choe J, Park J, Yu J-H, Kim S, Sung H (2019) Microstructural effects on the tensile and fracture behavior of selective laser melted H13 tool steel under varying conditions. Mater Charact 155:109817
[218] Park JS, Park JH, Lee M-G, Sung JH, Cha KJ, Kim DH (2016) Effect of energy input on the characteristic of AISI H13 and D2 tool steels deposited by a directed energy deposition process. Metall Mater Trans A 47(5):2529-2535

[219] Pellizzari M, Furlani S, Deirmina F, Siriki R, AlMangour B, Grzesiak D (2019) Fracture toughness of a hot work tool steel fabricated by laser-powder bed fusion additive manufacturing. Steel Res Int 91:1900449

[220] Riza SH, Masood S, Wen C (2015) A study on wear behaviour of laser direct metal deposited high strength $\mathrm{H} 13$ tool steel. Manuf Sci Technol 3(4):182-188

[221] Dörfert R, Zhang J, Clausen B, Freiße H, Schumacher J, Vollertsen F (2019) Comparison of the fatigue strength between additively and conventionally fabricated tool steel 1.2344. Addit Manuf 27:217-223

[222] Huber F, Bischof C, Hentschel O, Heberle J, Zettl J, Nagulin KY, Schmidt M (2019) Laser beam melting and heattreatment of 1.2343 (AISI H11) tool steel-microstructure and mechanical properties. Mater Sci Eng A 742:109-115

[223] Casati R, Coduri M, Lecis N, Andrianopoli C, Vedani M (2018) Microstructure and mechanical behavior of hotwork tool steels processed by selective laser melting. Mater Charact 137:50-57

[224] Junker D, Hentschel O, Schramme R, Schmidt M, Merklein M (2017) Performance of hot forging tools built by laser metal deposition of hot work tool steel X37CrMoV5-1. In: Proceedings of the laser in manufacturing conference

[225] Zhang M, Chen C, Qin L, Yan K, Cheng G, Jing H, Zou T (2018) Laser additive manufacturing of M2 high-speed steel. Mater Sci Technol 34(1):69-78

[226] Sander J, Hufenbach J, Giebeler L, Bleckmann M, Eckert J, Kühn U (2017) Microstructure, mechanical behavior, and wear properties of $\mathrm{FeCrMoVC}$ steel prepared by selective laser melting and casting. Scr Mater 126(1):41-44

[227] Boes J, Röttger A, Theisen W (2019) Processing of X65MoCrWV3-2 cold work tool steel by laser powder bed fusion. Steel Res Int 91:1900445

[228] Kempen K, Vrancken B, Buls S, Thijs L, Van Humbeeck J, Kruth J-P (2014) Selective laser melting of crack-free high density M2 high speed steel parts by baseplate preheating. J Manuf Sci Eng 136(6):061026

[229] Sander J, Hufenbach J, Bleckmann M, Giebeler L, Wendrock H, Oswald S, Gemming T, Eckert J, Kühn U (2017) Selective laser melting of ultra-high-strength TRIP steel: processing, microstructure, and properties. J Mater Sci 52(9):4944-4956. https://doi.org/10.1007/s10853-016-073 $1-9$

[230] Hufenbach J, Kohlar S, Kühn U, Giebeler L, Eckert J (2012) Microstructural and mechanical characterization of an ultra-high-strength $\mathrm{Fe} 86.7 \mathrm{Cr} 4.4 \mathrm{Mo} 0.6 \mathrm{~V}$ 1.1W 2.5 C 
4.7 alloy. J Mater Sci 47(1):267-271. https://doi.org/10.10 07/s10853-011-5794-z

[231] Kies F, Köhnen P, Wilms MB, Brasche F, Pradeep KG, Schwedt A, Richter S, Weisheit A, Schleifenbaum JH, Haase C (2018) Design of high-manganese steels for additive manufacturing applications with energy-absorption functionality. Mater Des 160:1250-1264

[232] Haase C, Bültmann J, Hof J, Ziegler S, Bremen S, Hinke C, Schwedt A, Prahl U, Bleck W (2017) Exploiting processrelated advantages of selective laser melting for the production of high-manganese steel. Materials 10(1):56-69
[233] Polatidis E, Čapek J, Arabi-Hashemi A, Leinenbach C, Strobl M (2020) High ductility and transformation-inducedplasticity in metastable stainless steel processed by selective laser melting with low power. Scr Mater 176:53-57

[234] Pham M, Dovgyy B, Hooper P (2017) Twinning induced plasticity in austenitic stainless steel $316 \mathrm{~L}$ made by additive manufacturing. Mater Sci Eng A 704:102-111

Publisher's Note Springer Nature remains neutral with regard to jurisdictional claims in published maps and institutional affiliations. 